\title{
Molecular biology of rat cytomegalovirus : genome- wide transcriptional program and molecular mimicry
}

Citation for published version (APA):

van Cleef, K. W. R. (2007). Molecular biology of rat cytomegalovirus : genome-wide transcriptional program and molecular mimicry. [Doctoral Thesis, Maastricht University]. Datawyse / Universitaire Pers Maastricht. https://doi.org/10.26481/dis.20070302kc

Document status and date:

Published: 01/01/2007

DOI:

10.26481/dis.20070302kc

Document Version:

Publisher's PDF, also known as Version of record

\section{Please check the document version of this publication:}

- A submitted manuscript is the version of the article upon submission and before peer-review. There can be important differences between the submitted version and the official published version of record.

People interested in the research are advised to contact the author for the final version of the publication, or visit the DOI to the publisher's website.

- The final author version and the galley proof are versions of the publication after peer review.

- The final published version features the final layout of the paper including the volume, issue and page numbers.

Link to publication

\footnotetext{
General rights rights.

- You may freely distribute the URL identifying the publication in the public portal. please follow below link for the End User Agreement:

www.umlib.nl/taverne-license

Take down policy

If you believe that this document breaches copyright please contact us at:

repository@maastrichtuniversity.nl

providing details and we will investigate your claim.
}

Copyright and moral rights for the publications made accessible in the public portal are retained by the authors and/or other copyright owners and it is a condition of accessing publications that users recognise and abide by the legal requirements associated with these

- Users may download and print one copy of any publication from the public portal for the purpose of private study or research.

- You may not further distribute the material or use it for any profit-making activity or commercial gain

If the publication is distributed under the terms of Article $25 \mathrm{fa}$ of the Dutch Copyright Act, indicated by the "Taverne" license above, 
Molecular biology of rat cytomegalovirus: genome-wide transcriptional program and molecular mimicry

Koen W.R. van Cleef 
(C) Copyright Koen van Cleef, Amsterdam, The Netherlands, 2007 Universitaire Pers Maastricht

ISBN 10: 90-5278-603-8

ISBN 13: 978-90-5278-603-2

Cover: Expression of the pr127 protein in the salivary gland of an RCMV-infected rat Production: Datawyse, Maastricht, The Netherlands 
Molecular biology of rat cytomegalovirus: genome-wide transcriptional program and molecular mimicry

\section{Proefschrift}

ter verkrijging van de graad van doctor aan de Universiteit Maastricht, op gezag van de Rector Magnificus Prof. Mr. G.P.M.F. Mols, volgens het besluit van het College van Decanen, in het openbaar te verdedigen op vrijdag 2 maart 2007 om 14.00 uur

$$
\text { door }
$$

Koen Willem René van Cleef

geboren te Boxtel op 1 december 1977

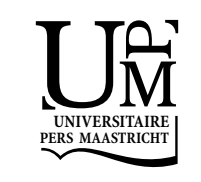




\section{Promotor:}

Prof. Dr. C.A. Bruggeman

\section{Co-promotor:}

Dr. C. Vink

\section{Beoordelingscommissie:}

Prof. Dr. M. Hofker (voorzitter)

Dr. E. Claas (LUMC, Leiden)

Prof. Dr. J.W. Cohen Tervaert

Prof. Dr. F.C.S. Ramaekers

Dr. D.N. Streblow (OHSU, Beaverton, USA)

The investigations described in this thesis were carried out at the Department of Medical Microbiology, Cardiovascular Research Institute Maastricht (CARIM), University of Maastricht, Maastricht, The Netherlands. The work was supported by grant 901-02-239 of the Netherlands Organization for Scientific Research (NWO). 


\section{Contents}

\section{Chapter 1}

General introduction and outline of the thesis

\section{Chapter 2}

Rat cytomegalovirus gene expression in cardiac allograft recipients is tissue-specific and does not parallel the profiles detected in vitro

\section{Chapter 3}

Identification and characterization of two antisense transcripts from the major immediate early region of rat cytomegalovirus

\section{Chapter 4}

The rat cytomegalovirus homologue of parvoviral rep genes, r127, encodes a nuclear protein with single- and double-stranded DNAbinding activity that is dispensable for virus replication

\section{Chapter 5}

Cytomegalovirus-encoded homologs of $G$ protein-coupled receptors and chemokines

\section{Chapter 6}

Summary and general discussion

Samenvatting en algehele discussie

Dankwoord

Curriculum vitae en publicaties 



\section{Chapter 1}

General introduction and outline of the thesis 


\section{General introduction}

\subsection{CMVs}

Cytomegaloviruses (CMVs) are members of the subfamily Betaherpesvirinae within the family Herpesviridae (Roizman, 1996). They are species-specific viruses that are widely disseminated in nature and which cause acute, persisting and latent infections in both humans and animals.

Infections with human CMV (HCMV) are very common (Britt and Alford, 1996). There are probably thousands of unique HCMV strains circulating in the general population throughout the world (Alford et al., 1981). The majority of the human population becomes infected with HCMV during childhood or adolescence and the prevalence of HCMV infections correlates with geographic conditions and socio-economic factors (Gold and Nankervis, 1982; Reynolds et al., 1981). Natural transmission of HCMV occurs by direct or indirect person-to-person contact and sources of virus are oropharyngeal secretions, urine, cervical and vaginal excretions, semen, breast milk, tears, feces and blood (Lang and Kummer, 1975; Reynolds et al., 1973; Stagno et al., 1980). HCMV can be transmitted by both horizontal (extrauterine) and vertical (intrauterine) transmission and HCMV infections are the most common congenital infections in humans (Stagno et al., 1982, 1983; Yow et al., 1988). In the United States, between 0.2 and $2.2 \%$ of the infants born are infected in utero (Stagno et al., 1982). Another 8 to $60 \%$ of the newborns become infected during the first six months of life, mainly as a result of an infection acquired during birth or following breast feeding (Reynolds et al., 1973; Stagno et al., 1980). Transmission among toddlers is particularly high in day care centers (Hutto et al., 1985; Pass et al., 1982). Between 40 to $80 \%$ of the children are infected before puberty in most developed countries (Gold and Nankervis, 1982; Reynolds et al., 1981). In other areas of the world, 90 to $100 \%$ of the population is infected during childhood (Gold and Nankervis, 1982; Lang, 1975; Reynolds et al., 1981). In the adult population, HCMV is mainly transmitted by contact with young children and sexual transmission (Adler, 1989; Collier et al., 1987; Handsfield et al., 1985; Pass et al., 1986, 1987; Sohn et al., 1991). Organ transplantation and exposure to blood products are important transmission routes in hospitalized patients (Ho et al., 1975; Pass et al., 1978; Prince et al., 1971; Singh et al., 1988; Winston et al., 1980).

The immune status of the host is an important determinant of the clinical outcome of an HCMV infection (Britt and Alford, 1996). Primary HCMV infections are usually subclinical in immunocompetent individuals, although occasionally they can cause clinical symptoms in these persons, such as a mononucleosis syndrome (Horwitz et al., 
1979; Klemola and Kaariainen, 1965; Klemola et al., 1967). Following primary infection, HCMV enters a life-long persistent or latent state in immunocompetent individuals from which it can reactivate if the immune system of the host is impaired. Persistence refers to a low level of virus replication, whereas latency is defined as the maintenance of viral DNA without the production of infectious virus. HCMV latency and reactivation are still poorly understood, but the bone marrow-derived myeloid progenitor cells appear to be the main reservoir for latent HCMV (Bego and St. Jeor, 2006; Sinclair and Sissons, 2006). In contrast to HCMV infections in immunocompetent individuals, severe problems can arise after HCMV infections or reactivations in immunocompromised individuals, such as AIDS patients and patients undergoing immunosuppressive therapies. In these persons, the loss of adaptive immune responses has been shown to lead to uncontrolled virus replication and widespread viral dissemination, resulting in high virus titers in virtually every organ. Retinitis and infections of the gastrointestinal tract are the most frequently occurring symptoms of HCMV infections in AIDS patients (Francis et al., 1989; Gross et al., 1990; Jabs et al., 1989). The most prominent HCMV-associated complication in bone marrow transplant recipients is pneumonia (Enright et al., 1993; Foot et al., 1993; Meyers et al., 1982). HCMV infections are also involved in the rejection of transplanted organs after solid organ transplantation (Grattan et al., 1989; Lautenschlager et al., 1997a; Reinke et al., 1994). Furthermore, as described above, congenital HCMV infections affect between 0.2 and $2.2 \%$ of the newborns in the United States (Stagno et al., 1982). Among the acute symptoms of congenital HCMV infections are hepatosplenomegaly, petechiae, jaundice and microcephaly (Boppana et al., 1992). The long-term sequelae, which are mainly caused by damage to the central nervous system, include hearing loss, visual impairment and mental retardation (Boppana et al., 1992; Pass et al., 1980; Williamson et al., 1992). Interestingly, HCMV has also been linked to the pathogenesis of vascular diseases. Since the demonstration that an avian herpesvirus could induce atherosclerosis in chickens (Fabricant et al., 1978, 1983; Minick et al., 1979), it is generally accepted that viruses can play a role in the development of vascular pathologies. Evidence for an association between HCMV and the genesis or exacerbation of atherosclerosis is based on sero-epidemiological data and detection of virus in atherosclerotic lesions (Adam et al., 1987; Hendrix et al., 1990; Melnick et al., 1994). Furthermore, HCMV was shown to enhance coronary restenosis (Speir et al., 1994, 1995; Zhou et al., 1996), but especially the role of HCMV as a cofactor in transplant-associated atherosclerosis is very well documented (Grattan et al., 1989; Koskinen et al., 1993; McDonald et al., 1989). 


\subsection{Structure of a $C M V$ virion}

As shown in Fig. 1, the typical structure of a CMV virion is similar to that of other herpesviruses (Mocarski, 1996). It is composed of a linear, double-stranded DNA genome that is encapsulated by an icosahedral protein capsid (Huang et al., 1973; Wright et al., 1964). The CMV genomes can be as large as $230 \mathrm{~kb}$ and they can encode for more than 200 protein products (Chee et al., 1990; Rawlinson et al., 1996; Vink et al., 2000). In HCMV, the capsid is mainly composed of pUL86 (major capsid protein; MCP) and pUL46 (minor capsid protein; mCP) (Chee et al., 1990; Gibson, 1981, 1983). The capsid is surrounded by an amorphous protein mass that is referred to as the tegument or matrix (Wright et al., 1964). The major constituents of the tegument in HCMV are ppUL32 (basic phosphoprotein; pp150) and ppUL83 (lower matrix protein; pp65) (Chee et al., 1990; Gibson, 1981, 1983). The capsid and tegument are enclosed in a lipid bilayer envelope with virally encoded glycoproteins (Wright et al., 1964). The most abundant glycoprotein in the envelope of HCMV is gpUL55 (glycoprotein B; gB) (Chee et al., 1990; Gibson, 1981, 1983). The size of a mature CMV virion can range from 150 to $200 \mathrm{~nm}$ (Wright et al., 1964).

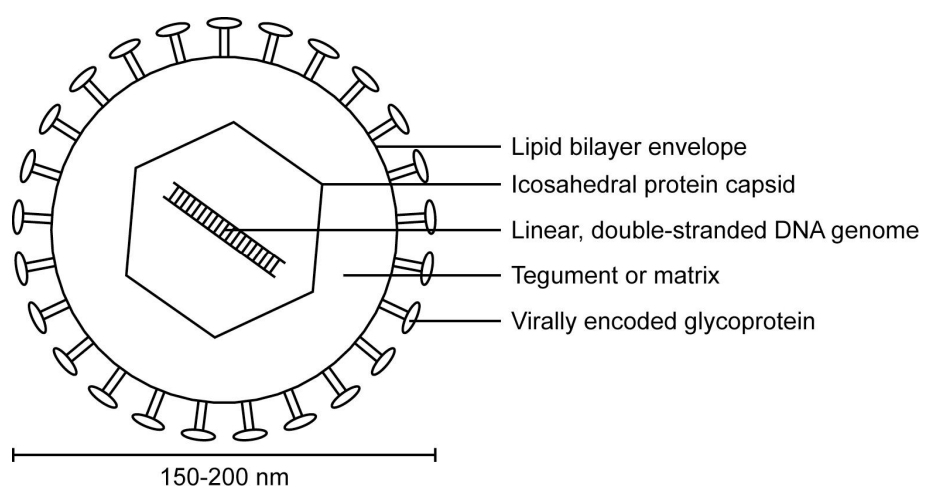

Fig. 1. Structure of a CMV virion.

\subsection{The CMV replication cycle}

The replication cycle of the CMVs is highly complex (Mocarski, 1996). Productive CMV infections cause a characteristic enlargement with intranuclear inclusions of infected host cells (cytomegalia) which can be observed as the typical 'owl's eye' cytopathic effect (Weller et al., 1960). CMVs can infect multiple cell types, but the most permissive cells are fibroblasts. When compared to other herpesviruses, the CMV 
replication cycle in fully permissive cell types is relatively slow: 48 to $72 \mathrm{~h}$ for HCMV and 24 to $36 \mathrm{~h}$ for both rat CMV (RCMV) and murine CMV (MCMV) (Stinski, 1983). The replication cycle of the CMVs starts with attachment of the virion to the cell surface of the host cell. Attachment involves binding of virally encoded glycoproteins in the viral envelope to cell surface proteins. Heparan sulfate proteoglycans (HSPGs) are probably the primary attachment sites for the CMVs (Compton et al., 1993). Viral entry was found to be initiated by glycoproteins $\mathrm{gB}$ and $\mathrm{gH}$, which bind independently to the epidermal growth factor receptor (EGFR) and integrin $\alpha v \beta 3$, respectively (Wang et al., 2003, 2005). Penetration into fibroblasts occurs by fusion of the viral envelope with the plasma membrane of the cell (Compton et al., 1992), whereas entry into epithelial and endothelial cells is mediated by endocytosis (Ryckman et al., 2006). After penetration, the capsid is transported to the cell nucleus where the viral DNA is released and replicated (Ogawa-Goto et al., 2003). The termini of the linear viral genome are first fused to generate monomeric DNA circles (LaFemina and Hayward, 1983). The viral DNA is then replicated by a rolling-circle mechanism that is initiated from a DNA sequence that is known as the origin of lytic-phase DNA replication (orilyt) (Anders et al., 1992; Masse et al., 1992). A crucial protein in this process, the virally encoded DNA polymerase (pUL54 in HCMV), is a main target for anti-viral compounds (De Clercq, 2004). The rolling-circle mechanism of DNA replication generates large concatemers in which the viral genomes are linked head-to-tail (McVoy and Adler, 1994). The concatemers are subsequently cleaved into unit-length genomes that are packaged into preformed capsids. The proteins that are involved in cleavage and packaging of the viral DNA are the so-called terminases. The terminase of HCMV consists of the subunits pUL56 and pUL89. The large subunit pUL56 is believed to mediate the specific binding to the packaging elements (pac motifs) on the concatemers as well as the ATPdependent translocation of the viral DNA into preformed capsids, whereas the small subunit pUL89 is thought to be required for cleavage of concatemeric DNA into unitlength genomes (Scheffczik et al., 2002). The capsids probably acquire an initial envelope at the inner nuclear membrane that is subsequently lost by fusion with the outer nuclear membrane. Final envelopment is likely to occur by budding into Golgiderived secretory vacuoles that are transported to the plasma membrane were the virus particles are released (Homman-Loudiyi et al., 2003).

During CMV replication, the viral genes are expressed following three temporal phases: immediate early (IE), early (E) and late (L) (Mocarski, 1996). The proteins that 
are expressed during the IE phase of infection predominantly have regulatory functions. The most prominent IE proteins are those derived from the major IE (MIE) region. These proteins play an important role in the regulation of the gene expression cascade during CMV replication. The proteins that are expressed during the $E$ phase of infection are mainly involved in the synthesis of viral DNA, such as DNA polymerase. Most of the proteins that are expressed during the $L$ phase of infection represent either structural proteins or proteins that are involved in assembly, maturation and egress of new virions. These proteins include capsid proteins, tegument proteins and glycoproteins of the envelope. In permissive cells, CMV replication undergoes all three temporal phases of viral gene expression leading to the production of new virions and eventually cell death (Mocarski, 1996).

\subsection{Treatment of CMV infections}

In general, symptomatic HCMV infections are treated with compounds that interfere with the synthesis of viral DNA, such as ganciclovir, cidofovir and foscarnet (De Clercq, 2004). However, these compounds do not clear latent HCMV and may cause serious toxic side-effects, such as deteriorated function of the central nervous system, renal function impairment, bone marrow hypoplasia and leukopenia (Jacobson, 1992; Kendle and Fan Havard, 1998; Noble and Faulds, 1998). Furthermore, the development of resistance to current anti-viral therapies constitutes a major threat for the treatment of HCMV infections (Erice et al., 1989; Harada et al., 1997; Sarasini et al., 1995). In particular, the development of ganciclovir-resistant isolates in AIDS patients is well known (Jabs et al., 1998). The generation of new therapeutic agents to treat HCMV infections has therefore a high priority. To facilitate the generation and evaluation of successful anti-viral therapies, a continuous study of the (molecular) biology of the CMVs is required.

\subsection{The RCMV/rat model}

Since HCMV infections are restricted to humans, several animal infection models have been developed to study the pathogenesis of CMV infections in vivo. Among the CMV species that have been used in these models are RCMV, MCMV and guinea pig CMV (GPCMV). One of the animal infection models is the RCMV (Maastricht strain)/rat model developed in our laboratory (Bruggeman et al., 1982).

To date, two major RCMV strains have been reported: the Maastricht strain and the England strain (Bruggeman et al., 1982; Priscott and Tyrrell, 1982). Interestingly, the 
Maastricht and England strains were shown to differ considerably in both restriction patterns and genome size (Burns et al., 1988; Meijer et al., 1986). Furthermore, the MIE sequences from the two strains were found to be dissimilar to such an extent that it seemed valid to classify them as different betaherpesvirus species rather than strains (Beisser et al., 1998a).

The Maastricht strain of RCMV was isolated in our laboratory in 1982 from the salivary glands of wild rats and subsequently passed into rat embryo fibroblasts (REFs) as well as laboratory rats (Bruggeman et al., 1982). Primary infection of immunocompetent rats with RCMV results in a widely disseminated infection (Bruggeman et al., 1983, 1985). Following intraperitoneal or subcutaneous inoculation of $\mathrm{RCMV}$, infectious virus is present in many organs at either day 4 post-infection (pi) for rats that are intraperitoneally inoculated or day $11 \mathrm{pi}$ for rats that are subcutaneously inoculated (Bruggeman et al., 1985). These organs include spleen, kidney, heart, bone marrow, thymus and blood. At later time-points pi, infectious virus can only be recovered from the salivary glands and not from any other organ. Infectious virus can be detected in the salivary glands as soon as 10 days pi, reaching peak levels at 28 days pi. When compared to the low virus titers yielded in other organs, the virus titers reached in the salivary glands are extremely high (Bruggeman et al., 1985). This indicates that the salivary glands are the primary site for RCMV infection.

RCMV infections do usually not cause overt disease in immunocompetent rats, but they are considered lethal in immunocompromised rats (Stals et al., 1990). Primary infection of immunocompromised rats with RCMV results in a high mortality rate and profound pathologies in many organs. These organs include liver, spleen, lung, kidney and bone marrow. The pathologies that are associated with RCMV infections in rats closely resemble those associated with HCMV infections in humans (Stals et al., 1990). Furthermore, RCMV and HCMV display similar sensitivities to anti-viral compounds that act on the viral DNA polymerase (Stals et al., 1991). Due to these features, the $\mathrm{RCMV/rat}$ model has generally been accepted as a suitable model system to study CMV infections in vivo. Moreover, the RCMV/rat model has proven its value in rat organ transplantation models and the evaluation of anti-viral compounds as well as in studying the role of CMV infections in vascular pathologies (Koskinen et al., 1994; Lautenschlager et al., 1997b; Lemstrom et al., 1995; Li et al., 1998; Martelius et al., 1999; Stals et al., 1993). 


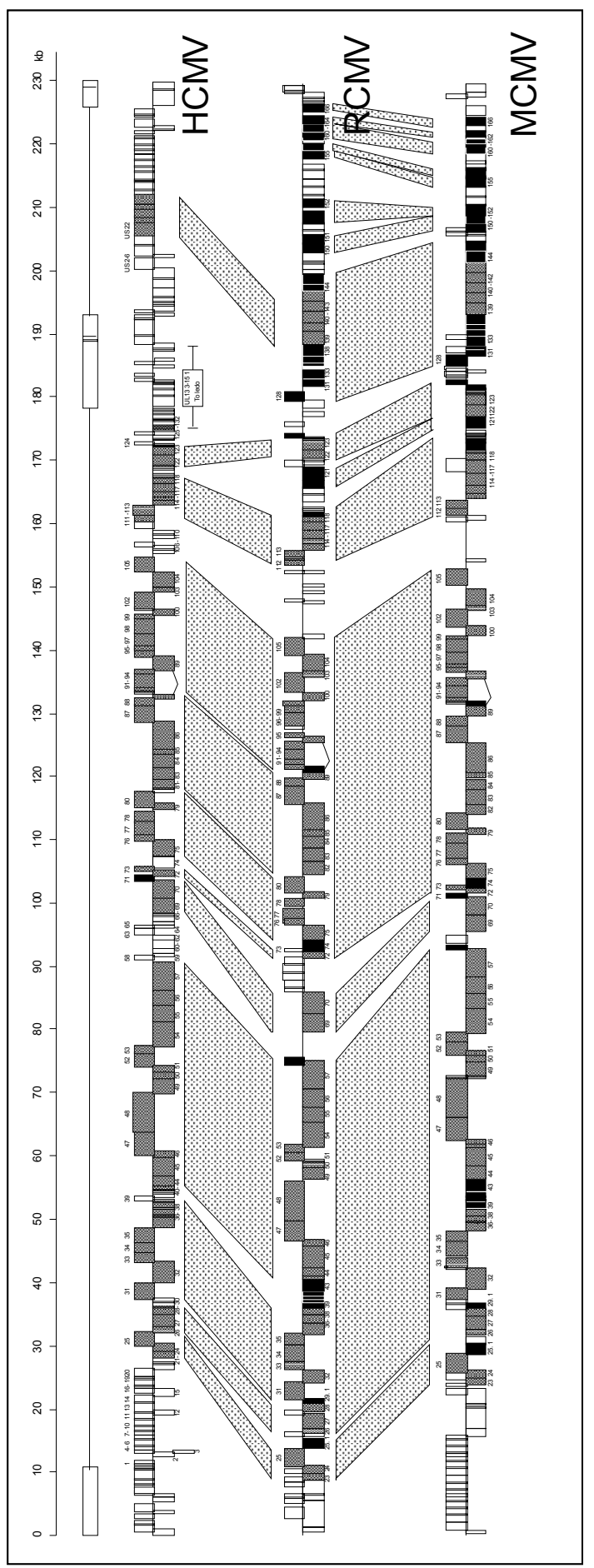

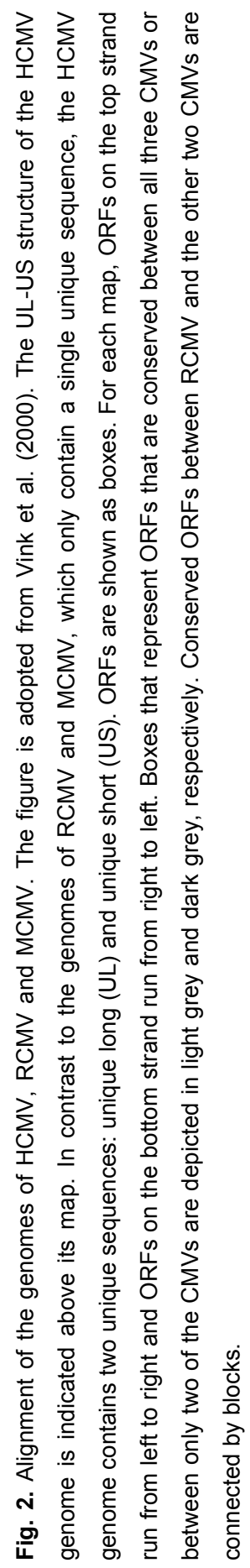




\subsection{The RCMV genome}

After the isolation of RCMV in 1982 (Bruggeman et al., 1982), several regions from its genome have been analyzed in more detail. These regions include the genome termini (Vink et al., 1996), the region comprising the genes encoding DNA polymerase, gB, ICP18.5 and major DNA-binding protein (Beuken et al., 1996), the oriLyt (Vink et al., 1997) and the MIE region (Beisser et al., 1998a). Furthermore, several studies have been performed that were focused on separate RCMV genes, including R32 (Beuken et al., 1999), R33 (Beisser et al., 1998b; Casarosa et al., 2003; Gruijthuijsen et al., 2002, 2004; Streblow et al., 2005), R44 (Kaptein et al., 2001), R78 (Beisser et al., 1999; Kaptein et al., 2003), R89 (Gruijthuijsen et al., 2000), r131 (Kaptein et al., 2004) and r144 (Beisser et al., 2000; Kloover et al., 2002). These studies already indicated that the RCMV genome is collinear with that of other CMVs. Further evidence for this notion came from the determination of the complete DNA sequence of the RCMV genome in 2000 (Vink et al., 2000). Following HCMV and MCMV (Chee et al., 1990; Rawlinson et al., 1996), RCMV was the third CMV of which the complete genomic sequence has been determined.

The RCMV genome consists of a linear, double-stranded DNA molecule with a length of 230,138 bp (Vink et al., 2000). Despite several unique characteristics, the RCMV genome is highly similar to the genomes of HCMV and MCMV, both in overall structure as well as gene content (Chee et al., 1990; Rawlinson et al., 1996; Vink et al., 2000). The RCMV genome, which is arranged as a single unique sequence flanked by 504-bp terminal direct repeats, contains at least 167 open reading frames (ORFs) (Vink et al., 2000). As can be seen in Fig. 2, most of these ORFs have counterparts in the genomes of both HCMV and MCMV (Chee et al., 1990; Rawlinson et al., 1996; Vink et al., 2000). Interestingly, among the RCMV ORFs are five ORFs that encode homologs of host proteins: R33 and R78 encode homologs of $G$ protein-coupled receptors (GPCRs) (Beisser et al., 1998b, 1999; Vink et al., 2000); r129 and r131 encode homologs of CC chemokines (CKs) (Akter et al., 2003; Kaptein et al., 2004; Vink et al., 2000); and r144 encodes a homolog of major histocompatibility complex (MHC) class I heavy chains (Beisser et al., 2000; Vink et al., 2000). An intriguing feature of the RCMV genome is ORF r127. This ORF is unique among the CMVs and it encodes a homolog of the proteins that are encoded by the rep genes of parvoviruses (Vink et al., 2000). The U94 genes of human herpesvirus type 6A (HHV-6A) and 6B (HHV-6B) were also found to represent homologs of the parvoviral rep genes (Dominguez et al., 1999; Gompels et al., 
1995; Isegawa et al., 1999; Thomson et al., 1991), but counterparts of these genes are not present in the genomes of other sequenced herpesviruses.

\section{Outline of the thesis}

The RCMV/rat infection model and the availability of the complete RCMV genomic sequence have provided powerful tools to study the function of CMV genes in the pathogenesis of infection in vivo. In this thesis, these tools are employed to study various aspects of RCMV gene expression as well as the role of a set of selected RCMV genes in the pathogenesis of infection.

As described above, the RCMV genome contains 167 ORFs. However, the extent of expression of these ORFs is still unknown. We therefore set out to study transcription of all RCMV genes simultaneously. In Chapter 2, the genome-wide transcriptional program of RCMV is presented. This chapter describes the generation of an RCMV-specific DNA microarray and the application of this microarray in the analysis of the viral transcription profiles in RCMV-infected cells in culture as well as in various organs and tissues of RCMV-infected rats. It is demonstrated that the RCMV transcription profiles in vivo are tissue-specific and dramatically differ compared to those in vitro.

Following the analysis of the RCMV genome-wide transcriptional program, Chapter 3 is dedicated to a key element in the initiation of the gene expression cascade during lytic RCMV replication: the MIE region. The structural organization of the MIE region of RCMV was previously shown to be similar to that of other CMVs (Beisser et al., 1998a). It consists of five exons that are differentially spliced to generate three different transcripts, i.e. IE1, IE2 and IE2A (Beisser et al., 1998a). Interestingly, in addition to these 'sense' transcripts, we have identified two antisense transcripts from the RCMV MIE region. These transcripts were designated IE-AS1 and IE-AS2. Remarkably, a similar antisense transcript from the MIE region has previously been identified for HCMV (Kondo et al., 1996). This transcript was designated as a CMV latency-associated transcript (CLT) (Kondo et al., 1996). With respect to the potential role of the HCMV antisense CLT in the regulation of latency, the identification of the two RCMV IE-AS transcripts is intriguing. Chapter 3 describes the structure and transcription characteristics of these transcripts as well as their potential role in the regulation of IE1 expression.

Chapter 4 will focus on one of the most fascinating characteristics of the RCMV genome: the r127 parvoviral rep gene homolog. Like the IE-AS transcripts, r127 may have a role during RCMV latency. As described above, the U94 genes of HHV-6A and - 
$6 \mathrm{~B}$ represent the only herpesviral homologs of $\mathrm{r} 127$ that have thus far been identified. Interestingly, the U94-encoded protein (RepH6) was hypothesized to play a role in the regulation of $\mathrm{HHV}-6 \mathrm{~A}$ and $-6 \mathrm{~B}$ latency. This hypothesis was based on two observations: (i) U94 is transcribed in latently infected peripheral blood mononuclear cells (PBMCs) from HHV-6A-infected individuals (Rotola et al., 1998) and (ii) both virus replication and expression of viral genes are restricted in HHV-6A-infected lymphocytes expressing HHV-6B U94 in vitro (Rotola et al., 1998). However, the exact role of the betaherpesviral homologs of the parvoviral Rep proteins in the pathogenesis of infection remains elusive. Although these proteins might be involved in the establishment or maintenance of latency, it is also possible that they play a role during the acute phase of infection. We therefore set out to characterize the RCMV r127 gene during lytic infection in vitro and during the acute phase of infection in vivo. In Chapter 4, the structure and the transcription characteristics of the r127 transcript, the expression pattern of the r127encoded protein (pr127) and the ability of pr127 to bind single- and double-stranded DNA are described. In addition, the generation and characterization is presented of a recombinant RCMV strain ( $R C M V \Delta r 127)$ in which the $r 127$ ORF is disrupted.

As described above, the RCMV genome also contains a number of genes which are similar to host genes. Of these genes, the most prominent are those encoding homologs of cellular GPCRs and CKs. The ability of the CMVs to establish a life-long latent infection requires a high level of adaptation to the defense mechanisms of their hosts. During the long co-evolution of virus and host, the CMVs have developed various sophisticated strategies to interfere with the host's immune system. Remarkably, many of the immunomodulatory proteins of the CMVs that are thought to be involved in manipulation of and evasion from the immune system are mimics of cellular proteins. Among these proteins, which are encoded by genes that appear to be hijacked from the host genome, are the homologs of cellular GPCRs and CKs. These CMV-encoded GPCRs and CKs are regarded as attractive targets for the development of novel antiviral therapies. In Chapter 5, the current state of knowledge on the putative functions of the CMV-encoded homologs of GPCRs and CKs in the pathogenesis of infection will be discussed. Special attention will be given to the exploitation of the RCMV/rat model as well as other animal infection models in generating a wealth of information on the CMVencoded GPCRs and CKs. For instance, studies on the GPCR-encoding genes R33 and $\mathrm{R} 78$ as well as on the CC CK-encoding gene r131 have shown that these genes encode proteins with crucial roles in the pathogenesis of RCMV infection (Beisser et al., 1998b, 
1999; Kaptein et al., 2003, 2004). These and several other studies have demonstrated that the CMV-encoded GPCRs and CKs can indeed be regarded as potential targets for the generation of new anti-viral compounds.

Finally, in Chapter 6, a summary and general discussion is presented of the results and conclusions that are reported in this thesis.

\section{References}

Adam E, Melnick JL, Probtsfield JL, Petrie BL, Burek J, Bailey KR, et al. High levels of cytomegalovirus antibody in patients requiring vascular surgery for atherosclerosis. Lancet 1987;2:291-3.

Adler SP. Cytomegalovirus and child day care. Evidence for an increased infection rate among daycare workers. N Engl J Med 1989;321:1290-6.

Akter P, Cunningham C, McSharry BP, Dolan A, Addison C, Dargan DJ, et al. Two novel spliced genes in human cytomegalovirus. J Gen Virol 2003;84:1117-22.

Alford CA, Stagno S, Pass RF, Huang ES. Epidemiology of cytomegalovirus. In: Nahmais A, Dowdle W, Schinazi R, editors. The human herpesviruses: an interdisciplinary perspective. Elsevier, New York 1981:159-71.

Anders DG, Kacica MA, Pari G, Punturieri SM. Boundaries and structure of human cytomegalovirus oriLyt, a complex origin for lytic-phase DNA replication. J Virol 1992;66:3373-84.

Bego MG, St. Jeor S. Human cytomegalovirus infection of cells of hematopoietic origin: HCMVinduced immunosuppression, immune evasion, and latency. Exp Hematol 2006;34:555-70.

Beisser PS, Kaptein SJF, Beuken E, Bruggeman CA, Vink C. The Maastricht strain and England strain of rat cytomegalovirus represent different betaherpesvirus species rather than strains. Virology 1998a;246:341-51.

Beisser PS, Vink C, van Dam JG, Grauls G, Vanherle SJV, Bruggeman CA. The R33 G proteincoupled receptor gene of rat cytomegalovirus plays an essential role in the pathogenesis of viral infection. J Virol 1998b;72:2352-63.

Beisser PS, Grauls G, Bruggeman CA, Vink C. Deletion of the R78 G protein-coupled receptor gene from rat cytomegalovirus results in an attenuated, syncytium-inducing mutant strain. J Virol 1999;73:7218-30.

Beisser PS, Kloover JS, Grauls GELM, Blok MJ, Bruggeman CA, Vink C. The r144 major histocompatibility complex class I-like gene of rat cytomegalovirus is dispensable for both acute and long-term infection in the immunocompromised host. J Virol 2000;74:1045-50.

Beuken E, Slobbe R, Bruggeman CA, Vink C. Cloning and sequence analysis of the genes encoding DNA polymerase, glycoprotein B, ICP18.5 and major DNA-binding protein of rat cytomegalovirus. J Gen Virol 1996;77:1559-62. 
Beuken E, Grauls G, Bruggeman CA, Vink C. The rat cytomegalovirus R32 gene encodes a virionassociated protein that elicits a strong humoral immune response in infected rats. J Gen Virol 1999;80:2719-28.

Boppana SB, Pass RF, Britt WJ, Stagno S, Alford CA. Symptomatic congenital cytomegalovirus infection: neonatal morbidity and mortality. Pediatr Infect Dis J 1992;11:93-9.

Britt WJ, Alford CA. Cytomegalovirus. In: Fields BN, Knipe DM, Howley PM, Chanock RM, Melnick JL, Monath TP, Roizman B, Straus SE, editors. Fields Virology, 3rd ed, vol 2. Lippincott-Raven Publishers, Philadelphia 1996:2493-523.

Bruggeman CA, Meijer H, Dormans PHJ, Debie WMH, Grauls GELM, van Boven CPA. Isolation of a cytomegalovirus-like agent from wild rats. Arch Virol 1982;73:231-41.

Bruggeman CA, Debie WMH, Grauls G, Majoor G, van Boven CPA. Infection of laboratory rats with a new cytomegalo-like virus. Arch Virol 1983;76:189-99.

Bruggeman CA, Meijer H, Bosman F, van Boven CPA. Biology of rat cytomegalovirus infection. Intervirology 1985;24:1-9.

Burns WH, Barbour GM, Sandford GR. Molecular cloning and mapping of rat cytomegalovirus DNA. Virology 1988;166:140-8.

Casarosa P, Gruijthuijsen YK, Michel D, Beisser PS, Holl J, Fitzsimons CP, et al. Constitutive signaling of the human cytomegalovirus-encoded receptor UL33 differs from that of its rat cytomegalovirus homolog $R 33$ by promiscuous activation of $G$ proteins of the $G_{q}$, $G_{i}$, and $G_{s}$ classes. J Biol Chem 2003;278:50010-23.

Chee MS, Bankier AT, Beck S, Bohni R, Brown CM, Cerny R, et al. Analysis of the protein-coding content of the sequence of human cytomegalovirus strain AD169. Curr Top Microbiol Immunol 1990;154:125-69.

Collier AC, Meyers JD, Corey L, Murphy VL, Roberts PL, Handsfield HH. Cytomegalovirus infection in homosexual men. Relationship to sexual practices, antibody to human immunodeficiency virus, and cell-mediated immunity. Am J Med 1987;82:593-601.

Compton T, Nepomuceno RR, Nowlin DM. Human cytomegalovirus penetrates host cells by $\mathrm{pH}$ independent fusion at the cell surface. Virology 1992;191:387-95.

Compton T, Nowlin DM, Cooper NR. Initiation of human cytomegalovirus infection requires initial interaction with cell surface heparan sulfate. Virology 1993;193:834-41.

De Clercq E. Antiviral drugs in current clinical use. J Clin Virol 2004;30:115-33.

Dominguez G, Dambaugh TR, Stamey FR, Dewhurst S, Inoue N, Pellett PE. Human herpesvirus 6B genome sequence: coding content and comparison with human herpesvirus $6 \mathrm{~A}$. J Virol 1999;73:8040-52.

Enright H, Haake R, Weisdorf D, Ramsay N, McGlave P, Kersey J, et al. Cytomegalovirus pneumonia after bone marrow transplantation. Risk factors and response to therapy. Transplantation 1993;55:1339-46. 
Erice A, Chou S, Biron KK, Stanat SC, Balfour HH, Jordan MC. Progressive disease due to ganciclovir-resistant cytomegalovirus in immunocompromised patients. $\mathrm{N}$ Engl J Med 1989;320:289-93.

Fabricant CG, Fabricant J, Litrenta MM, Minick CR. Virus-induced atherosclerosis. J Exp Med 1978;148:335-40.

Fabricant CG, Fabricant J, Minick CR, Litrenta MM. Herpesvirus-induced atherosclerosis in chickens. Fed Proc 1983;42:2476-9.

Foot AB, Caul EO, Roome AP, Darville JM, Oakhill A. Cytomegalovirus pneumonitis and bone marrow transplantation: identification of a specific high risk group. J Clin Pathol 1993;46:415-9.

Francis ND, Boylston AW, Roberts AH, Parkin JM, Pinching AJ. Cytomegalovirus infection in gastrointestinal tracts of patients infected with HIV-1 or AIDS. J Clin Pathol 1989;42:1055-64.

Gibson W. Structural and nonstructural proteins of strain Colburn cytomegalovirus. Virology 1981;111:516-37.

Gibson W. Protein counterparts of human and simian cytomegaloviruses. Virology 1983;128:391406.

Gold E, Nankervis GA. Cytomegalovirus. In: Evans AS, editor. Viral infections of humans: epidemiology and control, 2nd ed. Plenum Press, New York 1982:167-86.

Gompels UA, Nicholas J, Lawrence G, Jones M, Thomson BJ, Martin MED, et al. The DNA sequence of human herpesvirus-6: structure, coding content, and genome evolution. Virology 1995;209:29-51.

Grattan MT, Moreno-Cabral CE, Starnes VA, Oyer PE, Stinson EB, Shumway NE. Cytomegalovirus infection is associated with cardiac allograft rejection and atherosclerosis. JAMA 1989;261:3561-6.

Gross JG, Bozzette SA, Mathews WC, Spector SA, Abramson IS, McCutchan JA, et al. Longitudinal study of cytomegalovirus retinitis in acquired immune deficiency syndrome. Ophthalmology 1990;97:681-6.

Gruijthuijsen YK, Beuken E, Bruggeman CA, Vink C. Rat cytomegalovirus R89 is a highly conserved gene which expresses a spliced transcript. Virus Res 2000;69:119-30.

Gruijthuijsen YK, Casarosa P, Kaptein SJF, Broers JLV, Leurs R, Bruggeman CA, et al. The rat cytomegalovirus R33-encoded $\mathrm{G}$ protein-coupled receptor signals in a constitutive fashion. $\mathrm{J}$ Virol 2002;76:1328-38.

Gruijthuijsen YK, Beuken EVH, Smit MJ, Leurs R, Bruggeman CA, Vink C. Mutational analysis of the R33-encoded $\mathrm{G}$ protein-coupled receptor of rat cytomegalovirus: identification of amino acid residues critical for cellular localization and ligand-independent signalling. J Gen Virol 2004;85:897-909.

Handsfield HH, Chandler SH, Caine VA, Meyers JD, Corey L, Medeiros E, et al. Cytomegalovirus infection in sex partners: evidence for sexual transmission. J Infect Dis 1985;151:344-8. 
Harada K, Eizuru Y, Isashiki Y, Ihara S, Minamishima Y. Genetic analysis of a clinical isolate of human cytomegalovirus exhibiting resistance against both ganciclovir and cidofovir. Arch Virol 1997;142:215-25.

Hendrix MG, Salimans MM, van Boven CP, Bruggeman CA. High prevalence of latently present cytomegalovirus in arterial walls of patients suffering from grade III atherosclerosis. Am J Pathol 1990;136:23-8.

Ho M, Suwansirikul S, Dowling JN, Youngblood LA, Armstrong JA. The transplanted kidney as a source of cytomegalovirus infection. N Engl J Med 1975;293:1109-12.

Homman-Loudiyi M, Hultenby K, Britt W, Soderberg-Naucler C. Envelopment of human cytomegalovirus occurs by budding into Golgi-derived vacuole compartments positive for $\mathrm{gB}$, Rab 3, trans-Golgi network 46, and mannosidase II. J Virol 2003;77:3191-203.

Horwitz CA, Henle W, Henle G. Diagnostic aspects of the cytomegalovirus mononucleosis syndrome in previously healthy persons. Postgrad Med 1979;66:153-8.

Huang ES, Chen ST, Pagano JS. Human cytomegalovirus. I. Purification and characterization of viral DNA. J Virol 1973;12:1473-81.

Hutto C, Ricks R, Garvie M, Pass RF. Epidemiology of cytomegalovirus infections in young children: day care vs. home care. Pediatr Infect Dis 1985;4:149-52.

Isegawa Y, Mukai T, Nakano K, Kagawa M, Chen J, Mori Y, et al. Comparison of the complete DNA sequences of human herpesvirus 6 variants A and B. J Virol 1999;73:8053-63.

Jabs DA, Enger C, Bartlett JG. Cytomegalovirus retinitis and acquired immunodeficiency syndrome. Arch Ophthalmol 1989;107:75-80.

Jabs DA, Enger C, Dunn JP, Forman M. Cytomegalovirus retinitis and viral resistance: ganciclovir resistance. CMV Retinitis and Viral Resistance Study Group. J Infect Dis 1998;177:770-3.

Jacobson MA. Review of the toxicities of foscarnet. J Acquir Immune Defic Syndr 1992;5:S11-7.

Kaptein SJF, Beuken E, Grauls GELM, Bruggeman CA, Vink C. Rat cytomegalovirus open reading frame R44 is an early-late gene that encodes a nuclear protein. Arch Virol 2001;146:2211-8.

Kaptein SJF, Beisser PS, Gruijthuijsen YK, Savelkouls KGM, van Cleef KWR, Beuken E, et al. The rat cytomegalovirus $\mathrm{R} 78 \mathrm{G}$ protein-coupled receptor gene is required for production of infectious virus in the spleen. J Gen Virol 2003;84:2517-30.

Kaptein SJF, van Cleef KWR, Gruijthuijsen YK, Beuken EVH, van Buggenhout L, Beisser PS, et al. The r131 gene of rat cytomegalovirus encodes a proinflammatory CC chemokine homolog which is essential for the production of infectious virus in the salivary glands. Virus Genes 2004;29:43-61.

Kendle JB, Fan-Havard P. Cidofovir in the treatment of cytomegaloviral disease. Ann Pharmacother 1998;32:1181-92.

Klemola E, Kaariainen L. Cytomegalovirus as a possible cause of a disease resembling infectious mononucleosis. Br Med J 1965;5470:1099-102. 
Klemola E, Kaariainen L, von Essen R, Haltia K, Koivuniemi A, von Bonsdorff CH. Further studies on cytomegalovirus mononucleosis in previously healthy individuals. Acta Med Scand 1967;182:311-22.

Kloover JS, Grauls GELM, Blok MJ, Vink C, Bruggeman CA. A rat cytomegalovirus strain with a disruption of the $\mathrm{r} 144 \mathrm{MHC}$ class I-like gene is attenuated in the acute phase of infection in neonatal rats. Arch Virol 2002;147:813-24.

Kondo $\mathrm{K}, \mathrm{Xu} \mathrm{J}$, Mocarski ES. Human cytomegalovirus latent gene expression in granulocytemacrophage progenitors in culture and in seropositive individuals. Proc Natl Acad Sci USA 1996;93:11137-42.

Koskinen PK, Nieminen MS, Krogerus LA, Lemstrom KB, Mattila SP, Hayry PJ, et al. Cytomegalovirus infection and accelerated cardiac allograft vasculopathy in human cardiac allografts. J Heart Lung Transplant 1993;12:724-9.

Koskinen P, Lemstrom K, Bruggeman C, Lautenschlager I, Hayry P. Acute cytomegalovirus infection induces a subendothelial inflammation (endothelialitis) in the allograft vascular wall. A possible linkage with enhanced allograft arteriosclerosis. Am J Pathol 1994;144:41-50.

LaFemina RL, Hayward GS. Replicative forms of human cytomegalovirus DNA with joined termini are found in permissively infected human cells but not in non-permissive Balb/c-3T3 mouse cells. J Gen Virol 1983;64:373-89.

Lang DJ. The epidemiology of cytomegalovirus infections. In: Krugman S, Gershon AA, editors. Infections of the fetus and newborn infant. Alan R. Liss, New York 1975:35-45.

Lang DJ, Kummer JF. Cytomegalovirus in semen: observations in selected populations. J Infect Dis 1975;132:472-3.

Lautenschlager I, Hockerstedt K, Jalanko H, Loginov R, Salmela K, Taskinen E, et al. Persistent cytomegalovirus in liver allografts with chronic rejection. Hepatology 1997a;25:190-4.

Lautenschlager I, Soots A, Krogerus L, Kauppinen H, Saarinen O, Bruggeman C, et al. Effect of cytomegalovirus on an experimental model of chronic renal allograft rejection under triple-drug treatment in the rat. Transplantation 1997b;64:391-8.

Lemstrom K, Koskinen P, Krogerus L, Daemen M, Bruggeman C, Hayry P. Cytomegalovirus antigen expression, endothelial cell proliferation, and intimal thickening in rat cardiac allografts after cytomegalovirus infection. Circulation 1995;92:2594-604.

Li F, Yin M, van Dam JG, Grauls G, Rozing J, Bruggeman CA. Cytomegalovirus infection enhances the neointima formation in rat aortic allografts: effect of major histocompatibility complex class I and class II antigen differences. Transplantation 1998;65:1298-304.

Martelius T, Scholz M, Krogerus L, Hockerstedt K, Loginov R, Bruggeman C, et al. Antiviral and immunomodulatory effects of desferrioxamine in cytomegalovirus-infected rat liver allografts with rejection. Transplantation 1999;68:1753-61.

Masse MJ, Karlin S, Schachtel GA, Mocarski ES. Human cytomegalovirus origin of DNA replication (oriLyt) resides within a highly complex repetitive region. Proc Natl Acad Sci USA 1992;89:524650. 
McDonald K, Rector TS, Braulin EA, Kubo SH, Olivari MT. Association of coronary artery disease in cardiac transplant recipients with cytomegalovirus infection. Am J Cardiol 1989;64:359-62.

McVoy MA, Adler SP. Human cytomegalovirus DNA replicates after early circularization by concatemer formation, and inversion occurs within the concatemer. J Virol 1994;68:1040-51.

Meijer H, Dreesen JCFM, van Boven CPA. Molecular cloning and restriction endonuclease mapping of the rat cytomegalovirus genome. J Gen Virol 1986;67:1327-42.

Melnick JL, Hu C, Burek J, Adam E, DeBakey ME. Cytomegalovirus DNA in arterial walls of patients with atherosclerosis. J Med Virol 1994;42:170-4.

Meyers JD, Flournoy N, Thomas ED. Nonbacterial pneumonia after allogeneic marrow transplantation: a review of ten years' experience. Rev Infect Dis 1982;4:1119-32.

Minick CR, Fabricant CG, Fabricant J, Litrenta MM. Atheroarteriosclerosis induced by infection with a herpesvirus. Am J Pathol 1979;96:673-706.

Mocarski ES. Cytomegaloviruses and their replication. In: Fields BN, Knipe DM, Howley PM, Chanock RM, Melnick JL, Monath TP, Roizman B, Straus SE, editors. Fields Virology, 3rd ed, vol 2. Lippincott-Raven Publishers, Philadelphia 1996:2447-92.

Noble S, Faulds D. Ganciclovir. An update of its use in the prevention of cytomegalovirus infection and disease in transplant recipients. Drugs 1998;56:115-46.

Ogawa-Goto K, Tanaka K, Gibson W, Moriishi E, Miura Y, Kurata T, et al. Microtubule network facilitates nuclear targeting of human cytomegalovirus capsid. J Virol 2003;77:8541-7.

Pass RF, Long WK, Whitley RJ, Soong SJ, Diethelm AG, Reynolds DW, et al. Productive infection with cytomegalovirus and herpes simplex virus in renal transplant recipients: role of source of kidney. J Infect Dis 1978;137:556-63.

Pass RF, Stagno S, Myers GJ, Alford CA. Outcome of symptomatic congenital cytomegalovirus infection: results of long-term longitudinal follow-up. Pediatrics 1980;66:758-62.

Pass RF, August AM, Dworsky M, Reynolds DW. Cytomegalovirus infection in day-care center. N Engl J Med 1982;307:477-9.

Pass RF, Hutto C, Ricks R, Cloud GA. Increased rate of cytomegalovirus infection among parents of children attending day-care centers. N Engl J Med 1986;314:1414-8.

Pass RF, Little EA, Stagno S, Britt WJ, Alford CA. Young children as a probable source of maternal and congenital cytomegalovirus infection. N Engl J Med 1987;316:1366-70.

Prince AM, Szmuness W, Millian SJ, David DS. A serologic study of cytomegalovirus infections associated with blood transfusions. N Engl J Med 1971;284:1125-31.

Priscott PK, Tyrrell DAJ. The isolation and partial characterisation of a cytomegalovirus from the brown rat, Rattus norvegicus. Arch Virol 1982;73:145-60.

Rawlinson WD, Farrell HE, Barrell BG. Analysis of the complete DNA sequence of murine cytomegalovirus. J Virol 1996;70:8833-49.

Reinke P, Fietze E, Ode-Hakim S, Prosch S, Lippert J, Ewert R, et al. Late-acute renal allograft rejection and symptomless cytomegalovirus infection. Lancet 1994;344:1737-8. 
Reynolds DW, Stagno S, Hosty TS, Tiller M, Alford CA. Maternal cytomegalovirus excretion and perinatal infection. N Engl J Med 1973;289:1-5.

Reynolds DW, Stagno S, Alford CA. Chronic congenital and perinatal infections. In: Avery GB, editor. Neonatology pathophysiology and management of the newborn. JB Lippincott, Philadelphia 1981:748-489.

Roizman B. Herpesviridae. In: Fields BN, Knipe DM, Howley PM, Chanock RM, Melnick JL, Monath TP, Roizman B, Straus SE, editors. Fields Virology, 3rd ed, vol 2. Lippincott-Raven Publishers, Philadelphia 1996:2221-30.

Rotola A, Ravaioli T, Gonelli A, Dewhurst S, Cassai E, Di Luca D. U94 of human herpesvirus 6 is expressed in latently infected peripheral blood mononuclear cells and blocks viral gene expression in transformed lymphocytes in culture. Proc Natl Acad Sci USA 1998;95:13911-6.

Ryckman BJ, Jarvis MA, Drummond DD, Nelson JA, Johnson DC. Human cytomegalovirus entry into epithelial and endothelial cells depends on genes UL128 to UL150 and occurs by endocytosis and low-pH fusion. J Virol 2006;80:710-22.

Sarasini A, Baldanti F, Furione M, Percivalle E, Brerra R, Barbi M, et al. Double resistance to ganciclovir and foscarnet of four human cytomegalovirus strains recovered from AIDS patients. J Med Virol 1995;47:237-44.

Scheffczik H, Savva CGW, Holzenburg A, Kolesnikova L, Bogner E. The terminase subunits pUL56 and pUL89 of human cytomegalovirus are DNA-metabolizing proteins with toroidal structure. Nucleic Acids Res 2002;30:1695-703.

Sinclair J, Sissons P. Latency and reactivation of human cytomegalovirus. J Gen Virol 2006;87:1763-79.

Singh N, Dummer JS, Kusne S, Breinig MK, Armstrong JA, Makowka L, et al. Infections with cytomegalovirus and other herpesviruses in 121 liver transplant recipients: transmission by donated organ and the effect of OKT3 antibodies. J Infect Dis 1988;158:124-31.

Sohn YM, Oh MK, Balcarek KB, Cloud GA, Pass RF. Cytomegalovirus infection in sexually active adolescents. J Infect Dis 1991;163:460-3.

Speir E, Modali R, Huang ES, Leon MB, Shawl F, Finkel T, et al. Potential role of human cytomegalovirus and p53 interaction in coronary restenosis. Science 1994;265:391-4.

Speir E, Huang ES, Modali R, Leon MB, Shawl F, Finkel T, et al. Interaction of human cytomegalovirus with p53: possible role in coronary restenosis. Scand J Infect Dis Suppl 1995;99:78-81.

Stagno S, Reynolds DW, Pass RF, Alford CA. Breast milk and the risk of cytomegalovirus infection. N Engl J Med 1980;302:1073-6.

Stagno S, Pass RF, Dworsky ME, Alford CA. Maternal cytomegalovirus infection and perinatal transmission. In: Knox GE, editor. Clinical obstetrics and gynecology. JB Lippincott, Philadelphia 1982:563-76.

Stagno S, Pass RF, Dworsky ME, Alford CA. Congenital and perinatal cytomegalovirus infections. Semin Perinatol 1983;7:31-42. 
Stals FS, Bosman F, van Boven CPA, Bruggeman CA. An animal model for therapeutic intervention studies of CMV infection in the immunocompromised host. Arch Virol 1990;114:91-107.

Stals FS, de Clercq E, Bruggeman CA. Comparative activity of (S)-1-(3-hydroxy-2phosphonylmethoxypropyl)cytosine and 9-(1,3-dihydroxy-2-propoxymethyl)guanine against rat cytomegalovirus infection in vitro and in vivo. Antimicrob Agents Chemother 1991;35:2262-6.

Stals FS, Zeytinoglu A, Havenith M, de Clercq E, Bruggeman CA. Rat cytomegalovirus-induced pneumonitis after allogeneic bone marrow transplantation: effective treatment with (S)-1-(3hydroxy-2-phosphonyl-methoxypropyl)cytosine. Antimicrob Agents Chemother 1993;37:218-23.

Stinski MF. Molecular biology of cytomegaloviruses. In: Roizman B, editor. Herpesviruses. Plenum, New York 1983:67-113.

Streblow DN, Kreklywich CN, Smith P, Soule JL, Meyer C, Yin M, et al. Rat cytomegalovirusaccelerated transplant vascular sclerosis is reduced with mutation of the chemokine-receptor R33. Am J Transplant 2005;5:436-42.

Thomson BJ, Efstathiou S, Honess RW. Acquisition of the human adeno-associated virus type-2 rep gene by human herpesvirus type-6. Nature 1991;351:78-80.

Vink C, Beuken E, Bruggeman CA. Structure of the rat cytomegalovirus genome termini. J Virol 1996;70:5221-9.

Vink C, Beuken E, Bruggeman CA. Cloning and functional characterization of the origin of lyticphase DNA replication of rat cytomegalovirus. J Gen Virol 1997;78:2963-73.

Vink C, Beuken E, Bruggeman CA. Complete DNA sequence of the rat cytomegalovirus genome. J Virol 2000;74:7656-65.

Wang X, Huong SM, Chiu ML, Raab-Traub N, Huang ES. Epidermal growth factor receptor is a cellular receptor for human cytomegalovirus. Nature 2003;424:456-61.

Wang X, Huang DY, Huong SM, Huang ES. Integrin $\alpha \mathrm{v} \beta 3$ is a coreceptor for human cytomegalovirus. Nat Med 2005;11:515-21.

Weller TH, Hanshaw JB, Scott DE. Serologic differentiation of viruses responsible for cytomegalic inclusion disease. Virology 1960;12:130-2.

Williamson WD, Demmler GJ, Percy AK, Catlin FI. Progressive hearing loss in infants with asymptomatic congenital cytomegalovirus infection. Pediatrics 1992;90:862-6.

Winston DJ, Ho WG, Howell CL, Miller MJ, Mickey R, Martin WJ, et al. Cytomegalovirus infections associated with leukocyte transfusions. Ann Intern Med 1980;93:671-5.

Wright HT, Goodheart CR, Lielausis A. Human cytomegalovirus. Morphology by negative staining. Virology 1964;23:419-24.

Yow MD, Williamson DW, Leeds LJ, Thompson P, Woodward RM, Walmus BF, et al. Epidemiologic characteristics of cytomegalovirus infection in mothers and their infants. Am J Obstet Gynecol 1988;158:1189-95.

Zhou YF, Leon MB, Waclawiw MA, Popma JJ, Yu ZX, Finkel T, et al. Association between prior cytomegalovirus infection and the risk of restenosis after coronary atherectomy. $\mathrm{N}$ Engl $\mathrm{J}$ Med 1996;335:624-30. 


\section{Chapter 2}

Rat cytomegalovirus gene expression in cardiac allograft recipients is tissuespecific and does not parallel the profiles detected in vitro

Daniel N. Streblow, Koen W.R. van Cleef, Craig N. Kreklywich, Christine Meyer, Patricia Smith, Victor Defilippis, Finn Grey, Klaus Früh, Robert Searles, Cathrien Bruggeman, Cornelis Vink, Jay A. Nelson, Susan L. Orloff

J Virol 2007;in press 


\section{Abstract}

Rat cytomegalovirus (RCMV) is a $\beta$-herpesvirus with a 230-kbp genome containing over 167 open reading frames (ORFs). RCMV gene expression is tightly regulated in cultured cells, occurring in three distinct kinetic classes (immediate early, early and late). However, the extent of viral gene expression in vivo and its relationship to the in vitro expression is unknown. In this study, we used RCMV-specific DNA microarrays to investigate the viral transcriptional profiles in cultured, RCMV-infected endothelial cells, fibroblasts and aortic smooth muscle cells, and to compare these profiles to those found in tissues from RCMV-infected rat heart transplant recipients. In cultured cells, RCMV expresses approximately $95 \%$ of the known viral ORFs with few differences between cell types. By contrast, in vivo viral gene expression in tissues from rat heart allograft recipients is highly restricted. In the tissues studied, a total of 80 viral genes expressing levels twice above background (5-10,000 copies per $2 \mu \mathrm{g}$ of total RNA) were detected. In each tissue type there were a number of genes expressed exclusively in that tissue. Although viral mRNA and genomic DNA levels were lower in the spleen compared to submandibular glands, the number of individual viral genes expressed was higher in the spleen (61 vs. 40). This finding suggests that the number of viral genes expressed is specific to a given tissue and is not dependent upon viral load or viral mRNA levels. Our results demonstrate that the profiles as well as the amplitude of viral gene expression are tissue-specific and are dramatically different compared to those in infected cultured cells, indicating that RCMV gene expression in vitro does not reflect viral gene expression in vivo.

\section{Introduction}

Cytomegaloviruses (CMVs) are ubiquitous $\beta$-herpesviruses that establish life-long latent infections following primary infection. Although anti-viral therapy has significantly reduced disease in transplant and AIDS patients, human CMV (HCMV) still is a significant problem in congenital disease and bone marrow transplant patients (Pass, 2001). In these infected individuals, HCMV can manifest itself in a number of CMVrelated acute diseases, including retinitis, encephalitis, gastritis and mononucleosis. In addition, HCMV has also been associated with long-term diseases, such as atherosclerosis, chronic rejection following solid organ transplantation and, more recently, malignancies (Cobbs et al., 2002). CMV is one of the largest human viruses known with over 200 open reading frames (ORFs) and a number of viral genes have 
been implicated in the development of CMV-related diseases. However, the in vivo expression profiles of these and other viral genes are unknown. Therefore, a comprehensive profiling of CMV gene expression during infection in the host is warranted. In addition, it is important to determine whether one can use the viral gene expression patterns seen in in vitro models of virus-infected cells to predict those patterns seen in vivo.

In cultured cells, CMV gene expression occurs in three kinetic phases, designated as immediate early (IE), early (E) and late (L) (Mocarski, 2001). These phases were defined through the use of drugs that target either cellular translation or the viral DNA polymerase. Transcription of IE genes begins shortly following virus penetration and uncoating and does not require de novo protein synthesis. The IE proteins enhance transcription from both host and viral promoters leading to the expression of the $E$ genes, which include genes involved in viral DNA replication, such as the viral DNA polymerase gene (UL54). L viral genes are expressed following viral DNA synthesis, thus making expression of this class of genes sensitive to inhibitors of the viral DNA polymerase. The $L$ viral gene kinetic class is generally involved in viral DNA packaging, assembly and egress. Recently, virus-specific DNA microarray analysis has been utilized to classify global viral gene transcription of herpes simplex virus type 1 (HSV-1) and HCMV (Chambers et al., 1999; Goodrum et al., 2002, 2004; Stingley et al., 2000). Goodrum et al. (2002, 2004) used HCMV-specific microarrays to examine HCMV gene expression in latently infected $\mathrm{CD}^{+} 4^{+}$hematopoietic progenitors. A subset of HCMV genes representing IE, $E$ and $L$ stages of infection was detected in these latently infected cell cultures at 1, 5 and 8 days post infection (dpi). However, in these experiments, the investigators did not identify an obvious pattern of viral gene expression that represented a potential kinetic class of latency genes. The HCMV genes expressed during the establishment of latency in this system may represent an initial burst of expression followed by viral quiescence in the cell. Interestingly, the extent of viral gene expression was dependent upon the status of cellular differentiation. An important question related to these studies concerns the relevance of HCMV gene expression prior to the development of latency and how this relates to viral gene expression during viral persistence in vivo.

The rat CMV (RCMV)/rat model has proven to be an important tool for studying mechanisms involved in CMV-related diseases, including the effect of the virus on accelerated solid organ transplant rejection. Infection of immunocompetent rats leads to a limited subclinical infection that typically persists in the columnar epithelial cells of the 
submandibular glands (SMGs) for up to 180 dpi (Bruggeman et al., 1983a, 1985). RCMV infection of immunocompromised rats causes a widespread infection of most tissues, infecting a number of different cell types, including endothelial cells, epithelial cells, macrophages, polymorphonuclear cells and fibroblasts. In this report, we profiled viral gene expression utilizing microarrays containing DNA oligonucleotides specific for the 167 known RCMV ORFs (Vink et al., 2000). We compared viral gene expression in cultured rat embryo fibroblasts (REFs), vascular smooth muscle cells (SMCs) and aortic endothelial cells (ECs) to the expression profiles observed in the tissues from RCMVinfected allograft recipients, including SMG (the site of virus persistence), allograft heart, lung, liver, kidney and spleen. We observed that the pattern of RCMV gene expression in vivo differs dramatically from that in RCMV-infected cultured cells. Our data suggest that RCMV gene expression is highly tissue-specific. Importantly, the majority of the RCMV genes expressed at high levels in tissues is not known to be involved in virus replication, but may represent the profile of immune modulator genes required for $\mathrm{CMV}$ persistence.

\section{Materials and methods}

\section{1. $R C M V$}

SMG-derived stocks of the Maastricht strain of RCMV were titered using REFs (Beisser et al., 1998; Bruggeman et al., 1983b). Plaque assays were performed in confluent 24-well plates by infection with an appropriate serial virus dilution in $0.2 \mathrm{ml}$ of media and then incubated at $37^{\circ} \mathrm{C}$ for $90 \mathrm{~min}$. Following incubation, the infected cells were rinsed with PBS and overlaid with $1 \mathrm{ml}$ EMEM supplemented with $10 \%$ fetal calf serum (FCS), non-essential amino acids, pen/strep and $20 \mathrm{mM} \mathrm{L-glutamine} \mathrm{with} \mathrm{a} \mathrm{final}$ concentration of $0.6 \%$ agarose. After 7 days, the cells were fixed in $10 \%$ formalin in PBS and stained with $0.05 \%$ aqueous methylene blue. The plaques were counted by light microscopy.

\subsection{RCMV infection of tissue culture cells}

Primary aortic SMCs, aortic ECs and REFs were isolated from F344 rats (Harlan Sprague-Dawley) and maintained in DMEM supplemented with 10\% FCS and pen/strep/glutamine (Melnychuk et al., 2004; Streblow et al., 2003). EC phenotype was confirmed by staining these cells with antibodies directed against von Willebrand factor. These cells exhibited characteristics and morphology typical of their origin when maintained in culture beyond passage 15 (data not shown). REFs, SMCs and ECs were plated onto $60-\mathrm{mm}$ dishes and infected with RCMV upon confluence at a multiplicity of 
infection (moi) equal to 0.1 . After $2 \mathrm{~h}$, the cells were washed 3 times with PBS. The infected cells were harvested at $4,8,16,24,36$ and $48 \mathrm{~h}$ post infection (hpi) by first washing once with PBS, then adding $1 \mathrm{ml}$ of Trizol reagent. The reagent was allowed to lyse the cells for $5 \mathrm{~min}$. Subsequently, the samples were stored frozen at $-80^{\circ} \mathrm{C}$.

\subsection{Preparation of rat tissues}

In order to determine viral gene expression in vivo, we isolated RNA from SMG, lung, liver, kidney, spleen and graft heart from allograft recipients (Streblow et al., 2003). For these studies, adult male F344 rats (Harlan Sprague-Dawley) served as allogeneic heart donors, while Lewis rats (Harlan Sprague-Dawley) served as solid organ transplant recipients (Streblow et al., 2003). To prevent acute rejection, Lewis recipients were treated with low dose CsA for 10 days ( $5 \mathrm{mg} / \mathrm{kg} /$ day). In all animals, the native heart remained intact. Acute RCMV infection was accomplished by injecting $1 \times 10^{5}$ plaqueforming units (pfu) of RCMV intraperitoneally (ip) on day 1 following the heart transplant operation. The tissues were harvested from allograft recipients at $7,14,21$ and 28 days post transplantation. Total RNA was prepared from $0.25 \mathrm{~g}$ of rat tissues using the Trizol method. All animals were housed in the Portland VA Medical Center animal facilities in a specific-pathogen-free room. This facility is AAALAC accredited and complies with the requirements for animal care as stipulated by USDA and HHS.

\subsection{RCMV microarray techniques}

The Spotted Microarray Core (SMC) at the Vaccine and Gene Therapy Institute, Oregon Health and Science University (http://www.ohsu.edu/gmsr/smc/) printed the RCMV microarray used for this study. Each slide contains two unique 70-mer antisense oligos for each of the 167 predicted viral ORFs (Vink et al., 2000) and an additional 2,925 rat cellular genes. RCMV gene slides were printed on aminosilane-coated glass slides using the Cartesian PixSys 5500 XL microarray printer (Genomic Solutions, located at the SMC) and each cDNA was spotted twice to account for intrachip variation. The oligos were chosen with a 3' bias and compared against the NCBI database for alignment to the genome sequence of the RCMV Maastricht strain and for possible cross hybridization to cellular sequences.

First strand cDNA was synthesized from $2 \mu \mathrm{g}$ of total RNA using $1.0 \mu \mathrm{M}$ oligo(dT)-T7 primer (GGCCAGTGAATTGTAATACGACTCACTATAGGG[T] ${ }_{24}$ ) and $200 \cup$ SuperScript III reverse transcriptase (Invitrogen). Double-stranded cDNA was generated by the addition of second strand buffer (Invitrogen) according to the manufacturer's protocol 
and purified by phenol/chloroform/isoamyl alcohol extraction. The cDNA was amplified one round using the T7 Megascript kit (Ambion) to produce amplified RNA (aRNA), which was purified using the RNeasy Mini kit (Qiagen). Five $\mu \mathrm{g}$ of aRNA was reverse transcribed with $300 \cup$ SuperScript III reverse transcriptase in the presence of $9 \mu \mathrm{g}$ of random hexamers, $0.5 \mathrm{mM}$ dATP, dGTP and dCTP, $0.35 \mathrm{mM}$ dTTP and $0.15 \mathrm{mM}$ aminoallyl dUTP. aRNA was hydrolyzed with $0.3 \mathrm{~N} \mathrm{NaOH}\left(70^{\circ} \mathrm{C}\right.$ for $\left.10 \mathrm{~min}\right)$ and then neutralized with $0.625 \mathrm{M}$ HEPES ( $\mathrm{pH}$ 7.5). Amino-allyl-labeled cDNA was purified using the Cyscribe GFX purification kit (Amersham) and coupled to Cy3 or Cy5 fluorescent dye (Amersham) through the incorporated amino-allyl dUTP. The labeled cDNA was purified using the Cyscribe GFX purification kit and then hybridized to microarray slides in the presence of Slide Hybe \#2 (Ambion) at $65^{\circ} \mathrm{C}$ for $18 \mathrm{~h}$. The slides were washed consecutively with $0.5 \times$ SSC/0.1\% SDS, $0.06 x$ SSC/0.1\% SDS and $0.06 x$ SSC for $5 \mathrm{~min}$ at room temperature. All slides were scanned using Bioscience GeneScan Lite laser scanner and analyzed using Imagene digital processing software and Genesight data analysis software (Biodiscovery). Local background values were subtracted using Imagene 3.5.1 software and genes determined to be 'on' had values twice that of the background.

\subsection{QRT-PCR detection of RCMV gene expression}

Quantitative, real-time reverse transcription-PCR (QRT-PCR) was used to confirm and quantify the RCMV gene expression results obtained using microarray analysis. cDNA was generated as described above using SuperScript III reverse transcriptase and analyzed by real-time PCR techniques using primer sets recognizing RCMV gene sequences (Table 1). Primers sets were identified using Primer Express software (Applied Biosystems). PCR reactions were performed using the SYBR Green PCR master mix (Applied Biosystems), except for PCR reactions for R78, r119.1, r119.2, r151 and r152.4, which were performed using specific TaqMan probes and master mix. Following thermal activation of AmpliTaq Gold (10 min at $95^{\circ} \mathrm{C}$ ), a total of 40 cycles were performed $\left(15 \mathrm{~s}\right.$ at $95^{\circ} \mathrm{C}$ and $1 \mathrm{~min}$ at $58^{\circ} \mathrm{C}$ ) using the $\mathrm{ABI}$ Prism 7700 sequence detection system (Applied Biosystems). Plasmid clones containing each gene fragment were used as positive controls and quantification standards. PCR results were analyzed using $\mathrm{ABI}$ Prism 7700 sequence detection software. The sensitivity of detection of this assay was $<100$ plasmid copies for all of the tested RCMV genes. 
Table 1. Quantitative PCR primer sequences

\begin{tabular}{|l|l|}
\hline RCMV ORF & Primer Sequence \\
\hline R32 Forward & 5'-ATC CGG TCC ATG AGG TCG A \\
\hline R32 Reverse & 5'-GTG ATC AAT GAA TGT CGC GG \\
\hline R33 Forward & 5'-ACC CTG ACG TTC GTG ACG AC \\
\hline R33 Reverse & 5'-TGA TCG GCC AGT TCA GCA C \\
\hline R35 Forward & 5'-CCC TGA CCG TGT TCA AGA GG \\
\hline R35 Reverse & 5'-GAC TTT CGC ATG GCG ATC A \\
\hline R49 Forward & 5'-CGC GGT ATC GTT ATG GGT G \\
\hline R49 Reverse & 5'-ATG GGC AAG GAC AAA CTC GA \\
\hline R75 Forward & 5'-CTT CCG CAG AAC TCG CAG TG \\
\hline R75 Reverse & 5'-CCT GCG TCT ACA GCA CCT CCT A \\
\hline R78 Forward & 5'-CTT CTA CGC CCT GCA CTT CG \\
\hline R78 Reverse & 5' GCC AGC TCG TAG TAC CCG AC \\
\hline R114 Forward & 5'-ACC TTT ACG GAA CCG GAG TTG \\
\hline R114 Reverse & 5'-ACG GAC AAG GTC GAT AGG GA \\
\hline R116 Forward & 5'-TCC GGC TGA ATA AGA CCT CG \\
\hline R116 Reverse & 5'-CCC ATC CTC AAC AGC ACA CA \\
\hline r119.1 Forward & 5'-TTC GGA ATC GAT GGT GAC AAG \\
\hline r119.1 Reverse & 5'-CAC TCA TCG CCG TCA ACA GA \\
\hline r119.2 Forward & 5'-GTT CCA TCG GCA TCA TGT AAG A \\
\hline r119.2 Reverse & 5'-ACG ACG CTA ATG AAA CTG GCA \\
\hline r119.4 Forward & 5'-GTT CCA CTG AGA CTG CTT GCG \\
\hline r119.4 Reverse & 5'-CAG GAT TAT TTG GCG GCA AC \\
\hline r123 Forward & 5'-CCA CTA TCT TGG GCA CGG A \\
\hline r123 Reverse & 5'-ACC GAA ACC TTC AGA CAA CCA \\
\hline r148 Forward & 5'-TAC GAC CCA CGT CAA AAG TTG A \\
\hline r148 Reverse & 5'-ATC TCT ATG TCG TTT ACT GCG A \\
\hline r149 Forward & 5'-GAA CCG CGG ATT CGT AGT CTC \\
\hline r149 Reverse & 5'-ATT CCA GTG ACA CCG AGG GA \\
\hline r151 Forward & 5'-AAT CCA TTT TGT GGT CCA AGG A \\
\hline r151 Reverse & 5'-TCG ATG ACC GTT GGA GGA AC \\
\hline r152.4 Forward & 5'-ACC TTC GAG CCA ATG TGA ATG \\
\hline r152.4 Reverse & 5'-CAA CGT CTC AGA TGC GGA GA \\
\hline
\end{tabular}

\subsection{Statistical analysis}

Quantitative PCR data were analyzed by ANOVA and Student's $t$-test. $P$ values $<0.05$ were considered significant.

\section{Results}

\subsection{Profiling RCMV gene expression in vitro}

RCMV infects a number of different cell types both in vivo and in vitro, including ECs, SMCs, epithelial cells, fibroblasts and macrophages (Kloover et al., 2000; van der Strate et al., 2003). Similar to HCMV, the RCMV genome is about $230 \mathrm{kbp}$ and encodes 167 predicted ORFs (Vink et al., 2000). Whether CMV gene expression differs in various cell types or how in vivo viral gene expression compares to that observed in cultured cells has not been reported. In order to answer these important questions, we generated 
RCMV microarrays to profile viral gene expression both in vivo and in vitro. The RCMV microarray slides contain two unique, non-overlapping 70-mer antisense oligos for each of the 167 predicted viral ORFs (Vink et al., 2000) and an additional 2,925 rat cellular genes used to normalize the data. The oligos were chosen with a 3' bias and compared against the NCBI database for alignment to the RCMV Maastricht strain and for possible cross hybridization to cellular sequences. The specificity of the RCMV microarray was confirmed by hybridization of labeled RCMV genomic DNA, which bound each of the viral oligos on the chip, but did not display binding activity towards the cellular control oligos (data not shown).

In order to determine whether RCMV gene expression is cell type-specific, REFs, aortic SMCs and aortic ECs were infected with RCMV and harvested at 4, 8, 16, 24, 36 and $48 \mathrm{hpi}$. Then, RNA was purified from the cells and reverse transcribed into cDNA. The cDNA was amplified, labeled and hybridized to the RCMV microarray slides for $18 \mathrm{~h}$. The slides were washed, scanned and analyzed. A typical microarray analysis of RCMV gene expression in infected REFs is shown in Fig. 1. RCMV gene expression profiles for infected REFs, SMCs and ECs at 4, 16 and 48 hpi are depicted in Fig. 2 as the average intensity above background. At $4 \mathrm{hpi}$, only two genes, r123ex4 (IE1) and r128, are highly expressed in all cell types. However, by $16 \mathrm{hpi}$, nearly $80 \%$ of the RCMV genes is expressed at detectable levels. Ninety-six viral genes (60\% of the predicted viral ORFs) were expressed with E kinetics in RCMV-infected REFs treated with PAA and harvested at $48 \mathrm{hpi}$ (Table 2). Maximal RCMV gene expression occurs at 36 and $48 \mathrm{hpi}$, wherein over $87 \%$ of the viral genes is expressed (Fig. 2 and Table 2). Since labeled RCMV DNA bound to all of the viral oligos on the chip (data not shown), it is likely that the $10-13 \%$ of the RCMV genes that failed to be detected represent either genes with unknown splicing properties or genes that are expressed at very low levels. These genes were also not detected in RNA samples isolated from in vivo infected tissues, as described below. A positive signal on our RCMV DNA microarray required that any given gene expressed 510,000 copies of mRNA in $2 \mu \mathrm{g}$ of starting total RNA (data not shown). This was determined by comparing QRT-PCR evaluation of the expression of at least 15 RCMV genes to the microarray results from 10 different samples, wherein gene expression varied for the particular gene of interest from negative to positive. Interestingly, according to our microarray results, there are at least 7 genes expressed exclusively in ECs, 1 in SMCs and 3 in REFs. Our findings suggest that, other than a small subset of genes, $\mathrm{RCMV}$ gene expression is not cell type-specific in vitro. 

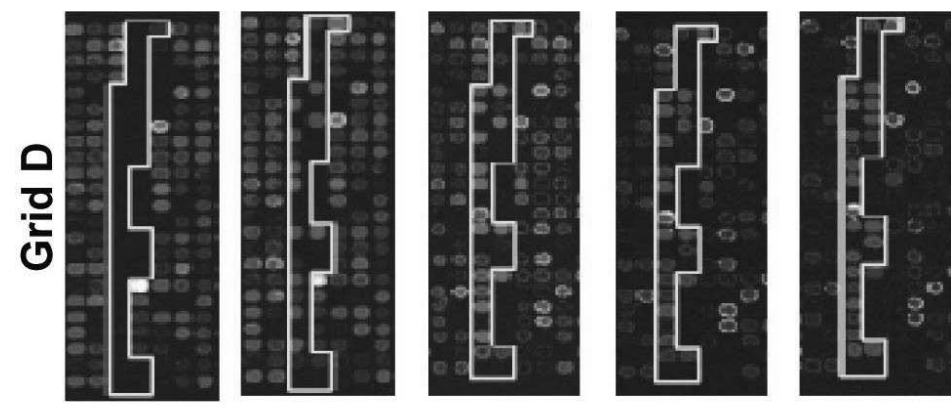

일
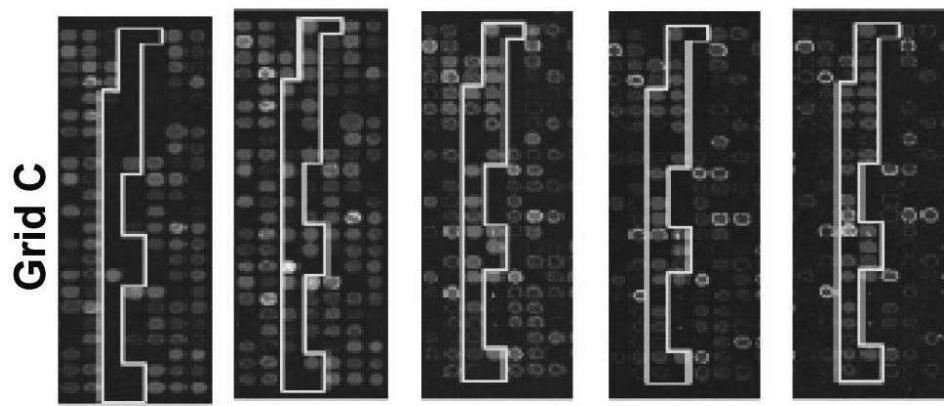

के 을

它

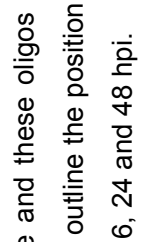
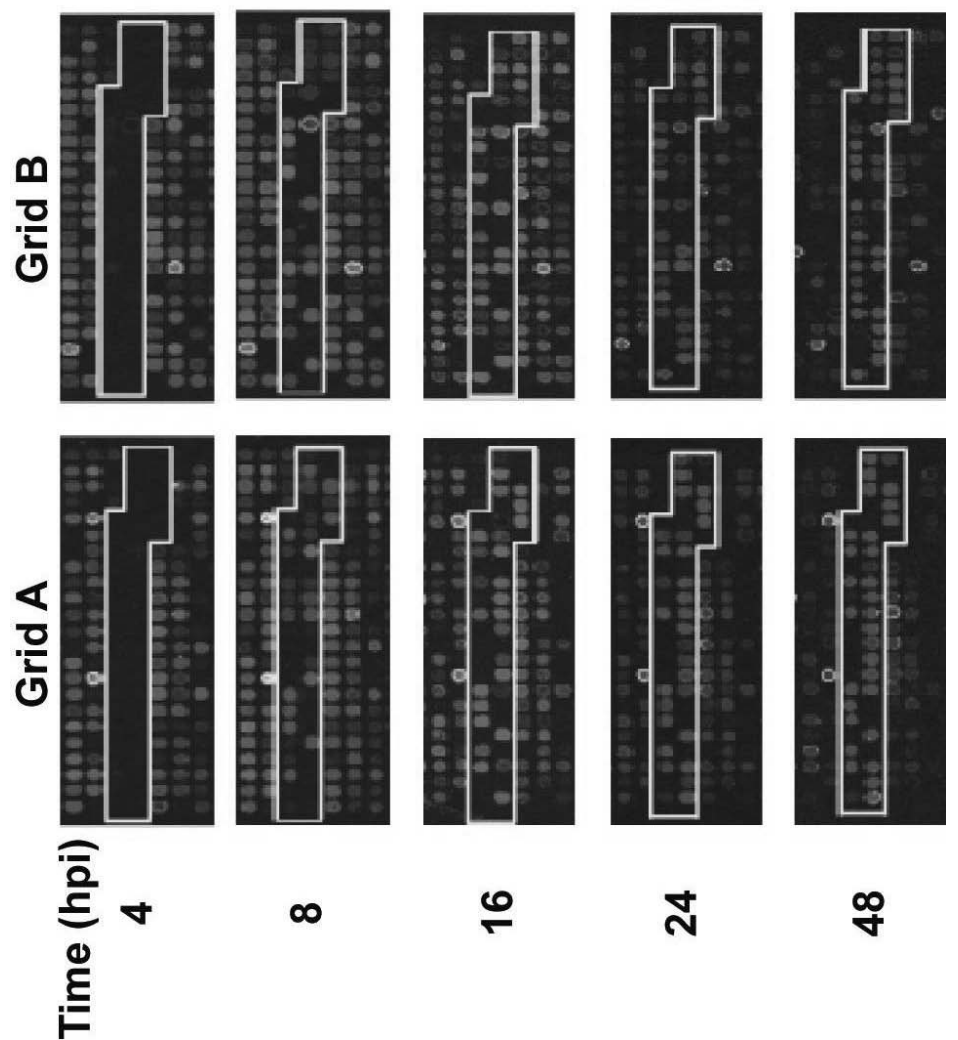

$\stackrel{0}{\mathbb{D}} \stackrel{0}{\mathbb{D}}$

뮨

ट $\stackrel{0}{0}$

ঠ

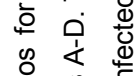

음 은 운

음 $\subseteq \sum_{\mathcal{X}}$

ป d

引 웡

(2) 0

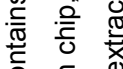

잉

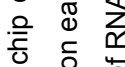

ᄃ

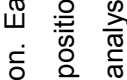

일

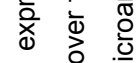

ब

$\gtrless$ 吾

$\sum_{\mathcal{X}} \frac{ \pm}{0}$

पั口 ब

步 品

离

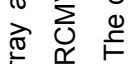

空

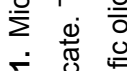

ㅎํㄴ 음 

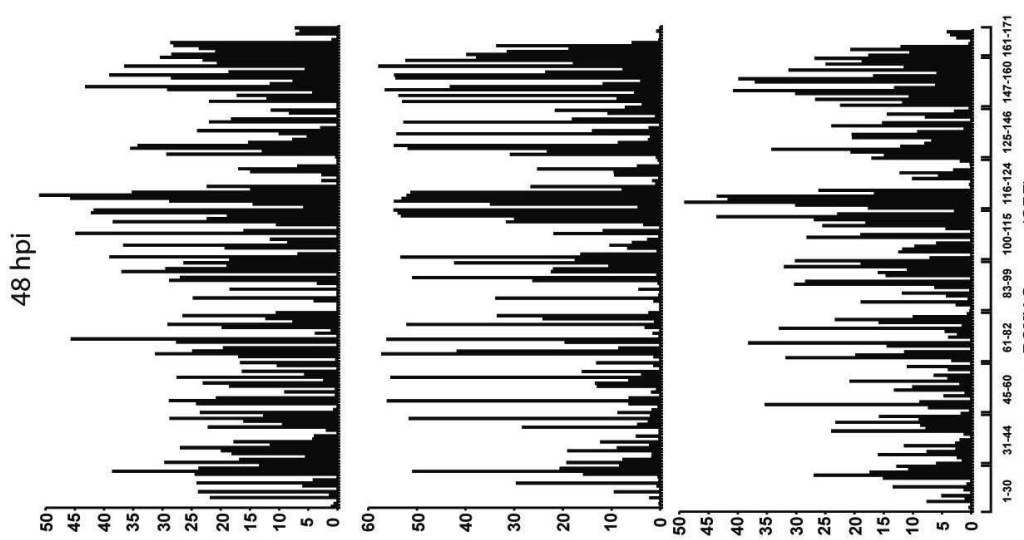

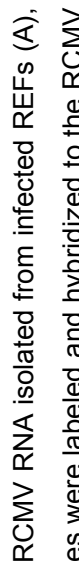
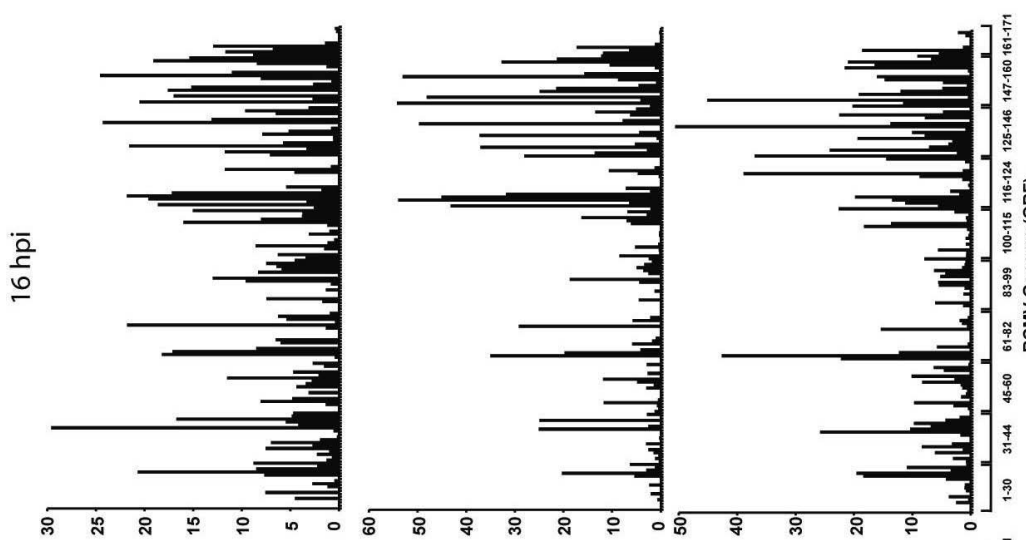

प है

$\frac{m}{\infty}$

ते

तั

तై 음

잉 엄

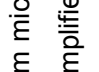

है $\frac{E}{2}$ के

क 2

竞

ब)

흘 흔

등 등

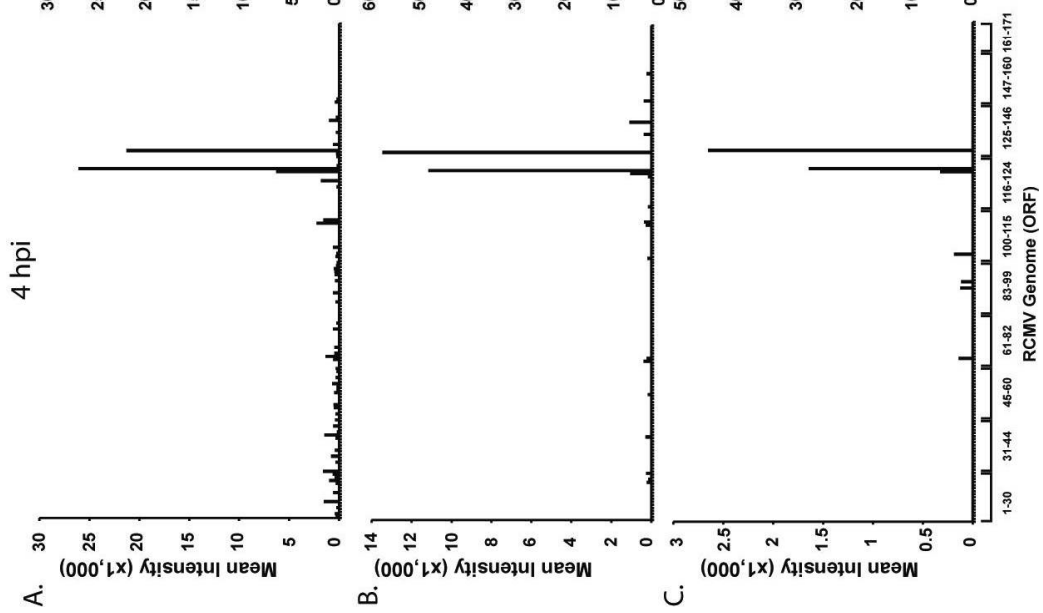

品

흔 은

프 0 는

ठ்

은 중

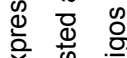

× \&

() $\frac{2}{2}$

ฮั

옹

ऽ

$\gtrless$ 을 응

บ $\frac{\pi}{0}$

त क त

iำ $\sum_{\text {क }}$ 
Table 2. Classification of RCMV gene expression in cultured REFs

\begin{tabular}{|c|c|c|c|}
\hline $\begin{array}{l}\text { Immediate } \\
\text { Early (4hr) }\end{array}$ & \multicolumn{2}{|c|}{ Early (PAA, 48hr) } & Late $(48 \mathrm{hr})$ \\
\hline \multirow{48}{*}{$\begin{array}{c}r 123 e x 4 \\
\text { r128 }\end{array}$} & r2 & R92 & r2.1 \\
\hline & r4 & R93 & r3 \\
\hline & r5 & R94 & R33 \\
\hline & R23 & R95 & R46 \\
\hline & R24 & R96 & R47 \\
\hline & r25.1 & R97 & R48 \\
\hline & $\mathrm{r} 25.3$ & R98 & R52 \\
\hline & R25 & R99 & R53 \\
\hline & R26 & R102 & r70.1 \\
\hline & R27 & R105 & R73 \\
\hline & R28 & r109 & r74 \\
\hline & R29 & R112ex1 & R75 \\
\hline & R31 & R113 & R76 \\
\hline & R32 & R114 & R84 \\
\hline & R34 & R115 & R85 \\
\hline & R35 & R116 & r90 \\
\hline & R36 & R117 & R100 \\
\hline & R37 & R118 & R104 \\
\hline & R38 & r119.1 & r106 \\
\hline & r39 & $\mathrm{r} 119.2$ & r107 \\
\hline & $\mathrm{r} 40$ & r119.3 & $\mathrm{r} 110$ \\
\hline & $\mathrm{r} 41$ & r119.4 & $\mathrm{r} 111.2$ \\
\hline & $\mathrm{r} 42$ & $\mathrm{r} 119.5$ & $\mathrm{r} 121.2$ \\
\hline & $\mathrm{r} 43.1$ & r119.6 & R121 \\
\hline & R43 & r142 & R122ex5 \\
\hline & R44 & r143 & r124 \\
\hline & R45 & r144 & r127 \\
\hline & R49 & r145 & r128 \\
\hline & R50 & $\mathrm{r} 146$ & r131 \\
\hline & R51 & $\mathrm{r} 147$ & r133 \\
\hline & R54 & $\mathrm{r} 149$ & r135 \\
\hline & R55 & r150 & $r 136$ \\
\hline & R56 & r151.1 & r137 \\
\hline & R57 & $\mathrm{r} 151.3$ & r138 \\
\hline & R69 & $\mathrm{r} 151$ & r139 \\
\hline & r70.2 & r152.1 & $\mathrm{r} 140$ \\
\hline & r70.3 & r152.3 & $\mathrm{r} 151.2$ \\
\hline & r70.4 & r152.4 & r152 \\
\hline & r70.5 & $\mathrm{r} 152.5$ & r155 \\
\hline & $\mathrm{R} 72$ & $\mathrm{r} 157$ & r168 \\
\hline & $\mathrm{R} 77$ & r158 & \\
\hline & R78 & $\mathrm{r} 160$ & \\
\hline & R80 & $r 161$ & \\
\hline & R82 & r162 & \\
\hline & R83 & r164 & \\
\hline & R87 & r166 & \\
\hline & R88 & $\mathrm{r} 167$ & \\
\hline & R91 & r171.1 & \\
\hline
\end{tabular}

\subsection{Profiling RCMV gene expression in vivo}

In order to explore viral gene expression in vivo, RCMV microarray slides were utilized to initially analyze RNA isolated from the SMGs from RCMV-infected heterotopic heart allograft recipients. For these studies, adult F344 rats served as allogeneic heart donors, while Lewis rats served as transplant recipients (Orloff et al., 2002; Streblow et al., 2003). RNA was isolated from heart allograft recipient tissues harvested at 7, 14, 21 
and 28 days post transplantation. The RNA was converted to cDNA, labeled and hybridized to the RCMV microarray chips as described above. Interestingly, at day 7, in RNA samples from each of the 4 rats tested, only two RCMV genes (R116 and r152.4) were expressed to at least twice the background level. These genes constitute approximately $1 \%$ of the known RCMV genes (Fig. 3). This finding is not surprising, since previous studies have demonstrated that RCMV takes approximately 14 days to establish infection in SMG (Bruggeman et al., 1983a, 1985; Kloover et al., 2000; Streblow et al., 2003). Approximately $11 \%$ of the RCMV genes is expressed at $14 \mathrm{dpi}$ and this number increases to nearly $25 \%$ by day 21 , which includes genes expressed with IE, E and L kinetics. The number of RCMV genes expressed decreased to $15 \%$ on day 28 (Fig. 3). Compared to the $87 \%$ transcriptionally active genes observed in the RCMV-infected tissue culture cells, the number of transcripts detected in vivo is quite low. This difference was not due to lower signal intensity. Rather, there was a clear bias in gene expression. For instance, even at day 21 , when the greatest numbers of RCMV genes are expressed, only a few of these genes are known to be involved in virus replication. In fact, most of the highly expressed genes are encoded in clusters on the right half of the RCMV genome, which is the region that contains genes thought to be involved in host cell manipulation and/or immune evasion (Vink et al., 2000). For example, r151 was highly expressed in the SMG of infected rats. The r151 gene is a homolog of the murine CMV (MCMV) m152 gene, which blocks cell surface expression of $\mathrm{MHC}$ class $\mathrm{I}$ in infected cells through retention of the protein in the cis-Golgi compartment (Gold et al., 2002; Kavanagh et al., 2001; Krmpotic et al., 1999).

To rule out that technical reasons were the cause of differences in expression patterns observed in vitro vs. in vivo, we used QRT-PCR to quantify the RCMV transcript levels. Shown in Fig. 4A are the normalized average copy numbers of R33 (vGPCR), $\mathrm{R} 75$ (gH), R114, R116, r119.1, r119.2, r119.4, r123 (IE1) and r151 as detected by QRTPCR in SMG tissues from 4 RCMV-infected rats. The levels of IE1 ( 123$)$ and other essential genes, such as $\mathrm{gH}$ (R75), were more than 100-fold lower than the expression levels of r119.1, r119.2 and r151. By contrast, in cultured RCMV-infected REFs, the expression levels of IE1 are much higher than those of r119.1 at early time points (4 and $8 \mathrm{hpi}$ ), whereas at later time points, the expression levels of these genes are similar (Fig. 4B). Additionally, by $16 \mathrm{hpi}$, the expression levels of $\mathrm{gH}$ in the RCMV-infected cultured cells are 10- to 100-fold higher than those of r119.1. These findings confirm the trend observed by microarray and indicate that in vitro RCMV gene expression profiles do not accurately predict the levels of gene expression found in vivo. 

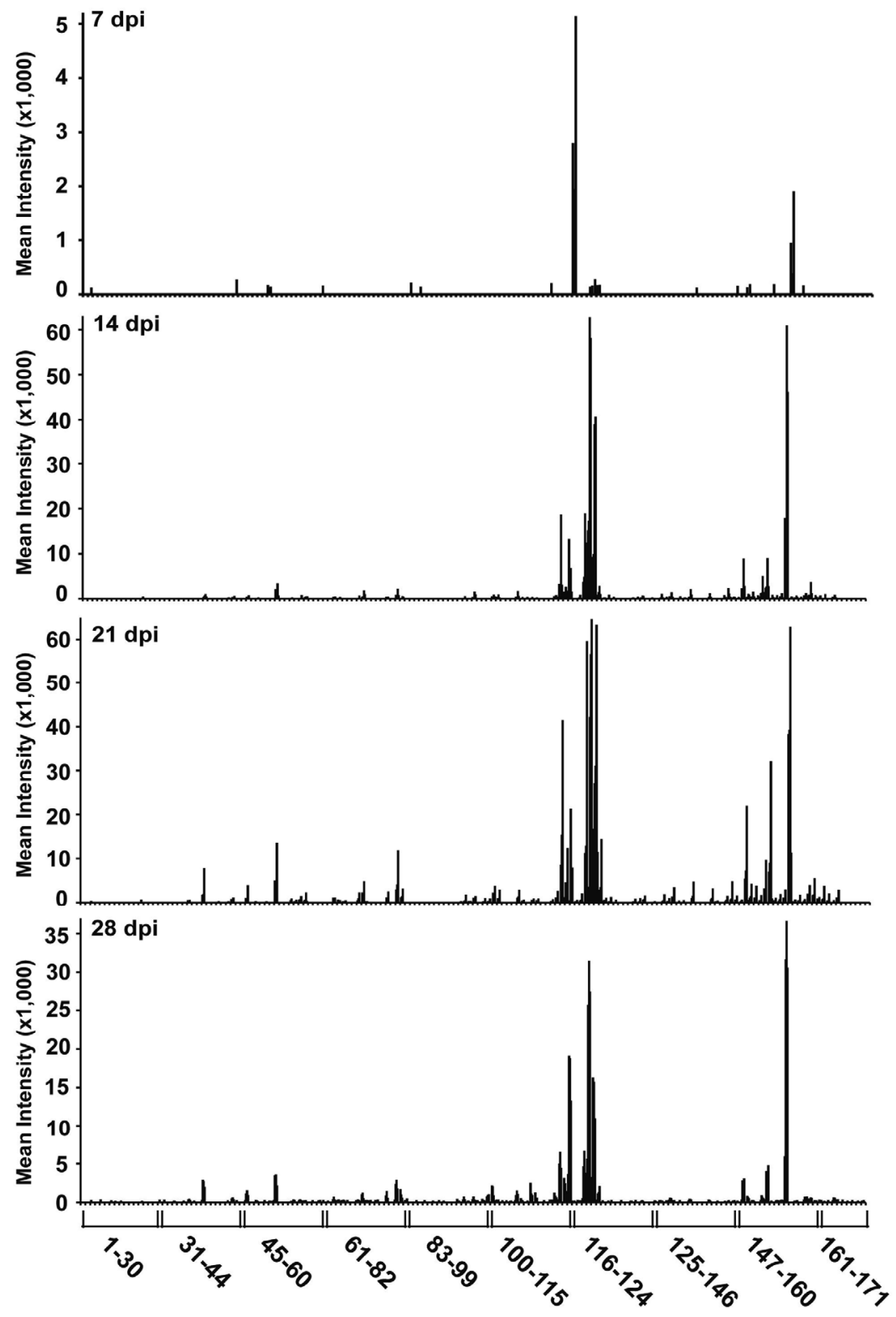

RCMV Genome (ORF)

Fig. 3. RCMV in vivo gene expression. Fluorescent intensities from microarray analysis of RCMV RNA isolated from infected rat SMGs that were harvested at 7, 14, 21 and 28 dpi. At each time point, SMG samples were isolated from 4 individually infected rats and analyzed on separate microarray chips. Data shown contain gene intensities acquired from each of these 4 separate arrays. 


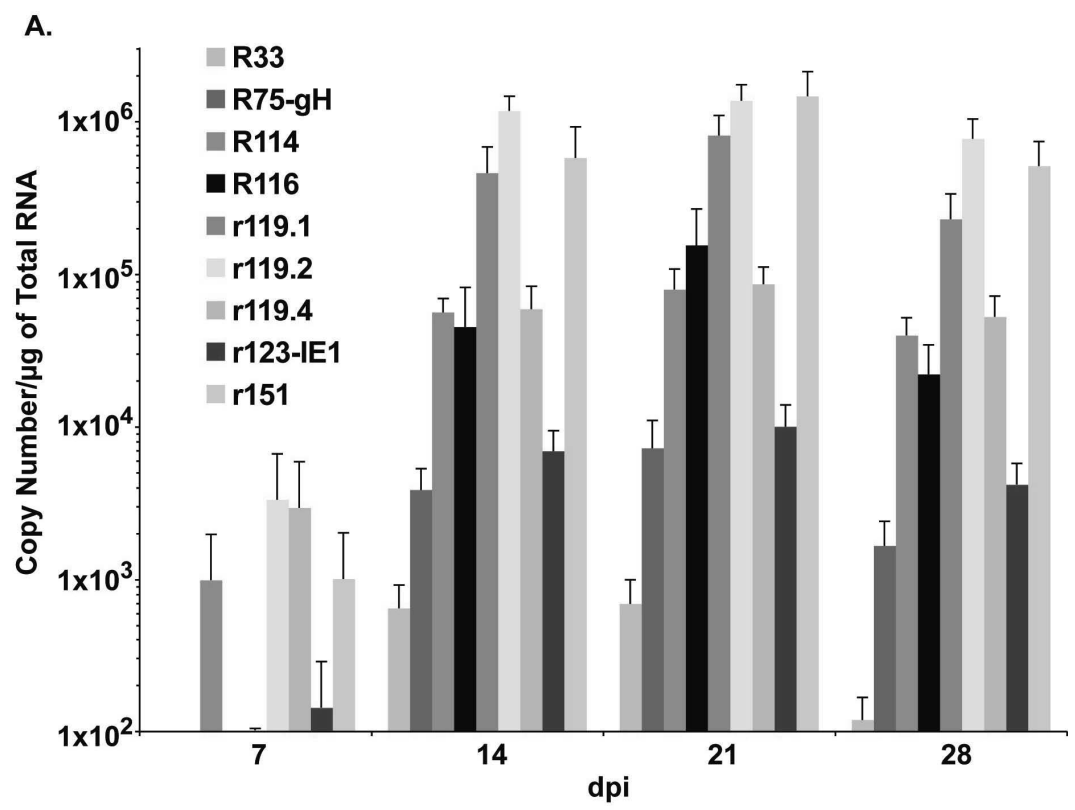

B.

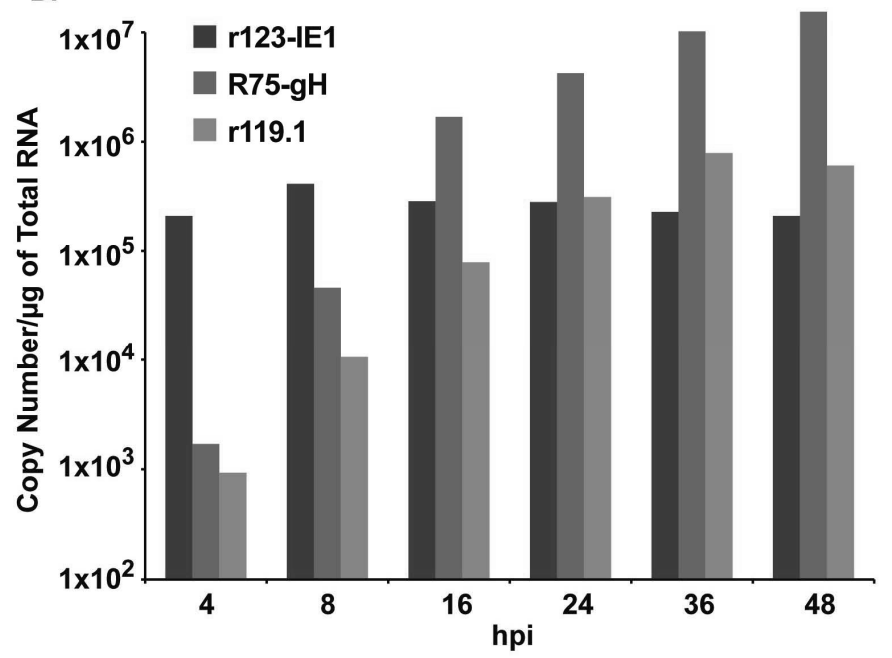

Fig. 4. Confirmation of in vivo RCMV gene expression. QRT-PCR analysis was used to confirm and quantify viral gene expression in RNA samples from (A) in vivo infected SMGs at 7, 14, 21 and 28 dpi and (B) in vitro infected REFs. Primers specific for the RCMV genes R33, R75 (gH), R114, $\mathrm{R} 116, \mathrm{r} 119.1, \mathrm{r} 119.2, \mathrm{r} 119.4, \mathrm{r} 123$ (IE1) and $\mathrm{r} 151$ were used to quantify viral gene expression. RNA samples were normalized to expression of L32 (cellular ribosomal protein) and the relative copy number was determined using plasmids containing each viral gene. 


\subsection{RCMV gene expression is tissue-specific}

To determine whether the RCMV gene expression pattern of SMG is also observed in other tissues, we profiled viral transcription in lung, liver, kidney, spleen, native and allograft heart harvested from the transplant recipients $(n=4)$. The tissues harvested at days 7, 14, 21 and 28 were pre-screened for viral DNA and mRNA by quantitative PCR in order to identify tissues containing appropriate levels of viral message to be detected by microarray analysis. Previous studies have indicated that wild-type RCMV DNA levels directly reflect viral load in rat tissues (Kaptein et al., 2003, 2004). At 7 dpi, viral DNA levels in the allograft heart, spleen, lung, liver, SMG and kidney ranged from $5 \times 10^{4}$ to $2 \times 10^{5}$ RCMV genomic equivalents per $\mu \mathrm{g}$ of input DNA (Table 3 ). The level of viral DNA in the SMG at 14 dpi was approximately $1 \times 10^{7}$ genomic equivalents per $\mu \mathrm{g}$ of input DNA, which increased at 21 and $28 \mathrm{dpi}$ to approximately $1-3 \times 10^{8}$. All of the tissues, except the native heart, tested positive for viral mRNAs (r119.2 and r151) at $7 \mathrm{dpi}$ (data not shown), which was consistent with the detection of viral DNA (Table 3). As expected, due to normal viral clearance, none of the samples collected from these tissues at 14, 21 or 28 dpi contained sufficient viral mRNA to be used for microarray analysis, except the SMG.

Table 3. Detection of RCMV DNA*

\begin{tabular}{|c|c|c|c|c|c|c|}
\hline Day & Tissue & Animal 1 & Animal 2 & Animal 3 & Animal 4 & Average \\
\hline \multirow{6}{*}{7} & Graft Heart & $2.5 \times 10^{5}$ & $9.8 \times 10^{3}$ & $6.6 \times 10^{5}$ & $5.0 \times 10^{3}$ & $2.3 \times 10^{5} \pm 3.1 \times 10^{5}$ \\
\hline & Spleen & 0 & $5.2 \times 10^{5}$ & 0 & 0 & $1.3 \times 10^{5} \pm 2.6 \times 10^{5}$ \\
\hline & Lung & $3.6 \times 10^{4}$ & $8.8 \times 10^{4}$ & $8.4 \times 10^{4}$ & $6.9 \times 10^{3}$ & $5.4 \times 10^{4} \pm 3.9 \times 10^{4}$ \\
\hline & Liver & $2.5 \times 10^{5}$ & $5.1 \times 10^{4}$ & $1.6 \times 10^{5}$ & $1.4 \times 10^{4}$ & $1.2 \times 10^{5} \pm 1.1 \times 10^{5}$ \\
\hline & Kidney & $9.0 \times 10^{4}$ & $3.3 \times 10^{4}$ & $1.6 \times 10^{5}$ & 0 & $7.2 \times 10^{4} \pm 7.1 \times 10^{4}$ \\
\hline & Salivary Gland & $2.6 \times 10^{5}$ & $9.2 \times 10^{4}$ & $2.0 \times 10^{4}$ & $1.5 \times 10^{5}$ & $1.3 \times 10^{5} \pm 1.0 \times 10^{5}$ \\
\hline 14 & Salivary Gland & $1.0 \times 10^{7}$ & $4.6 \times 10^{6}$ & $3.3 \times 10^{7}$ & $2.3 \times 10^{7}$ & $1.8 \times 10^{7} \pm 1.3 \times 10^{7}$ \\
\hline 21 & Salivary Gland & $5.9 \times 10^{8}$ & $8.0 \times 10^{8}$ & $1.9 \times 10^{7}$ & $6.5 \times 10^{7}$ & $3.7 \times 10^{8} \pm 3.9 \times 10^{8}$ \\
\hline 28 & Salivary Gland & $2.3 \times 10^{8}$ & $2.2 \times 10^{7}$ & $2.6 \times 10^{7}$ & $4.5 \times 10^{7}$ & $1.4 \times 10^{8} \pm 1.2 \times 10^{8}$ \\
\hline
\end{tabular}

*Genomic copies per $1 \mu \mathrm{g}$ of total DNA determined by quantitative PCR (TaqMan).

Comparisons of the viral gene expression profiles for lung, liver, kidney, spleen, allograft heart and SMG are shown in Fig. 5 and Table 4. As observed for SMG, fewer viral transcripts were detected in infected tissues compared to those expressed in vitro. Moreover, the RCMV gene expression profiles appear to be unique to each tissue type. Most of the tissues expressed genes from each kinetic class (IE, E and L), making it difficult to classify in vivo virus replication based on traditional in vitro replication kinetics. Interestingly, while viral gene expression levels were consistently highest in the SMG, there were more RCMV genes expressed above background in both spleen and liver 

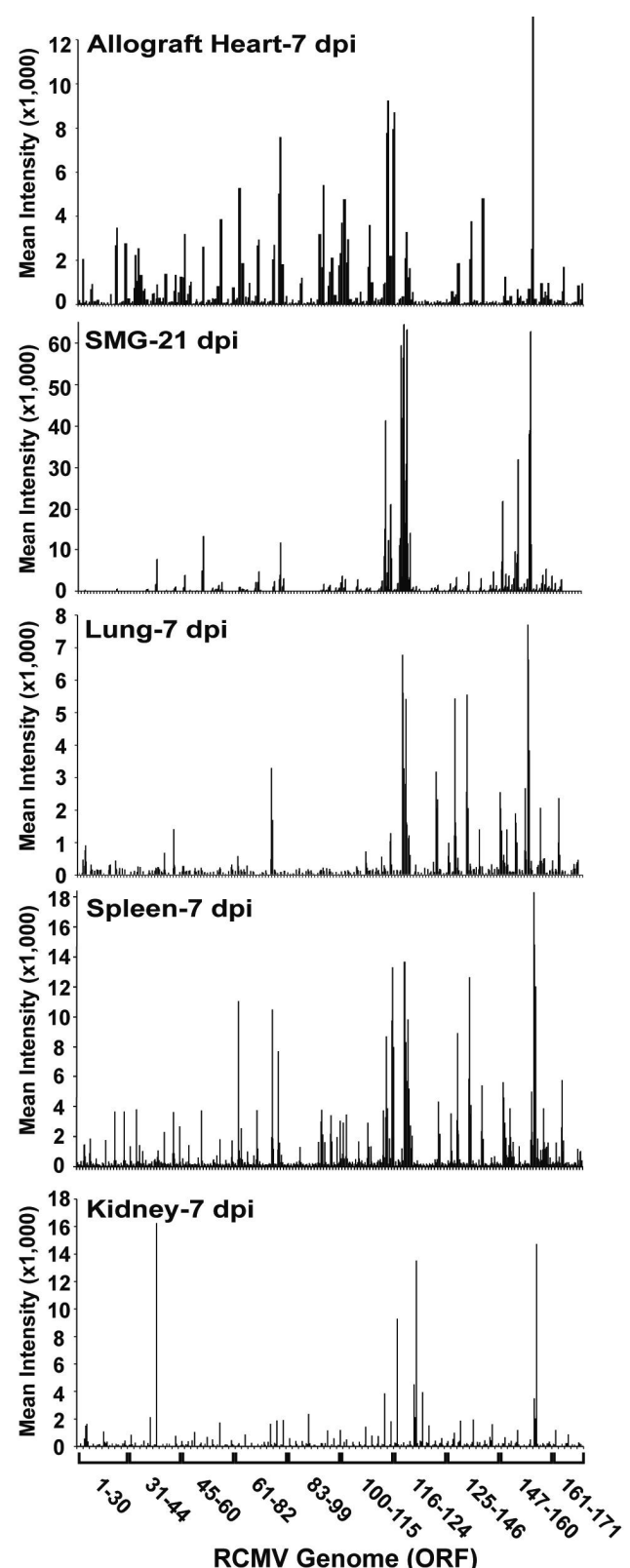

Fig. 5. Microarray analysis of RCMV gene expression in infected rat tissues. Total RNA was extracted from RCMV-infected spleen, lung, kidney and allograft heart at $7 \mathrm{dpi}$ and SMG at $21 \mathrm{dpi}$. The RNA was processed and analyzed using our RCMV microarray chips $(n=4)$. The mean gene intensity from each of the 4 biological replicates is plotted on the $y$-axis and the RCMV gene number on the x-axis. 


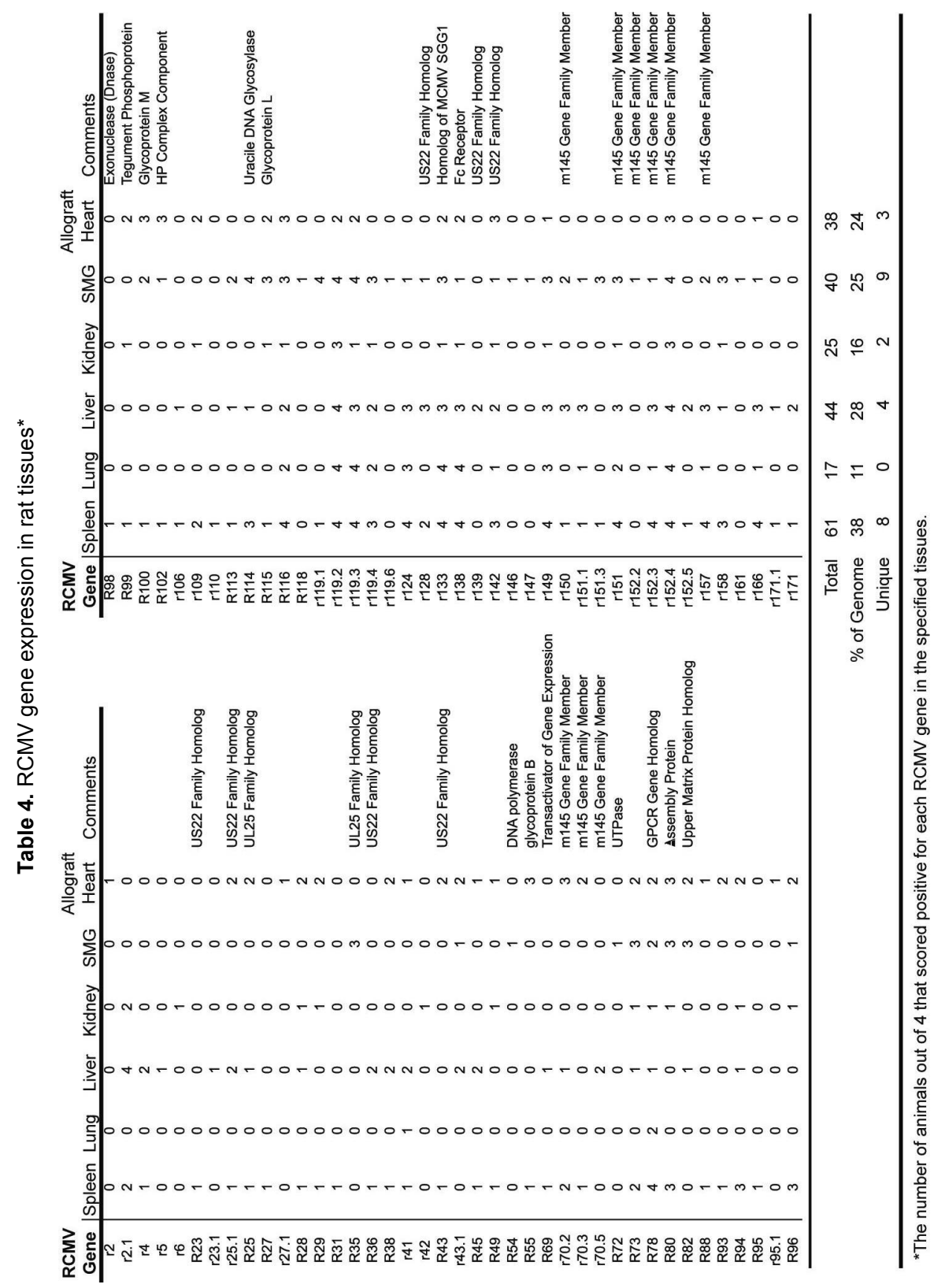


than in the SMG. In fact, a total of 61 viral genes was expressed at levels 2-fold above background in the spleen (38\% of the RCMV genome) compared to 40 in the SMG (25\% of the genome). These findings indicate that the number of viral genes expressed at detectable levels in vivo is not dependent upon the viral DNA copy number and that the pattern of expression of RCMV genes is tissue-specific. As shown in Table 4, compared to the spleen, a reduced number of viral genes was detected in the other organs; 44 viral genes were detected in the liver, 38 in the allograft heart, 25 in the kidney and 17 in the lung. A total of 9 RCMV genes was detected in all of the tissues tested, which include R78 (vGPCR), R116, r119.2, r119.3, r133, r138 (Fc receptor homolog), r142 (m142 homolog, macrophage tropism determinant), r149 and r152.4. Apart from r133, all of these genes are expressed with $E$ kinetics in vitro. Four viral genes (R73 [gN], r119.4, r151 and r166) were expressed at detectable levels in 5 out of 6 tissues. Eleven RCMV genes were detected in 4 out of 6 tissues (R28, r41, R80 [assembly protein], R94 [tegument protein], R96 [viral kinase], R115, r124, r151.1, r152.3, r157 [homolog of MCMV m157, which binds Ly49H] and r158), most of which are encoded on the right half of the viral genome. There were 26 genes uniquely detected in a single tissue type and 9 of these genes were specific for the SMG. As shown in Table 4, a subset of genes expressed in each tissue was not detectable. Some of the weakly expressed genes scored negative because their intensity was below the detection limit of the microarray assay $\left(0.5-1 \times 10^{4}\right.$ copies $/ 2 \mu \mathrm{g}$ of total RNA). We attribute differences in detection to the level of virus infection, which varies between individual rats (see Table 3 ). In general, the genes that are consistently detected in vivo are regarded as dispensable for virus replication in vitro and may be involved in immune evasion, cell cycle manipulation, antiapoptosis and/or cell survival. These regulatory genes would potentially include 9 members of the m145 gene family and 7 of the US22 gene family.

In order to confirm the tissue-specific expression pattern of the RCMV genes, QRTPCR was performed in triplicate on RNA isolated from the tissues of 3 individual rats. TaqMan probes and primers specific for R78, r119.1, r119.2, r151 and r152.4 were generated. Average copy numbers were normalized to expression of the cellular house keeping gene L32 and the ratio between each of the genes was determined (Fig. 6). Three of the genes, $\mathrm{r} 119.2, \mathrm{r} 151$ and $\mathrm{r} 152.4$, are highly expressed to similar levels in all of the tissues that were tested. The expression of these genes was at most 3-fold different ( $\mathrm{r} 119.2 / \mathrm{r} 152.4$ in the native heart samples), which was not statistically significant $(p=0.15)$. R78 and $r 119.1$ were two of a number of genes that, according to our microarray analysis, appeared to be expressed in a tissue-specific manner. In all 
tissues tested, R78 and r119.1 were expressed at similar levels, except the SMG, wherein r119.1 is expressed at a considerably higher level (approximately 60-fold) than is R78. By contrast, R78 expression in RCMV-infected REFs at $24 \mathrm{hpi}$ is significantly higher than both r119.1 and r119.2. Expression levels for r119.1 in the allograft heart and SMG tissues was increased relative to R78, whereas the expression levels of these two genes were similar in the liver, lung, kidney and spleen. When compared to expression levels of r119.2, r151 and r152.4, r119.1 was dramatically lower in these tissues. This is an interesting finding, since these infected tissues express a unique viral transcriptome. For example, in the spleen, 61 genes are expressed to detectable levels, whereas 44 and 17 genes are expressed in liver and lung, respectively. The expression levels of r119.1 in allograft heart and SMG were similar to that of r119.2, r151 and r152.4 (Fig. 4A and 6), suggesting that expression of these genes may be similarly controlled.

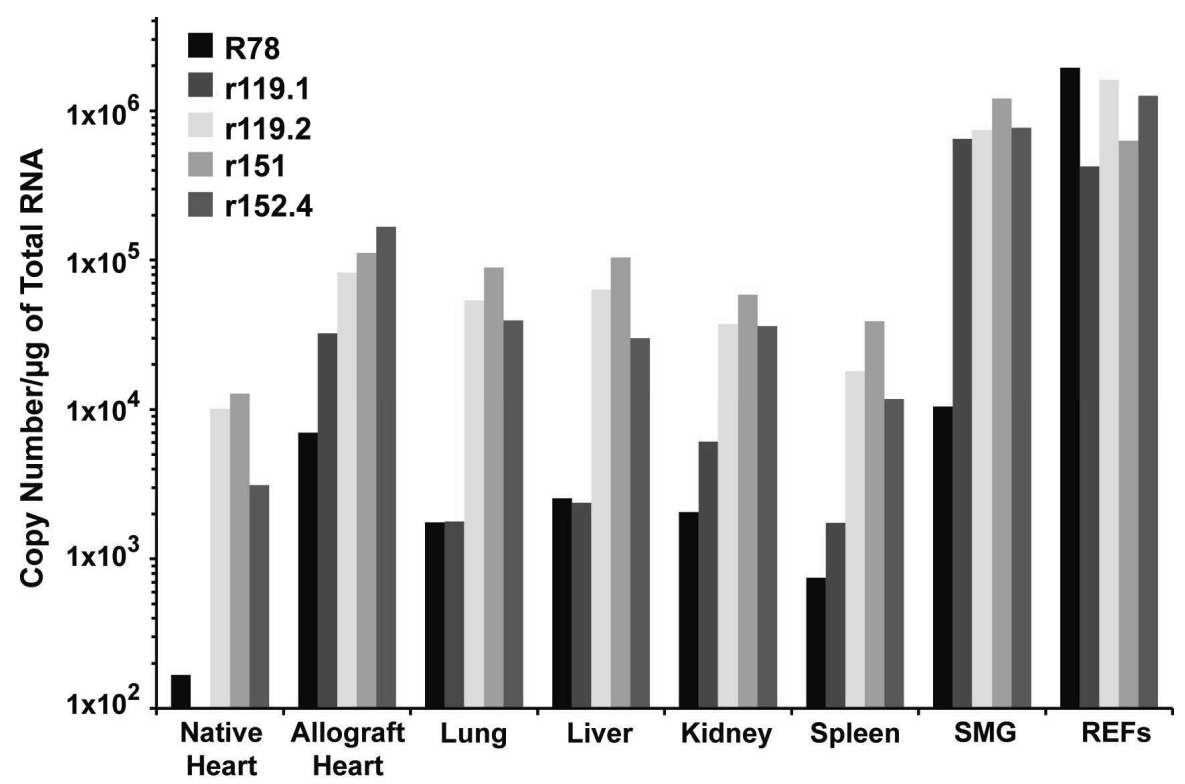

Fig. 6. RCMV gene expression is tissue-specific. QRT-PCR analysis was used to confirm and quantify viral gene expression in RNA samples from in vivo infected native heart, allograft heart, lung, liver, kidney, spleen and SMG. All tissues were harvested at $7 \mathrm{dpi}$, except the SMG (21 dpi). RCMV-infected REFs that were harvested at $24 \mathrm{hpi}$ were used for in vitro to in vivo comparisons. Primers specific for the RCMV genes R78, r119.1, r119.2, r151 and r152.4 were used to quantify viral gene expression. RNA samples were normalized to expression of L32 (cellular ribosomal protein) and the relative copy number was determined using plasmids containing each viral gene. The limit of detection for this assay was 100 copies. 


\section{Discussion}

Originally our plan for these studies was to compare RCMV gene expression in only allograft vs. native hearts to determine the viral mechanisms associated with CMVaccelerated allograft rejection and vascular disease. However, after profiling other tissues from the infected transplant recipients, it became evident that there were major differences in viral gene expression between the various tissues. Because of these significant findings, we expanded our study to include all major tissues in the transplant recipient. In the current report, we used a global microarray approach to examine RCMV gene expression in infected cultured cells and in tissues from infected rats. By studying CMV gene expression at the viral transcriptome level, we avoided biasing this study to a limited number of viral genes. This process has enabled us to identify the viral gene expression profiles during acute infection of heart transplant recipients. In cultured cells, RCMV expresses approximately $95 \%$ of the known viral ORFs and we observed very little difference in the expression patterns between infected SMCs, ECs and REFs. However, viral gene expression in tissues from infected rat heart allograft recipients is very different. The results from the in vivo transcription analysis allow the following conclusions to be drawn. 1) The profiles and amplitude of viral gene expression differ dramatically compared to infected cultured cells, indicating that CMV gene expression in vitro does not accurately reflect viral gene expression in vivo. 2) Viral gene expression in tissues is skewed toward genes that are not known to have direct roles in virus replication or assembly, but most likely represent genes involved in immune evasion or host cell survival. Other viral genes are expressed, as detected by RT-PCR, but the expression levels are below the detection threshold of the microarray assay. 3) Viral DNA load and viral mRNA levels do not correlate with profiles of gene expression. 4) Viral gene expression is tissue-specific, suggesting that the virus either actively adapts to its environment in order to control gene expression or that it merely passively responds to transcriptional controls implemented by the host environment. Our findings emphasize the importance of in vivo analysis using animal models in translational research.

The first global analysis of CMV gene expression was performed by Chambers et al. (1999) using microarray chips designed to 151 of the 200 known HCMV ORFs. This study demonstrated the feasibility of microarray technology to monitor the gene expression profiles of large complex viruses, such as the herpesviruses. They determined the temporal kinetic class of each of the HCMV ORFs, including that of many uncharacterized ORFs. An interesting finding of this study was that many of the genes of a specific temporal class contain common, potential regulatory motifs within their 
promoter regions, suggesting that HCMV can express its genes with specific transcriptional programs, much like what is observed in tissues during development. Our results demonstrate that the in vivo gene profiles for RCMV are different compared to those observed in cultured cells and that viral gene expression patterns are tissuespecific. An explanation for our findings of limited in vivo viral gene expression is that multiplicity of infection in the tissues is low or that clearance of the productively infected cells leaves only abortively infected cells that express fewer genes to high levels. Our data do not support nor directly refute these scenarios. On the contrary, we detect the highest virus titers in the SMG between days 21 and 28 , during the time of limited viral gene expression. Thus, another explanation may involve the number of different infected cell types per tissue; the more types of infected cells, the wider the viral gene profile. Interestingly, infection in the SMG is limited to the striated duct cells (Kloover et al., 2000) and the number of highly expressed genes is limited to 40 in this tissue. Other tissues, like the spleen, display a wider viral gene profile and multiple cell types may be infected. However, the fact that RCMV gene expression occurs in a tissue-specific manner suggests that there exists a level of transcriptional control at the tissue level. This tissue-specificity suggests that the virus may have multiple transcriptional programs dependent upon the cellular environment or that other post-transcriptional events, such as mRNA stability, may be important to elicit this effect. What we do not yet know is whether the virus and/or the host cell determine this level of control. The ability of the virus to control gene expression in a tissue-specific manner may be regulated by specific motifs within the viral promoters that are active in some tissues but not in others. This level of transcriptional control does not exist in vitro for RCMV-infected cells, wherein eventually almost all of the viral ORFs are expressed to a detectable level. We were unable to detect any obvious regulatory motif pattern in the promoters of the RCMV genes that are highly expressed in vivo. However, a more intensive study is warranted to identify these regions in order to determine the selective mechanisms of in vivo gene expression. An interesting parallel in the ability of CMV to regulate viral gene expression is observed during natural human papillomavirus infections of the skin. Papillomaviruses contain only two promoters, an early and a late one. The early promoter is active in many different cell types, but appears to be most active in keratinocytes, suggesting that the promoter is cell/tissue type-specific (Apt, et al., 1993; McCance, 2005; Yukawa et al., 1996). The late promoter is differentiation-dependent and is activated only during terminal differentiation of the epithelial cells of the granular layer (McCance, 2005). An important question that arises from virus gene expression studies with papillomavirus 
and those we present here, is what are the cell type-specific factors that promote the activation of some viral genes and repression of others?

Shenk and co-workers utilized similar HCMV microarrays, containing 191 viral ORFs, to monitor viral gene expression on a global level (Adamo et al., 2004; Bresnahan and Shenk, 2000; Goodrum et al., 2002, 2004; Heider et al., 2002). Utilization of these HCMV microarrays to identify the viral gene expression patterns in specific subsets of CD34 hematopoietic stem cells demonstrated that HCMV infection of these cells produced an initial transient burst of gene expression, followed by a period of viral transcriptional quiescence and genome maintenance. The infected $\mathrm{CD} 34^{+}$cells were capable of reactivating virus when co-cultured with fibroblasts. The HCMV expression profiles in CD34 ${ }^{+}$cells parallel our in vivo RCMV gene expression profiles on a number of levels. First, gene expression in the $\mathrm{CD} 34^{+}$cells was significantly different from that in HCMVinfected fibroblasts. Second, viral expression in CD $34^{+}$cells was very limited and did not correspond to conventional IE, E and L viral gene expression profiles. Finally, many of the viral genes expressed in the $\mathrm{CD}_{3} 4^{+}$stem cells are not directly involved in virus replication. The significance of the early burst of viral gene expression is not understood. However, it might play a role in the establishment of latency. Clearly, many, if not all, of the herpesviruses can regulate their gene expression patterns during persistence and latency. For example, Epstein-Barr virus infection of $B$ cells results in one of five transcriptional programs depending upon the activation and differentiation status of the host cell (reviewed by Thorley-Lawson and Gross, 2004). Most of these transcriptional programs are involved in maintaining persistence of the viral genome during periods of cell quiescence and during cellular replication. In addition, HSV-1 expresses the viral latency-associated transcript (LAT) during all stages of replication, but it is exclusively expressed during latent infections of neurons (reviewed by Rajcani et al., 2004). Expression of LAT is required for cell survival during reactivation. Similarly, CMV expression in the SMG (a major site of virus persistence), even in the presence of high levels of viral genome, is tightly regulated and highly skewed. The viral genes expressed in the SMG may be involved in preserving the infected host cell, allowing immune escape and/or promoting transmission to a new host. Thus, a common theme among these viruses is the ability to control viral gene expression as a method of persistence in the infected host, whether it is during latency or during smoldering infection states, both of which occur in a CMV-infected host.

Our in vivo observations indicate that gene expression of the immune modulators occurs at higher levels than previously predicted based upon in vitro studies. It may be 
that the differential level of in vivo viral gene expression between the two gene groups responsible for immune evasion and virus replication allows the virus to persist by turning over small amounts of infectious virus while remaining relatively undetected by the host's immune system. A relevant question that surfaces from these findings is why the virus specifically over-expresses certain viral genes and not others? For example, is there relevance to the fact that, in our study, the RCMV-encoded Fc receptor, r138, was highly expressed in the spleen, liver and lung? In these tissues, r138 is expressed to nearly the same level as r119.2, whereas in the SMG, r138 is expressed to 30 -fold lower levels than r119.2 (Fig. 5 and Table 4). Is the virus more prone to antibody-mediated immune pressures in lung, liver and spleen compared to SMG tissues? Our findings suggest that the virus does not produce its full arsenal of immune modulator genes in every infected cell type in vivo, but rather selectively regulates their respective gene expression. The host response to viral infection is probably not the same in every tissue. Thus, the expression of CMV-encoded immune evasion genes involved in preventing immune recognition would similarly need to be specific for each of these types of responses. Consequently, the virus would need to express multiple transcriptional programs appropriate for the specific host cell type and the type of immune response prompted by the infected cell and/or by its juxtaposition to the immune system.

In conclusion, we explored the characteristics of RCMV gene expression in cultured cells and in tissues from a rat cardiac transplant model. Combined, our findings indicate that viral gene expression is highly complex. One cannot predict in vivo viral gene expression solely based upon the in vitro viral transcriptome analysis. In fact, most studies aimed at identifying viral expression during latency and reactivation have focused on the IE proteins, which we found to be expressed at very low levels compared to other viral genes likely involved in immune modulation. The most efficient and effective way for $\mathrm{CMV}$ to remain undetected by the host during persistence is by regulating viral gene expression in such a way as to over-express the immune evasion genes while repressing viral genes involved in replication. One of the reasons that CMV encodes so many genes might be that different gene expression programs are used in different cell and tissue types. This is also highly relevant for the analysis of immune modulators. If the wrong tissues and organs are studied, the effect might be missed. Identifying the viral transcriptomes of different tissues and at different time points, associated with virusinduced disease, such as accelerated allograft rejection, will aid in the design of novel targeted therapeutics. 


\section{Acknowledgements}

This work was supported by research grants to S.L. Orloff from the Department of Veterans Affairs and from the National Institutes of Health (HL 66238-01) and grants from the National Institutes of Health to D.N. Streblow (HL083194) and J.A. Nelson (AI21640, HL65754 and HL71695). D.N. Streblow is also supported by an AHA Scientist Development Grant. C. Vink is supported by a grant from the Royal Netherlands Academy of Arts and Sciences.

\section{References}

Adamo JE, Schroer J, Shenk T. Human cytomegalovirus TRS1 protein is required for efficient assembly of DNA-containing capsids. J Virol 2004;78:10221-9.

Apt D, Chong T, Liu Y, Bernard HU. Nuclear factor I and epithelial cell-specific transcription of human papillomavirus type 16. J Virol 1993;67:4455-63.

Beisser PS, Vink C, Van Dam JG, Grauls G, Vanherle SJ, Bruggeman CA. The R33 G proteincoupled receptor gene of rat cytomegalovirus plays an essential role in the pathogenesis of viral infection. J Virol 1998;72:2352-63.

Bresnahan WA, Shenk T. A subset of viral transcripts packaged within human cytomegalovirus particles. Science 2000;288:2373-6.

Bruggeman CA, Debie WM, Grauls G, Majoor G, van Boven CP. Infection of laboratory rats with a new cytomegalo-like virus. Arch Virol 1983a;76:189-99.

Bruggeman CA, Schellekens H, Grauls G, Debie WM, van Boven CP. Rat cytomegalovirus: induction of and sensitivity to interferon. Antiviral Res 1983b;3:315-24.

Bruggeman CA, Meijer H, Bosman F, van Boven CP. Biology of rat cytomegalovirus infection. Intervirology 1985;24:1-9.

Chambers J, Angulo A, Amaratunga D, Guo H, Jiang Y, Wan JS, et al. DNA microarrays of the complex human cytomegalovirus genome: profiling kinetic class with drug sensitivity of viral gene expression. J Virol 1999;73:5757-66.

Cobbs CS, Harkins L, Samanta M, Gillespie GY, Bharara S, King PH, et al. Human cytomegalovirus infection and expression in human malignant glioma. Cancer Res 2002;62:3347-50.

Gold MC, Munks MW, Wagner M, Koszinowski UH, Hill AB, Fling SP. The murine cytomegalovirus immunomodulatory gene $\mathrm{m} 152$ prevents recognition of infected cells by M45-specific CTL but does not alter the immunodominance of the M45-specific CD8 T cell response in vivo. $J$ Immunol 2002;169:359-65.

Goodrum FD, Jordan CT, High K, Shenk T. Human cytomegalovirus gene expression during infection of primary hematopoietic progenitor cells: A model for latency. Proc Natl Acad Sci USA 2002;99:16255-60. 
Goodrum F, Jordan CT, Terhune SS, High K, Shenk T. Differential outcomes of human cytomegalovirus infection in primitive hematopoietic cell subpopulations. Blood 2004;104:68795.

Heider JA, Bresnahan WA, Shenk TE. Construction of a rationally designed human cytomegalovirus variant encoding a temperature-sensitive immediate-early 2 protein. Proc Natl Acad Sci USA 2002;99:3141-6.

Kaptein SJ, Beisser PS, Gruijthuijsen YK, Savelkouls KG, van Cleef KW, Beuken E, et al. The rat cytomegalovirus R78 $\mathrm{G}$ protein-coupled receptor gene is required for production of infectious virus in the spleen. J Gen Virol 2003;84:2517-30.

Kaptein SJ, van Cleef KW, Gruijthuijsen YK, Beuken EV, van Buggenhout L, Beisser PS, et al. The r131 gene of rat cytomegalovirus encodes a proinflammatory $C C$ chemokine homolog which is essential for the production of infectious virus in the salivary glands. Virus Genes 2004;29:4361.

Kavanagh DG, Gold MC, Wagner M, Koszinowski UH, Hill AB. The multiple immune-evasion genes of murine cytomegalovirus are not redundant: $\mathrm{m} 4$ and $\mathrm{m} 152$ inhibit antigen presentation in a complementary and cooperative fashion. J Exp Med 2001;194:967-78.

Kloover JS, Hillebrands JL, de Wit G, Grauls G, Rozing J, Bruggeman CA, et al. Rat cytomegalovirus replication in the salivary glands is exclusively confined to striated duct cells. Virchows Arch 2000;437:413-21.

Krmpotic A, Messerle M, Crnkovic-Mertens I, Polic B, Jonjic S, Koszinowski UH. The immunoevasive function encoded by the mouse cytomegalovirus gene $\mathrm{m} 152$ protects the virus against T cell control in vivo. J Exp Med 1999;190:1285-96.

McCance DJ. Transcriptional regulation by human papillomaviruses. Curr Opin Genet Dev 2005; $15: 515-9$

Melnychuk RM, Streblow DN, Smith PP, Hirsch AJ, Pancheva D, Nelson JA. Human cytomegalovirus-encoded $\mathrm{G}$ protein-coupled receptor US28 mediates smooth muscle cell migration through $\mathrm{G} \alpha 12$. J Virol 2004;78:8382-91.

Mocarski ES. Cytomegaloviruses and their replication. In: Fields BN, editor. Virology, 4th ed, vol 2. Lippincott-Raven, Philadelphia 2001:2629-73.

Orloff SL, Streblow DN, Soderberg-Naucler C, Yin Q, Kreklywich C, Corless CL, et al. Elimination of donor-specific alloreactivity prevents cytomegalovirus-accelerated chronic rejection in rat small bowel and heart transplants. Transplantation 2002;73:679-88.

Pass RF. Cytomegalovirus. In: Knipe DM, Griffin DE, Lamb RA, Martin MA, Roizman B, Straus SE, editors. Fields Virology, 4th ed. Lippincott Williams \& Wilkins, Philadelphia 2001:2675-705.

Rajcani J, Andrea V, Ingeborg R. Peculiarities of herpes simplex virus (HSV) transcription: an overview. Virus Genes 2004;28:293-310.

Stingley SW, Ramirez JJ, Aguilar SA, Simmen K, Sandri-Goldin RM, Ghazal P, et al. Global analysis of herpes simplex virus type 1 transcription using an oligonucleotide-based DNA microarray. J Virol 2000;74:9916-27. 
Streblow DN, Kreklywich C, Yin Q, De La Melena VT, Corless CL, Smith PA, et al. Cytomegalovirus-mediated upregulation of chemokine expression correlates with the acceleration of chronic rejection in rat heart transplants. J Virol 2003;77:2182-94.

Thorley-Lawson DA, Gross A. Persistence of the Epstein-Barr virus and the origins of associated lymphomas. N Engl J Med 2004;350:1328-37.

van der Strate BW, Hillebrands JL, Lycklama a Nijeholt SS, Beljaars L, Bruggeman CA, Van Luyn $\mathrm{MJ}$, et al. Dissemination of rat cytomegalovirus through infected granulocytes and monocytes in vitro and in vivo. J Virol 2003;77:11274-8.

Vink C, Beuken E, Bruggeman CA. Complete DNA sequence of the rat cytomegalovirus genome. J Virol 2000;74:7656-65.

Yukawa K, Butz K, Yasui T, Kikutani H, Hoppe-Seyler F. Regulation of human papillomavirus transcription by the differentiation-dependent epithelial factor Epoc-1/skn-1a. J Virol 1996;70:106. 


\section{Chapter 3}

Identification and characterization of two antisense transcripts from the major immediate early region of rat cytomegalovirus

Koen W.R. van Cleef, Marinus J. Blok, Kim G.M. Savelkouls, Gert E.L.M. Grauls, Cathrien A. Bruggeman, Cornelis Vink

Arch Virol 2005;150:2593-9 


\section{Abstract}

We have identified and characterized two antisense transcripts from the rat cytomegalovirus (RCMV) major immediate early (MIE) region. These transcripts, designated IE-AS1 and IE-AS2, are complementary to part of the sense IE1 transcript. The IE-AS transcripts were first detected in peripheral blood leukocytes (PBL) of RCMVinfected rats at 7 days post-infection (pi) in the absence of IE1 transcription. Nevertheless, both the IE1 and IE-AS transcripts were found at the same time in the salivary glands of RCMV-infected rats at 7 and 120 days pi as well as in RCMV-infected rat embryo fibroblasts (REFs) at $48 \mathrm{~h}$ pi.

Cytomegaloviruses (CMVs) are widespread species-specific betaherpesviruses that cause acute, persisting and latent infections in both humans and animals. Infections with human CMV (HCMV) are mainly asymptomatic in immunocompetent individuals, but can be life-threatening in immunocompromised individuals, such as AIDS patients and organ transplant recipients.

In our laboratory, we are studying the interaction between rat CMV (RCMV) and its host as a model for HCMV infection and disease (Bruggeman et al., 1982). In this regard, we previously elucidated the structural organization of one of the most crucial regions of the RCMV genome, i.e. the major immediate early (MIE) region (Beisser et al., 1998). This region was found to have an overall organization similar to that of other CMVs. It was found to contain five exons that are differentially spliced to generate three different transcripts, namely IE1, IE2 and IE2A (Fig. 1A) (Beisser et al., 1998). In order to further monitor transcription of IE1 in vitro and in vivo, an IE1-specific, qualitative, nested reverse transcription-PCR (RT-PCR) assay was developed. This assay, which has a lower detection limit of approximately 10 copies of RNA, was designed such as to amplify a 196-bp fragment. This fragment is $97 \mathrm{bp}$ smaller than the fragment that is generated after amplification of genomic MIE DNA, as the IE1 primers were derived from sequences flanking the 97-bp intron 3 within the RCMV MIE region (Fig. 1A). Interestingly, in a study in which the dissemination of RCMV in immunocompetent rats was investigated, aberrant MIE transcripts were identified. In this study, three-week-old, male, specific-pathogen-free (SPF) Wistar Kyoto rats (Central Animal Facilities, University of Maastricht) were infected by intraperitoneal injection of $1 \times 10^{5}$ plaqueforming units (PFU) of RCMV (Maastricht strain). The rats were sacrificed at either 7 or 120 days post-infection (pi). Various organs and tissues were collected and subjected to the IE1-specific RT-PCR assay, which was performed on total RNA, essentially as 
A

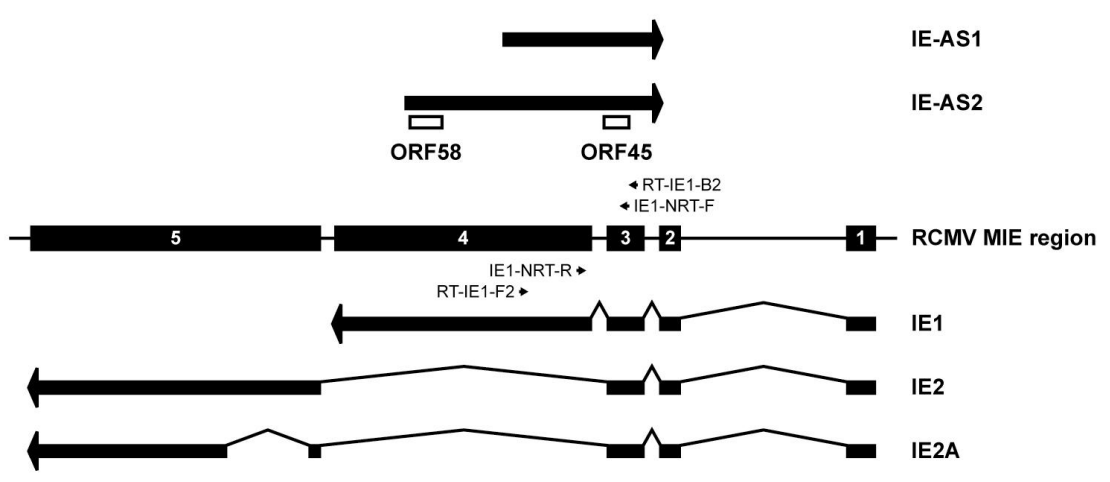

$0.5 \mathrm{~kb}$

B
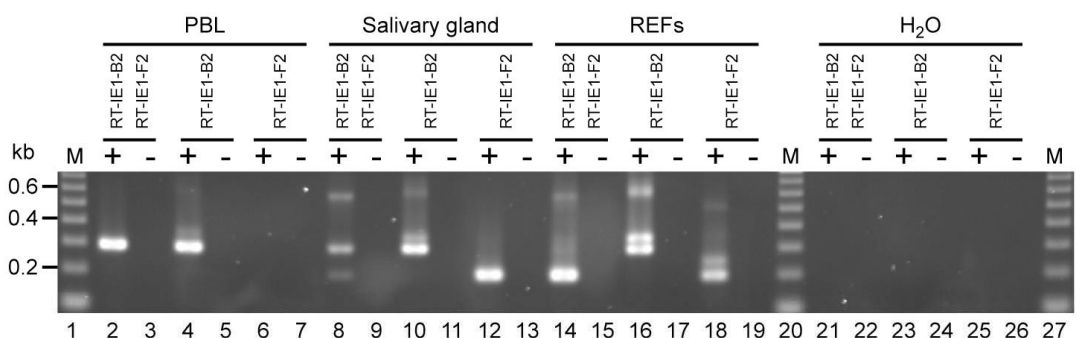

C
4

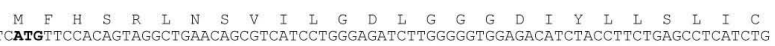

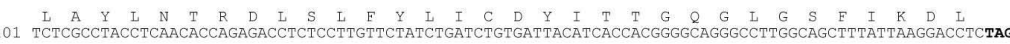 201 TGAGATCAATT'TGTCTGTATAAGCGTGAAAGGTAGCCTTTTCTAGAACTCTTCTGATGATTGACAGGGTATTTTCATTATACTGACTCATCTGTATGAGA 301 ATGAAAAACGCCATGTTCCGCCTAGACTGCTTTATCATGTTTTCTTGAGCTACTAAGGCTAATCTCTGGCCATAGAGAAGGGCCCGAACATCTTCCCTGA 401 GACTAGCATAGGTCTCTCTACACATTCTGGGAAAGGTGTCTCTGTTATAGTACTTCCTGTTTCGTAACAGGGTAGCCATCTCCTCTCTGAGTTGTAGGAC $\sqrt{3}$ 501 CITAGCGATGATGTTCGAATTTGAAAAGTTATCATCCGTGATAACCTGATCCTGTTTCCACCTGAGTAACTGATTTCTAACAGTTGCCATGATCTTAACG 601 CTGGAGGGTGGGTCGTAGAGACCCGCTGCTCTCTGTGCGGCTTCCAAAAGTTTGCTACCTATCTCTCTGTGTAAGATGAACTTGGTCACGACCCTGCTGC 701 CGTCTAGGTGTCTTITGAACACGCCTTCTAGTGATITGGCATAGGTAGAAGCCTCTCCCAGTITITCCATCCACTCGTCCTTTIGTGGITCGTTGAGACC 801 AAATGGCATGAATTCAGTGTAGCTTTCATATAGGGCTCTTCCGAAAGTGTTACTCTTATCTTCCGGATCACCTGAGTTATITATGATTGCTACATGTTTA 901 TCAACTATGATATATACTTCTTCTGATICTITGTACACTTTTTIGGCGAATCTCATCACCATITCATGATGAATGATTTCCAACATCTGCAACGTCACTC 1001 TGGTACAGACTTCAAGGCTTTTCACTGTAAACCATAGATAGAGGCAAAGTTGCTTATTGCCTCTTGTTTACCACCCCCTACCTCAGGCGTGAACATGCAT $1101 \underset{G}{C} \quad \begin{aligned} & I \\ & \text { GTGCATAAAAGACAGTCTTACCTGCCAGGTCTTTGATCTGCGCATCTGCACCGGAATCGCCCATCTTGCCGGAGAGAGTGTCCATGGCTTCGATCATAGG }\end{aligned}$
1201 TICGGTGGGAGTGTAATCTGGTTCTGGATCGGTTAgAATATCTTCCAGGGACATGTCACATCTGACAAGTTCGGTGGTCTGGGTTGTGAGTTCATCAGCG 1301 ATCATTTTGGGAATTCTGTAAAGATTTATAATAGGTAAAGAAATGTATGTTTTCTATATGGGTCTGCCTATAAAAAATAAAAATGTCCCACCTTTTTATG $1401 \frac{\mathrm{T} \pi \mathrm{R}}{1}$ 
Fig. 1 (page 58). Identification and characterization of two RCMV IE-AS transcripts. (A) Schematic illustration of the RCMV MIE region. The figure is adopted from the respective figures published by Beisser et al. (1998) and Sandford et al. (1993). Exons are shown as black boxes and transcripts are represented by black arrows that indicate their orientation. ORF58 and ORF45 are shown as white boxes. The position and orientation of primers RT-IE1-F2, RT-IE1-B2, IE1-NRT-R and IE1NRT-F are indicated by black arrowheads. (B) Strand-specific RT-PCR assays. Total RNA samples from PBL at 7 days pi, salivary gland at 120 days pi and RCMV-infected REFs at $48 \mathrm{~h}$ pi were subjected to strand-specific RT-PCR reactions either with (+) or without (-) the addition of reverse transcriptase. In these reactions, the cDNA synthesis was performed in the presence of both primers RT-IE1-F2 and RT-IE1-B2 or either only primer RT-IE1-F2 or RT-IE1-B2. All reactions were also performed on $\mathrm{H}_{2} \mathrm{O}$ instead of total RNA. RT-PCR products were analyzed by agarose gel electrophoresis and ethidium bromide staining. The sizes of the DNA markers (M) are shown on the left-hand side of the gel. (C) Primary structure of the IE-AS cDNA. The sequence of the IE-AS CDNA was deduced from the sequences of the 5'- and 3'-RACE products. The translation start (ATG) and stop (TAG) codons and the consensus polyadenylation sequence (AATAAA) are marked. Arrowheads pointing down indicate the number of 5'-RACE clones in which the transcription start site was mapped to a particular residue and arrowheads pointing up indicate the number of 3'RACE clones in which the poly $(\mathrm{A})^{+}$tail was identified immediately $3^{\prime}$ of a particular residue. The amino acid sequences that are predicted to be encoded by the IE-AS transcripts are indicated above the cDNA sequence.

described previously (van Cleef et al., 2004). The primers used in the IE1-specific RTPCR assay are shown in Table 1.

Remarkably, although the spliced 196-bp IE1 product was not amplified from peripheral blood leukocytes (PBL) of RCMV-infected rats at 7 days pi, a fragment with a length of $293 \mathrm{bp}$ was amplified from these samples (Fig. 1B, lane 2). The length of this fragment indicates that it is derived from amplification of either genomic MIE DNA or unspliced MIE RNA. However, since the 293-bp fragment was not generated when reverse transcriptase was omitted from the reaction mixture (Fig. 1B, lane 3 ), it is not likely that it is derived from genomic DNA. Apart from the spliced 196-bp IE1 product, the 293-bp fragment was also amplified from salivary gland samples of RCMV-infected rats at both 7 (data not shown) and 120 days pi (Fig. 1B, lane 8), as well as from RCMVinfected rat embryo fibroblasts (REFs) at $48 \mathrm{~h}$ pi (Fig. 1B, lane 14).

To determine the polarity of the novel MIE-derived transcript, strand-specific RT-PCR reactions were performed in which one of the RT-PCR primers was omitted from the reaction mixture during cDNA synthesis. The omitted primer was subsequently added to the mixture after the inactivation of reverse transcriptase. As shown in Fig. 1B, reverse 


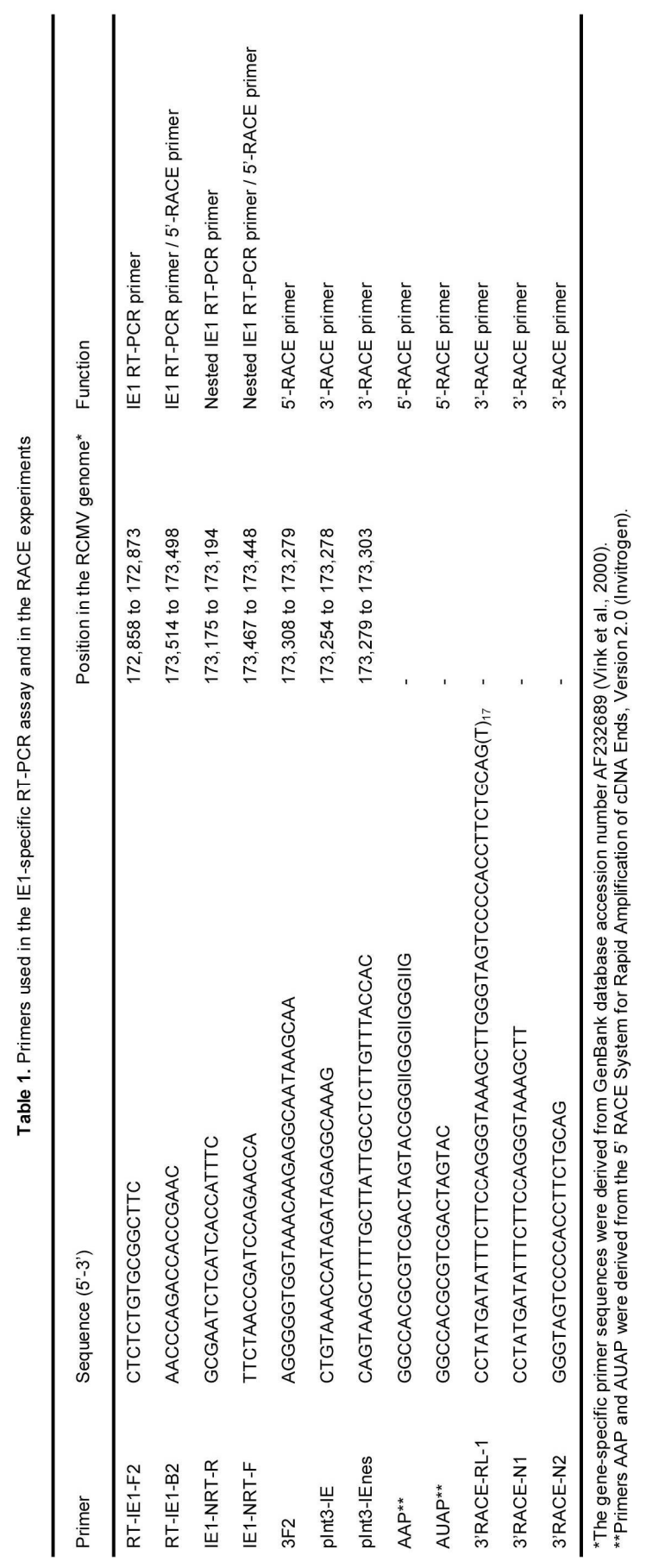


transcription on total RNA from both the salivary gland samples and the RCMV-infected REFs in the presence of primer RT-IE1-F2, which is complementary to the sense strand of MIE exon 4, resulted in amplification of the expected, spliced 196-bp fragment (lanes 12 and 18). This fragment was not amplified from the PBL samples (Fig. 1B, lane 6). However, reverse transcription in the presence of primer RT-IE1-B2 on total RNA from the salivary gland and the PBL samples, as well as on total RNA from the RCMVinfected REFs, resulted in amplification of the 293-bp fragment (Fig. 1B, lanes 4, 10 and 16). As primer RT-IE1-B2 is complementary to the antisense strand of MIE exon 3 , the 293-bp product is likely to be derived from an antisense, unspliced MIE transcript. Fragments with sizes other than 196 or 293 bp in Fig. 1B are the result of amplification mediated by inner (nested) and outer primer pair combinations, as confirmed by amplification using different subsets of primers (data not shown).

The novel, antisense MIE transcript, which will be referred to as IE-AS, could not be detected in RCMV-infected REFs at either IE, early $(E)$ or late $(L)$ times of infection by Northern blot analysis (data not shown). This indicates that it may only be transcribed at relatively low levels. As an alternative to Northern blot analysis, a limited dilution RTPCR assay was performed on total RNA from RCMV-infected REFs at IE, E and L times of infection. Surprisingly, the IE-AS transcript was found in each phase of infection at approximately similar levels (data not shown). Thus, in contrast to transcription of IE1, which was exclusively detected during the IE phase of infection (Beisser et al., 1998), transcription of IE-AS does not seem to be restricted to either the IE, E or L phase of infection.

To elucidate the structure of the IE-AS transcript, rapid amplification of 5' and 3' cDNA ends (5'- and 3'-RACE) was performed on mRNA from RCMV-infected REFs. During a 1-h infection period, the REFs were exposed to RCMV at a multiplicity of infection (MOI) of 1.0. The REFs were harvested at $48 \mathrm{~h}$ pi and poly $(\mathrm{A})^{+} \mathrm{RNA}$ was isolated using the QuickPrep Micro mRNA Purification Kit (Amersham Biosciences). Amplification of the 5 ' end of the IE-AS transcript was performed with the 5 ' RACE System for Rapid Amplification of cDNA Ends, Version 2.0 (Invitrogen). Gene-specific primer RT-IE1-B2 was used for the conversion of mRNA into cDNA. The CDNA was subsequently tailed with a stretch of $C$ residues. A first round of PCR was then performed with gene-specific primer IE1-NRT-F and primer AAP. Gene-specific primer $3 F 2$ and primer AUAP were used in a second round of PCR. To amplify the 3' end of the IE-AS transcript, mRNA was reverse transcribed into cDNA using primer 3'RACE-RL-1. Subsequently, a first round of PCR was performed with gene-specific primer plnt3-IE and 
primer 3'RACE-N1. Gene-specific primer plnt3-IEnes and primer 3'RACE-N2 were used in a second round of PCR. Amplified RACE fragments were cloned into vector pGEM-T Easy (Promega) and sequenced. The gene-specific primers that were used for the 5'and 3'-RACE experiments were designed in such a way as to generate overlapping 5 and 3' cDNA fragments, allowing determination of the structure of the complete IE-AS transcript. The primers used in the RACE experiments are shown in Table 1.

Amplification of the 5 ' end of the IE-AS cDNA resulted in two major fragments with lengths of approximately 1.1 and $0.6 \mathrm{~kb}$. Amplification of the 3 ' end of the IE-AS cDNA resulted only in one major fragment with a length of approximately $0.4 \mathrm{~kb}$. The 5'- and 3'RACE fragments were cloned and sequenced, and they were indeed found to represent the overlapping 5' and 3' ends, respectively, of the IE-AS cDNA. The sequence of this cDNA is shown in Fig. 1C. For the 1.1-kb 5'-RACE product, four independent clones were sequenced. In these clones, the 5 ' end of the IE-AS transcript was mapped to a $G$ residue which corresponds to position 172,230 of the RCMV genome (Vink et al., 2000). This residue is localized within exon 4 of the MIE region. However, the exact 5'-terminal nucleotide could not be determined, since a stretch of $C$ residues was added to the cDNA during first-strand cDNA synthesis. As a consequence, each of the nucleotides in italics in Fig. 1C may represent the actual 5' end of the IE-AS transcript. For the 0.6-kb 5'-RACE product, three independent clones were sequenced. The 5' end of the IE-AS transcript in these clones was mapped to an A residue which corresponds to position 172,773 of the RCMV genome (Vink et al., 2000). This residue is also localized within exon 4 of the MIE region. The two IE-AS transcription start sites are separated by $0.5 \mathrm{~kb}$. A consensus TATA element upstream of the two start sites is lacking. Two independent 3'-RACE clones were sequenced. In these clones, which were found to differ in length by only nine nucleotides, the poly $(A)^{+}$tail was identified immediately $3^{\prime}$ of either a $T$ or an $A$ residue, which correspond to position 173,623 and 173,632, respectively, of the RCMV genome (Vink et al., 2000). Both residues are localized within intron 2 of the MIE region. The exact 3'-terminal nucleotide in the latter clone, however, could not be determined, since an oligo(dT) primer was used for the conversion of mRNA into cDNA. Each of the underlined nucleotides in Fig. $1 \mathrm{C}$ may therefore represent the actual 3 ' end of the IE-AS transcript. A consensus polyadenylation sequence, corresponding to position 173,605 to 173,610 of the RCMV genome (Vink et al., 2000), was found in both clones.

Taken together, these data indicate that at least two different major IE-AS transcripts exist. These transcripts, designated IE-AS1 and IE-AS2, are unspliced and have lengths of approximately 0.9 and $1.4 \mathrm{~kb}$, respectively. The position of these transcripts within the 
RCMV MIE region is shown in Fig. 1A. As shown in Fig. 1A and C, the IE-AS2 transcript was found to contain two open reading frames (ORFs) greater than 30 codons (ORF58 and ORF45), whereas a single ORF was identified in the IE-AS1 transcript (ORF45). ORF58 and ORF45 have the potential to encode proteins with a predicted molecular mass of 6.4 and $5.0 \mathrm{kDa}$, respectively. Both IE-AS transcripts are complementary to part of the IE1 transcript and the detection of these transcripts in the PBL samples in the absence of IE1 transcription suggested that they might be involved in downregulation of IE1 expression. Although the IE1 and IE-AS transcripts were found simultaneously in the salivary gland samples and in the RCMV-infected REFs, also here the IE-AS transcripts could play a role in the modulation of IE1 expression.

An antisense transcript similar to the RCMV IE-AS transcripts has previously been identified for HCMV (Kondo et al., 1996). This transcript was reported to be transcribed in latently infected granulocyte-macrophage progenitor cells in culture and in bone marrow of healthy seropositive individuals. Therefore, the antisense transcript was designated as a CMV latency-associated transcript (CLT) (Kondo et al., 1996). The HCMV antisense CLT was found to contain several ORFs. Two of these ORFs have a similar position and size as RCMV IE-AS ORF58 and ORF45. The corresponding proteins encoded by these ORFs, however, show only a limited degree of similarity (data not shown).

Although the IE-AS transcripts may indeed encode functional proteins, it is also possible that the transcripts themselves play a role in the regulation of gene expression by the formation of double-stranded (ds) RNA with the complementary, sense IE1 transcript. However, we have no direct evidence for the existence of this dsRNA formation during RCMV infection. Clearly, the challenge of future studies will be elucidation of the function of the IE-AS transcripts.

\section{Acknowledgments}

K. W. R. v. C. and M. J. B. contributed equally to this work. C. V. is supported by a fellowship of the Royal Netherlands Academy of Arts and Sciences (KNAW). K. W. R. v. C. is supported by grant 901-02-239 of the Netherlands Organization for Scientific Research (NWO) to C. V.

Nucleotide sequence data reported are available in the GenBank database under accession number AF232689. 


\section{References}

Beisser PS, Kaptein SJF, Beuken E, Bruggeman CA, Vink C. The Maastricht strain and England strain of rat cytomegalovirus represent different betaherpesvirus species rather than strains. Virology 1998;246:341-51.

Bruggeman CA, Meijer H, Dormans PHJ, Debie WMH, Grauls GELM, van Boven CPA. Isolation of a cytomegalovirus-like agent from wild rats. Arch Virol 1982;73:231-41.

Kondo $\mathrm{K}, \mathrm{Xu} \mathrm{J}$, Mocarski ES. Human cytomegalovirus latent gene expression in granulocytemacrophage progenitors in culture and in seropositive individuals. Proc Natl Acad Sci USA 1996;93:11137-42.

Sandford GR, Ho K, Burns WH. Characterization of the major locus of immediate-early genes of rat cytomegalovirus. J Virol 1993;67:4093-103.

van Cleef KWR, Scaf WMA, Maes K, Kaptein SJF, Beuken E, Beisser PS, et al. The rat cytomegalovirus homologue of parvoviral rep genes, $r 127$, encodes a nuclear protein with single- and double-stranded DNA-binding activity that is dispensable for virus replication. J Gen Virol 2004;85:2001-13.

Vink C, Beuken E, Bruggeman CA. Complete DNA sequence of the rat cytomegalovirus genome. J Virol 2000;74:7656-65. 


\section{Chapter 4}

The rat cytomegalovirus homologue of parvoviral rep genes, $r 127$, encodes a nuclear protein with single- and double-stranded DNA-binding activity that is dispensable for virus replication

Koen W.R. van Cleef, Wendy M.A. Scaf, Karen Maes, Suzanne J.F. Kaptein, Erik Beuken, Patrick S. Beisser, Frank R.M. Stassen, Gert E.L.M. Grauls, Cathrien A. Bruggeman, Cornelis Vink

J Gen Virol 2004;85:2001-13 


\section{Abstract}

An intriguing feature of the rat cytomegalovirus (RCMV) genome is open reading frame (ORF) r127, which shows similarity to the rep genes of parvoviruses as well as the U94 genes of human herpesvirus type 6A (HHV-6A) and 6B (HHV-6B). Counterparts of these genes have not been found in other herpesviruses. Here, it is shown that the r127 gene is transcribed during the early and late phases of virus replication in vitro as an unspliced $1.1-\mathrm{kb}$ transcript containing the complete r127 ORF. Transcripts of r127 were also detected in various organs of RCMV-infected rats at 1 week post-infection (p.i.), but only in the salivary gland at 4 months p.i. By using rabbit polyclonal antibodies raised against the r127-encoded protein (pr127), pr127 was found to be expressed as early as $12 \mathrm{~h}$ p.i. within the nuclei of RCMV-infected cells in vitro. Expression of pr127 was also observed within the nuclei of cells in various organs of RCMV-infected rats at 3 weeks p.i. Moreover, pr127 was demonstrated to bind single- as well as double-stranded DNA. Finally, an RCMV r127 deletion mutant (RCMV $\Delta$ r127) was generated, in which the r127 ORF is disrupted. This deletion mutant, however, was shown to replicate with a similar efficiency as wild-type RCMV (wt RCMV), both in vitro and in vivo. Taken together, it is concluded that the RCMV r127 gene encodes a nuclear protein with single- and doublestranded DNA-binding activity that is dispensable for virus replication, not only in vitro, but also during the acute phase of infection in vivo.

\section{Introduction}

Cytomegaloviruses (CMVs) are widespread species-specific betaherpesviruses that cause acute, persisting and latent infections in both humans and animals. Infections with human CMV (HCMV) are mainly asymptomatic in immunocompetent individuals, but can be life-threatening in immunocompromised individuals, such as AIDS patients and organ transplant recipients.

In our laboratory, we are studying the interaction between rat CMV (RCMV) and its host as a model for HCMV infection and disease (Bruggeman et al., 1982). RCMV contains a linear, double-stranded DNA genome with a length of $230.1 \mathrm{~kb}$. The complete DNA sequence of the RCMV genome has been determined recently and was found to contain at least 167 open reading frames (ORFs) (Vink et al., 2000). Most of these ORFs have counterparts in the genomes of both HCMV and murine CMV (MCMV) (Chee et al., 1990; Rawlinson et al., 1996; Vink et al., 2000). However, an exception is RCMV ORF r127, which is unique among the CMVs. This ORF has the capacity to encode a 337- 
amino acid protein (pr127) which shows similarity to the non-structural proteins (NS or Rep proteins) that are encoded by the rep genes of parvoviruses (Vink et al., 2000). The predicted amino acid sequence of the 127 -encoded protein is most closely related to the sequences of the Rep1/2 proteins of three avian parvoviruses, namely barbary duck parvovirus (BDPV), muscovy duck parvovirus (MDPV) and goose parvovirus (GPV) (Vink et al., 2000; Zadori et al., 1995). Although the RCMV rep gene homologue is unique among the CMVs, it is not unique among the betaherpesviruses: the U94 genes of human herpesvirus type 6A (HHV-6A) and 6B (HHV-6B) also show similarity to the parvoviral rep genes (Dominguez et al., 1999; Gompels et al., 1995; Isegawa et al., 1999; Thomson et al., 1991). The U94 ORF was first discovered in HHV-6A and was found to encode a 490-amino acid protein (RepH6) that is most closely related to the Rep proteins of the adeno-associated viruses (AAVs), including Rep68/78 of AAV-2 (Srivastava et al., 1983; Thomson et al., 1991). Interestingly, a counterpart of U94 has not been identified in the genome of HHV-7, which is closely related to HHV-6A and $-6 \mathrm{~B}$ (Nicholas, 1996). Remarkably, although RCMV r127 and HHV-6A and -6B U94 have a conserved genomic position as well as orientation (Dominguez et al., 1999; Gompels et al., 1995; Isegawa et al., 1999; Vink et al., 2000), rep gene homologues have so far not been found in the genomes of other herpesviruses.

The best characterized rep gene product is Rep68/78 of AAV-2 (reviewed by Berns, 1996). Rep68/78 is involved in many aspects of the virus replication cycle of AAV-2. It is required for viral DNA replication, modulation of viral and cellular gene expression and site-specific integration of the viral genome into human chromosome 19. Rep68/78 possesses several activities that correspond to its role in the virus replication cycle, including sequence-specific DNA-binding activity, site- and strand-specific endonuclease activity and ATP-dependent helicase activity (Berns, 1996).

The role of $\mathrm{RepH} 6$ in the virus replication cycles of HHV-6A and $-6 \mathrm{~B}$ is less well documented. However, RepH6 seems to have a conserved function with its AAV-2 counterpart, since HHV-6A U94 is able to complement the replication of a rep-deficient AAV-2 genome (Thomson et al., 1994). In addition, U94 is transcribed in latently infected peripheral blood mononuclear cells (PBMCs) from HHV-6A-infected individuals (Rotola et al., 1998), suggesting a role for RepH6 in the regulation of latency. This possibility is supported by the fact that virus replication and expression of viral genes are restricted in HHV-6A-infected lymphocytes expressing HHV-6B U94 in vitro (Rotola et al., 1998). Nevertheless, not much is known about the role of RepH6 in the pathogenesis of viral infection. Moreover, it is not possible to study the role of $\mathrm{RepH} 6$ in animal models. We 
therefore set out to study the biological function of pr127, the RepH6 homologue of RCMV. Here, we show that the RCMV r127 gene encodes a nuclear protein with singleand double-stranded DNA-binding activity. Furthermore, we demonstrate that the r127encoded protein is dispensable for virus replication in vitro and in vivo.

\section{Methods}

\subsection{Cells and virus}

Primary rat embryo fibroblasts (REFs) and the rat fibroblast cell line Rat2 (ATCC CRL 1764) were cultured as described previously (Bruggeman et al., 1982, 1985). RCMV (Maastricht strain) was propagated in REFs and virus titres were determined by plaque assays according to standard procedures (Bruggeman et al., 1982, 1985).

\subsection{Poly $(A)^{+} R N A$ isolation from $R C M V$ - and mock-infected REFs}

Poly $(A)^{+}$RNA was isolated from RCMV-infected REFs at immediate early (IE), early (E) and late $(L)$ times of infection. During the 1-h infection period, the REFs were exposed to RCMV at a multiplicity of infection (m.o.i.) of 1.0. IE mRNA was extracted from REFs that had been treated with $100 \mu \mathrm{g}$ cycloheximide $\mathrm{ml}^{-1}$ from $1 \mathrm{~h}$ prior to infection until they were harvested at $16 \mathrm{~h}$ post-infection (p.i.). E mRNA was obtained from REFs that had been treated with $200 \mu \mathrm{g}$ phosphonoacetic acid $\mathrm{ml}^{-1}$ from $3 \mathrm{~h}$ p.i. until harvesting at $16 \mathrm{~h}$ p.i., and L mRNA was isolated from REFs that were harvested at $72 \mathrm{~h}$ p.i. Mock mRNA was extracted from REFs that had not been infected with RCMV. Poly $(A)^{+}$RNA was purified with the QuickPrep Micro mRNA Purification Kit (Amersham Biosciences) and dissolved in RNase-free $\mathrm{H}_{2} \mathrm{O}$. Quantification of mRNA was done by standard determination of the absorbance at $260 / 280 \mathrm{~nm}$.

\subsection{Northern blot analysis}

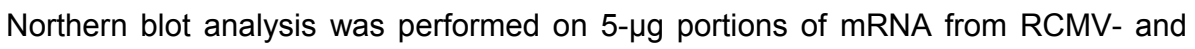
mock-infected REFs (see above). Samples were separated by electrophoresis through an agarose/formaldehyde gel, blotted onto a Hybond-N nylon membrane (Amersham Biosciences) and hybridized to a DNA probe representing the full-length r127 ORF. This

probe was generated after amplification of ORF r127 by PCR using primers 5'-r127 (5'-A CGTGGATCCATGAAGACTAGAACCGG-3') and 3'-r127 (5'-ACGTAAGCTTAACATCCT AGTCAC-3'). These primers introduced unique BamHI and HindIII restriction sites into the amplified fragment. Construct $\mathrm{pRXO}$, which contains the RCMV Xbal O fragment (Meijer et al., 1986), was used as target DNA. The amplified fragment of $1.0 \mathrm{~kb}$ was 
digested with BamHI and HindIII and cloned into the corresponding restriction sites of cloning vector pUC119, generating plasmid p302. The sequence of ORF r127 was confirmed by DNA sequencing using the Thermo Sequenase Cycle Sequencing Kit (Amersham Biosciences) with Cy5-labelled M13 universal primers and an ALFexpress automated DNA sequencer (Amersham Biosciences). Construct p302 was then digested with $\mathrm{BamHI}$ and HindIII and the resulting fragment containing ORF r127 was labelled with $\left[\alpha-{ }^{32}\right.$ P]dATP (ICN) using the Random Primed DNA Labeling Kit (Roche Applied Science). The radioactive signal was visualized by autoradiography.

\subsection{5'- and 3'-RACE}

Rapid amplification of 5 ' and $3^{\prime}$ cDNA ends (5'- and 3'-RACE) was performed on $\mathrm{L}$ mRNA (see above) using the SMART RACE cDNA Amplification Kit (BD Biosciences) and the Marathon cDNA Amplification Kit (BD Biosciences). Gene-specific primers r127P4 (5'-GGACTCCCGGGTTCCCAAGTACCTC-3'; position 178,973 to 178,997 of the RCMV genome; Vink et al., 2000) and r127P3 (5'-AGATGCGAGTCCCCGGTCGATAAA C-3'; position 179,164 to 179,140 ) were used for the 5'- and 3'-RACE, respectively. Amplified fragments were cloned into vector pGEM-T Easy (Promega) and their sequence was determined by DNA sequencing, as described above.

\subsection{Total RNA isolation from tissues of RCMV-infected rats}

Three-week-old, male Wistar rats (Central Animal Facilities, University of Maastricht) were infected by intraperitoneal injection of $1 \times 10^{5}$ plaque-forming units (p.f.u.) of RCMV and sacrificed at either 1 week or 4 months p.i. Salivary gland, spleen, kidney, liver and lung tissues were excised and total RNA was isolated as described previously (Gauthier et al., 1997). RNA was dissolved in RNase-free $\mathrm{H}_{2} \mathrm{O}$ and quantified by determination of the absorbance at $260 / 280 \mathrm{~nm}$.

\subsection{Generation of in vitro-transcribed RNA}

Construct p302 (see above) was digested with BamHI and HindIII and the resulting 1.0-kb fragment containing ORF r127 was cloned into BamHI- and Hindlll-digested vector pGEM-3Z (Promega), generating plasmid p271. In this construct, ORF r127 is located downstream of the T7 RNA polymerase promoter. A 1.2-kb fragment of construct p271 containing the T7 promoter and ORF r127 was amplified by PCR using M13 universal primers. An $0.5-\mu g$ portion of the amplified fragment was transcribed in the 
presence of T7 RNA polymerase (Amersham Biosciences) and subsequently treated with DNase I (Amersham Biosciences). RNA was purified by extraction with phenol/chloroform, recovered by ethanol precipitation, dissolved in RNase-free $\mathrm{H}_{2} \mathrm{O}$ and quantified by determination of the absorbance at $260 / 280 \mathrm{~nm}$.

\section{7. $R T-P C R$}

Reverse transcription-PCR (RT-PCR) was performed on $0.5-\mu \mathrm{g}$ portions of total RNA from tissues of RCMV-infected rats (see above). Each sample was denatured for 5 min at $65{ }^{\circ} \mathrm{C}$ in the presence of $0.4 \mu \mathrm{g}$ tRNA $\mu l^{-1}$ (Roche Applied Science). Samples were then chilled on ice and added to $50 \mu \mathrm{l}$ pre-chilled reaction mixture containing $10 \mathrm{mM}$ Tris/ $\mathrm{HCl}$ (pH 8.3), $50 \mathrm{mM} \mathrm{KCl,} 3 \mathrm{mM} \mathrm{MgCl} 2,2 \mathrm{mM}$ DTT, $0.2 \mathrm{mM}$ of each dNTP, $10 \mathrm{U}$ RNAguard (Amersham Biosciences), $0.25 \mathrm{U}$ HotStarTaq DNA polymerase (Qiagen), $5 \mathrm{U}$ SuperScript II reverse transcriptase (Invitrogen) and $0.2 \mu \mathrm{M}$ each of primer P3 (5'-CGTA TCGTCTGATCCGAACC-3'; position 178,908 to 178,889 of the RCMV genome) and P4 (5'-GGGATCTCTCCACCAGATGA-3'; position 178,661 to 178,680). Each sample was reverse transcribed for $20 \mathrm{~min}$ at $50^{\circ} \mathrm{C}$. Subsequently, the HotStarTaq DNA polymerase was activated for $15 \mathrm{~min}$ at $95^{\circ} \mathrm{C}$. The reverse-transcribed target was then amplified by 40 cycles of denaturation for $30 \mathrm{~s}$ at $94{ }^{\circ} \mathrm{C}$, primer annealing for $30 \mathrm{~s}$ at $59{ }^{\circ} \mathrm{C}$ and primer extension for $30 \mathrm{~s}$ at $72{ }^{\circ} \mathrm{C}$. A 1- $\mu$ l aliquot of the RT-PCR product was subjected to another 30 cycles of PCR with nested primers P1 (5'-CCATAACCTCAACCCTCGTG-3'; position 178,889 to 178,870 of the RCMV genome) and P2 (5'-CTACACAGGCAGCCAG GTCT-3'; position 178,690 to 178,709). Each sample was also processed in the absence of reverse transcriptase to monitor any residual DNA contamination. Furthermore, two additional reactions were run in parallel for each sample. In one of these reactions, the sample was spiked with 10-20 copies of in vitro-transcribed RNA (see above) to address whether possible contaminants interfered with the amplification. In the other reaction, the sample was subjected to RT-PCR with rat $\beta$-actin gene-specific primers RT-ACT-B (5'-G GTGGGTATGGGTCAGAAGG-3') and RT-ACT-F (5'-TGCCGATAGTGATGACCTGA-3') to confirm the integrity of the sample.

\subsection{Generation of MBP-pr127 and 6H-pr127 expression constructs}

Construct p302 (see above) was digested with BamHI and HindllI and the resulting 1.0-kb fragment containing ORF r127 was cloned into the corresponding restriction sites of expression vectors pMAL-c (New England Biolabs) and pRSET A (Invitrogen), 
generating plasmids p248 and p232. These constructs encode proteins containing the complete r127-derived amino acid sequence fused to the $C$ terminus of either maltosebinding protein (MBP-pr127; construct p248) or a tag consisting of six consecutive histidine residues $(6 \mathrm{H}-\mathrm{pr} 127$; construct $\mathrm{p} 232)$.

\subsection{Expression and purification of MBP-pr127 and MBP- $\beta$-gal- $\alpha$}

Construct p248 (see above) and expression vector PMAL-c were introduced into Escherichia coli BL21(DE3)pLysS and the resulting strains were grown overnight at 37 ${ }^{\circ} \mathrm{C}$ in LB medium containing $50 \mu \mathrm{g}$ ticarcillin $\mathrm{ml}^{-1}$ and $20 \mu \mathrm{g}$ chloramphenicol $\mathrm{ml}^{-1}$. The cultures were diluted 1:100 in $300 \mathrm{ml}$ LB medium with ticarcillin and chloramphenicol and grown at $37^{\circ} \mathrm{C}$ to an $\mathrm{OD}_{600}$ of 0.6 . Protein expression was then induced by the addition of IPTG to a final concentration of $0.3 \mathrm{mM}$. After $3 \mathrm{~h}$ of protein expression at $37^{\circ} \mathrm{C}$, the bacteria were harvested by centrifugation and resuspended in $10 \mathrm{ml}$ buffer $\mathrm{A}$ (10 mM sodium phosphate buffer, pH 7.2, 1 mM EDTA, $1 \mathrm{mM} \beta$-mercaptoethanol) supplemented with $1 \mathrm{M} \mathrm{NaCl}$. The suspensions were sonicated and cleared by centrifugation. To the supernatants, $10 \mathrm{ml}$ buffer $\mathrm{A}$ was added. The materials were then loaded onto 2-ml amylose columns (New England Biolabs). The columns were washed with $7.5 \mathrm{ml}$ buffer B (buffer A supplemented with $0.5 \mathrm{M} \mathrm{NaCl}$ ) containing $0.25 \%$ Tween 20 and subsequently with $7.5 \mathrm{ml}$ buffer B. Proteins were eluted with $7.5 \mathrm{ml}$ buffer B containing $10 \mathrm{mM}$ maltose. Fractions of $0.5 \mathrm{ml}$ eluted protein were collected and analysed by SDSPAGE. Peak fractions were pooled, dialysed into buffer B containing $10 \%$ glycerol and stored at $-80^{\circ} \mathrm{C}$.

\subsection{Generation of rabbit polyclonal antibodies directed against MBP-pr127}

A rabbit was immunized by intramuscular injection of $1 \mathrm{mg}$ purified MBP-pr127 (see above) in Specol adjuvant (Animal Sciences Group, Wageningen University and Research Centre). An intramuscular booster injection, containing $1 \mathrm{mg}$ purified MBPpr127, was given at week 9. Blood was obtained before and 13 weeks after immunization, and sera were prepared as described previously (Harlow and Lane, 1988). The reactivity of these sera against the RCMV pr127 protein was determined by Western blot analysis. 


\subsection{Western blot analysis}

Constructs p248 and p232 (see above) and expression vector pMAL-c were introduced into E. coli BL21(DE3)pLysS and protein expression was induced essentially as described above. Proteins from crude bacterial extracts were separated by SDSPAGE and transferred to a PROTRAN BA 83 nitrocellulose membrane (Schleicher \& Schuell). The blots were then incubated with a 1:1000 dilution of either rabbit anti-MBPpr127 antiserum or rabbit pre-immune serum (see above) and subsequently with horseradish peroxidase (HRP)-conjugated goat anti-rabbit immunoglobulins (DakoCytomation). The blots were stained with diaminobenzidine.

\subsection{Immunocytochemical analysis of RCMV-and mock-infected Rat2 cells}

During a 1-h infection period, Rat2 cells were either mock-infected or infected with RCMV at an m.o.i. of 0.1 . The cells were fixed and permeabilized at $8,12,24$ and $72 \mathrm{~h}$ p.i. The cells were then incubated with a 1:100 dilution of either rabbit anti-MBP-pr127 antiserum or rabbit pre-immune serum (see above) and subsequently with fluorescein isothiocyanate (FITC)-conjugated swine anti-rabbit immunoglobulins (DakoCytomation). The fluorescent label was visualized with an Axiovert 100 fluorescence microscope (Zeiss). Staining of cells with monoclonal antibody RCMV8 was carried out as described previously (Bruning et al., 1987; Kaptein et al., 2001).

\subsection{Immunohistochemical analysis of tissues of RCMV- and mock-infected rats}

Ten-week-old, male Brown Norway rats (Central Animal Facilities, University of Maastricht) were immunocompromised by 5 Gy of total-body Röntgen irradiation 1 day prior to infection, as described previously (Stals et al., 1990). Rats were either mockinfected or infected by intraperitoneal injection of $3 \times 10^{5}$ p.f.u. of RCMV. The animals were sacrificed at 3 weeks p.i. and $4-\mu \mathrm{m}$ paraffin tissue sections were prepared from salivary gland, spleen and liver. Serial tissue sections were mounted on glass slides and deparaffinized. Sections were then incubated with a 1:100 dilution of either rabbit antiMBP-pr127 antiserum or rabbit pre-immune serum (see above) and subsequently with biotin-conjugated swine anti-rabbit immunoglobulins (DakoCytomation) and streptavidinbiotinylated alkaline phosphatase (AP) complex (DakoCytomation). Sections were stained with Fast Red (Speel et al., 1992). Staining of sections with monoclonal antibody RCMV8 was performed as described previously (Bruning et al., 1987; Kaptein et al., 2001). 


\subsection{DNA-binding assay}

Portions of $150 \mu \mathrm{g}$ of either purified MBP-pr127 or MBP- $\beta$-gal- $\alpha$ (see above) in $1 \mathrm{ml}$ binding buffer (10 mM Tris/ $\mathrm{HCl}, \mathrm{pH} 7.4,25 \mathrm{mM} \mathrm{KCl,} 0.5 \mathrm{mM}$ EDTA, $0.05 \%$ Tween 20, $100 \mathrm{mM} \mathrm{NaCl}$ ) were added to 1-ml single- and double-stranded DNA-cellulose columns (Amersham Biosciences). The columns were washed with $5 \mathrm{ml}$ binding buffer and proteins were eluted with $0.5-\mathrm{ml}$ fractions of binding buffer supplemented with 0,100 , $200,400,600,800,1000$ and $1500 \mathrm{mM} \mathrm{NaCl}$. Fractions of eluted protein were collected and analysed by SDS-PAGE.

\subsection{Generation of an RCMV $\Delta$ r127 recombination plasmid}

Vector pRc/CMV (Invitrogen) was digested with Xhol and the resulting 2.1-kb fragment containing a neomycin resistance gene (neo) was cloned into Sall-digested vector pBluescript SK (+) (Stratagene), generating plasmid p474. Construct p474 was then digested with $\mathrm{Clal}$ and $\mathrm{Xhol}$ and the $2.1-\mathrm{kb}$ neo fragment was used to replace the 0.5-kb Clal-Xhol fragment within ORF $\mathrm{r} 127$ of construct pRXO. The resulting $\mathrm{RCMV} \Delta \mathrm{r} 127$ recombination plasmid was designated $\mathrm{p} 475$.

\subsection{Generation of an RCMV r127 deletion mutant}

Approximately $2 \times 10^{7}$ Rat2 cells were trypsinized and harvested by centrifugation. The cells were washed and resuspended in $500 \mu \mathrm{l}$ of serum-free culture medium. To the cell suspension, $20 \mu \mathrm{g}$ of construct p475 (see above) was added. The suspension was transferred to an 0.4-cm electroporation cuvette (Bio-Rad) and pulsed at $0.25 \mathrm{kV}$ and $500 \mu \mathrm{F}$ in a Gene Pulser electroporator (Bio-Rad). The transfected cells were subsequently seeded in culture flasks. At $16 \mathrm{~h}$ after transfection, the cells were infected with low-passage RCMV at an m.o.i. of 1.0. The culture medium was supplemented with $50 \mu \mathrm{g} \mathrm{G} 418 \mathrm{ml}^{-1}$ at $24 \mathrm{~h}$ p.i. Recombinant virus was plaque-purified and cultured on REFs as described previously (Beisser et al., 1998, 1999, 2000; Kaptein et al., 2003). The integrity and plaque purity of the RCMV r127 deletion mutant (RCMV $\Delta$ r127) were determined by Southern blot analysis.

\subsection{Southern blot analysis}

DNA was isolated from wild-type (wt) RCMV- and RCMV $\Delta$ r127-infected REFs and digested with $\mathrm{Xbal}$ and $\mathrm{Xhol}$. The digested samples were separated by electrophoresis through an agarose gel and blotted onto a Hybond-N+ nylon membrane (Amersham 
Biosciences). Constructs pRXO and p474 (see above) were used as RXO- and neospecific probes, respectively. These constructs were labelled with the DIG DNA Labeling Kit (Roche Applied Science). The DIG Easy Hyb solution (Roche Applied Science) was used for hybridization, and the DIG Wash and Block Buffer Set (Roche Applied Science) and the DIG Luminescent Detection Kit (Roche Applied Science) were used for detection.

\subsection{Replication of wt RCMV and RCMV $\Delta r 127$ in vitro}

During a 1-h infection period, REFs were infected with either wt RCMV or RCMV $\Delta$ r127 at an m.o.i. of 0.01 . At days 1, 3, 5 and 7 p.i., culture medium samples were taken and subjected to plaque assays. The data were statistically analysed by applying Student's $t$-test. $P$ values of $<0.05$ were considered to indicate statistical significance.

\subsection{Replication of wt RCMV and RCMV $\Delta r 127$ in vivo}

Two groups of 10 seven-week-old, male, specific-pathogen-free (SPF) Lewis/M rats (Central Animal Facilities, University of Maastricht) were immunocompromised by 5 Gy of total-body Röntgen irradiation 1 day prior to infection, as described previously (Stals et al., 1990). Rats were infected by intraperitoneal injection of $1 \times 10^{6}$ p.f.u. of either wt RCMV or RCMV $\Delta$ r127. At days 4 and 28 p.i., 5 rats from each group were sacrificed. Salivary gland, spleen, kidney, liver, pancreas and thymus tissues were collected and subjected to plaque assays. The data were statistically analysed by applying Student's $t$ test. $P$ values of $<0.05$ were considered to indicate statistical significance.

\section{Results}

\subsection{The RCMV r127 gene}

The 1011-bp ORF of the $\mathrm{r} 127$ gene was found to be localized between nucleotides 178,310 and 179,320 of the 230,138 -bp RCMV genome. ORF r127 runs from right to left and is located immediately $5^{\prime}$ of ORF $\mathrm{r} 128$, which runs in the opposite direction (Fig. 1). A potential TATA box (5'-TTAAAA-3'; position 179,398 to 179,393 of the RCMV genome) and a consensus polyadenylation sequence (5'-AATAAA-3'; position 178,260 to 178,255) are located up- and downstream, respectively, of ORF r127 (Vink et al., 2000). This ORF has the potential to encode a 337-amino acid protein with a calculated molecular mass of $37.8 \mathrm{kDa}$, which was found to be $28 \%$ identical to the Rep1/2 proteins of BDPV and MDPV and $27 \%$ identical to the Rep1/2 protein of GPV (Table 1) (Vink et al., 2000; 
Zadori et al., 1995). Lower similarities were found to the rep gene products of other parvoviruses and to the proteins that are encoded by the U94 genes of HHV-6A and $-6 \mathrm{~B}$.

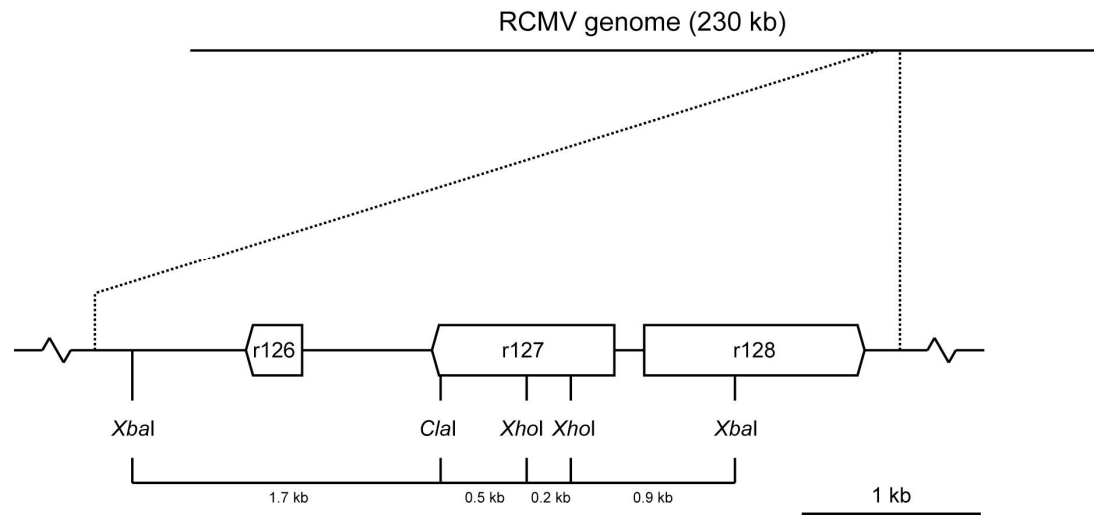

Fig. 1. Map of the 230-kb RCMV genome and position of ORFs $r 126, r 127$ and $r 128$. A section of the map, containing the RCMV Xbal O fragment (Meijer et al., 1986), has been enlarged below the main map. The direction of the arrow indicates the orientation of the sense strand of the corresponding ORF.

Table 1. Identities* (\%) among parvoviral Rep(-like) proteins**

\begin{tabular}{|c|c|c|c|c|c|}
\hline & $\begin{array}{l}\text { RCMV } \\
\text { pr127 }\end{array}$ & $\begin{array}{c}\text { HHV-6A } \\
\text { RepH6 }\end{array}$ & $\begin{array}{l}\text { BDPV } \\
\text { Rep1 }\end{array}$ & $\begin{array}{l}\text { MDPV } \\
\text { Rep1 }\end{array}$ & $\begin{array}{l}\text { GPV } \\
\text { Rep1 }\end{array}$ \\
\hline \multicolumn{6}{|l|}{ RCMV pr127 (337 aa) ${ }^{\star * *}$} \\
\hline HHV-6A RepH6 (490 aa) & 21 & & & & \\
\hline BDPV Rep1 (627 aa) & 28 & 22 & & & \\
\hline MDPV Rep1 (626 aa) & 28 & 22 & 98 & & \\
\hline GPV Rep1 (627 aa) & 27 & 22 & 90 & 89 & \\
\hline AAV-2 Rep78 (621 aа) & 24 & 24 & 47 & 47 & 46 \\
\hline
\end{tabular}




\subsection{The 127 gene is transcribed during RCMV infection in vitro}

Northern blot analysis was performed to investigate transcription of the r127 gene during RCMV infection in vitro. Transcription of $\mathrm{r} 127$ was examined in RCMV-infected cells at IE, $E$ and $L$ times of infection. As shown in Fig. 2A, r127-specific transcripts were exclusively detected during the $E$ and $L$ phases of infection (panel $B$, lanes 3 and 4 ) and not during the IE phase of infection (lane 2). Transcription of r127 was dependent on RCMV infection, since it was not observed in mock-infected cells (Fig. 2A, panel B, lane 1). One major $\mathrm{r} 127$-specific mRNA was identified with an estimated length of approximately $1.3 \mathrm{~kb}$ (Fig. 2A, panel B, lanes 3 and 4). This mRNA is most abundantly transcribed during the $\mathrm{E}$ phase of infection. Ethidium bromide staining of the agarose/formaldehyde gel confirmed the integrity of all mRNA samples and clearly demonstrated that similar amounts of mRNA were used for each experiment (Fig. 2A, panel A). Since we used a double-stranded DNA probe to detect the r127-specific transcripts, we could not designate these transcripts as either sense or antisense. Nevertheless, we predicted the 1.3-kb mRNA to represent a sense transcript containing the complete 1.0-kb r127 ORF. This prediction was based on the position of a potential TATA box and a consensus polyadenylation sequence near the $5^{\prime}$ and $3^{\prime}$ end, respectively, of ORF r127 (see above).

In order to determine the structure of the r127 transcript, 5'- and 3'-RACE experiments were performed. Gene-specific primers r127P4 and r127P3 (see Methods) were designed in such a way that they would generate overlapping $5^{\prime}$ and $3^{\prime}$ cDNA ends, which allowed us to determine the complete structure of the $r 127$ transcript. As shown in Fig. 2B, the 5'- and 3'-RACE experiments resulted in major amplified fragments with lengths of approximately 0.5 and $1.0 \mathrm{~kb}$, respectively (lanes 2 and 3). These fragments were cloned and sequenced, and it was found that they represented the overlapping $5^{\prime}$ and 3 ' ends of the r127 cDNA. The sequence of this cDNA is shown in Fig. 2C. The r127 transcript is unspliced, has a length of approximately $1.1 \mathrm{~kb}$ and contains the complete r127 ORF. Five independent 5'-RACE clones were sequenced. In these clones, the r127 transcription start site was mapped to a residue located either 50 (two clones), 49 (one clone) or 48 (two clones) nucleotides upstream of the predicted ATG initiation codon. Nine independent $3^{\prime}$-RACE clones were sequenced. In seven of these clones, the $\operatorname{poly}(\mathrm{A})^{+}$tail was identified immediately $3^{\prime}$ of a residue located either 18 (five clones), 17 (one clone) or 14 (one clone) nucleotides downstream of the consensus polyadenylation sequence. The $3^{\prime}$ end of the other two 3'-RACE clones was located 12 nucleotides upstream of the polyadenylation signal. These clones may have been generated after 
A

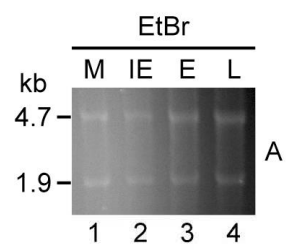

$\mathrm{kb}$
$1.3-$ $\frac{\text { r127 probe }}{M \text { IE E L }}$

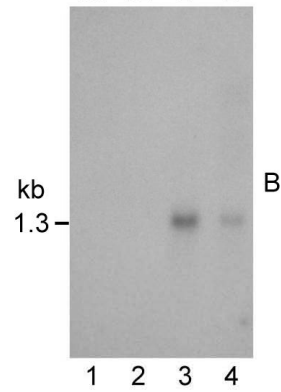

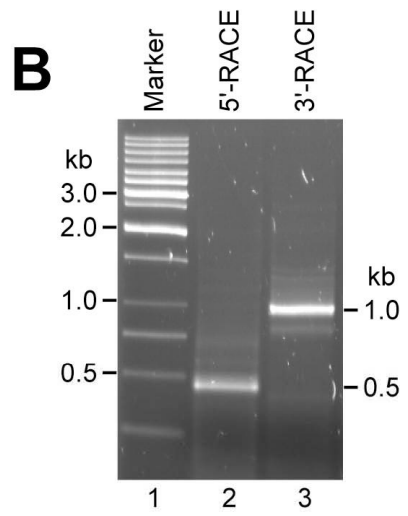

$\mathrm{C}$

\section{$\prod^{212}$}

\begin{tabular}{lllllllllllllllllll}
$M$ & $K$ & $T$ & $R$ & $T$ & $G$ & $K$ & $S$ & $T$ & $E$ & $K$ & $S$ & $S$ & $G$ & $I$ & $S$ & $G$ \\
\hline
\end{tabular}

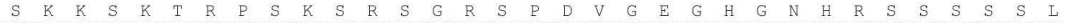
101 CAGCAAAAAGAGTAAGACCCGCCCATCCAAATCTCGTTCCGGCAGGTCACCCGACGTCGGAGAAGGACACGGGAACCATAGGTCATCCTCGTCATCCCTA

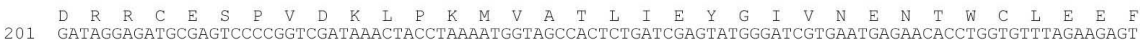
$301 \underset{\text { TCGAGTCCTATCTCGAGGTTCAGAGTGACCCCGTGAAGAGAGCTCGGGCCCGGAAGGCTATCTCTGTGGCTCGGAGGTACTTGGGAACCCGGGAGTCCCC }}{E}$

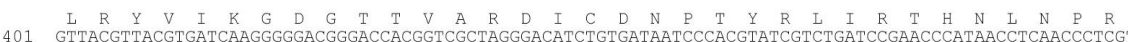
IACGITACGIGATCAAGGGGGACGGGACCACGGTCGCTAGGGACATCTGTGATAATCCCACGTATCGTCTGATCCGAACCCATARCCTCAACCCICG

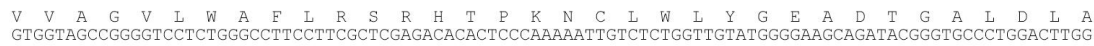

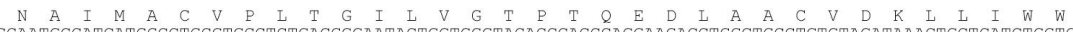
601 CСAATCCCAT $\underset{\text { GAGAGATCCCCCCGAGAACGTTCTAGTCTCAGATACTTATAGAAGCCTCCTGGCCGGGATGTTGCTTAAAGTTCGGGCCAAAGAGGTGACTAAGTCTTTG }}{\mathrm{R}}$

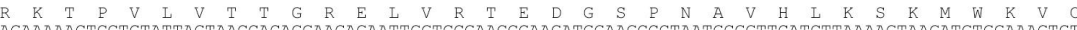

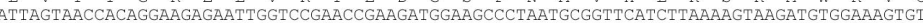

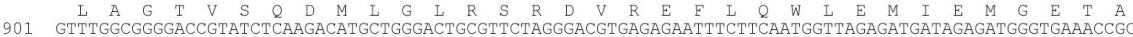

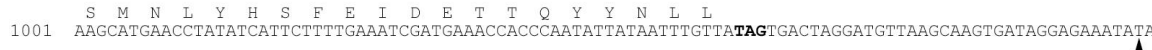

1101 GAAATAGAAAATAAAAATATTTTATAAAGACTC

D

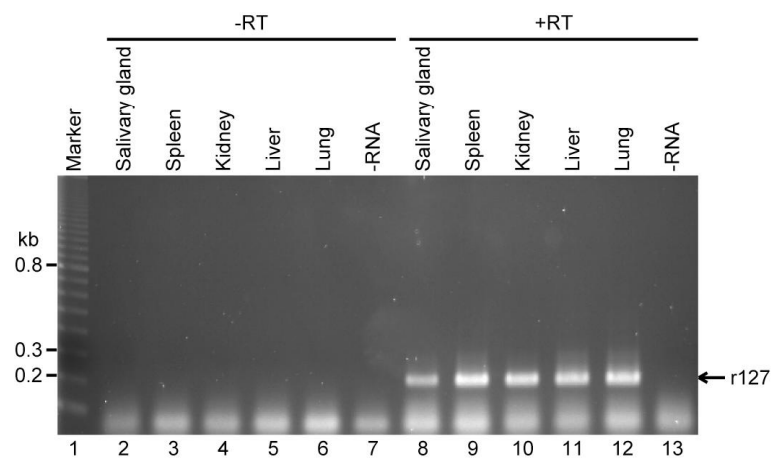


Fig. 2 (page 78). The r127 gene is transcribed during RCMV infection in vitro and in vivo. (A) Northern blot analysis. Portions of Mock (M; lane 1), IE (lane 2), E (lane 3) and L (lane 4) mRNA were separated by agarose/formaldehyde gel electrophoresis, analysed by ethidium bromide staining (EtBr; panel A), blotted onto a Hybond-N nylon membrane and hybridized to an $\mathrm{r} 127-$ specific probe (panel B). The lengths of the rRNA bands and the estimated length of the r127 transcript are shown on the left-hand side of the gel and blot, respectively. (B) 5'- and 3'-RACE. Portions of L mRNA were subjected to 5'- and 3'-RACE experiments (lanes 2 and 3). 5'- and 3'RACE products were analysed by agarose gel electrophoresis and ethidium bromide staining. The sizes of the DNA markers (lane 1) and the estimated lengths of the 5'- and 3'-RACE products are shown on the left- and right-hand side, respectively, of the gel. (C) Primary structure of the r127 CDNA. The sequence of the r127 cDNA was deduced from the sequences of the 5'- and 3'-RACE products. The translation start (ATG) and stop (TAG) codons and the consensus polyadenylation sequence (AATAAA) are marked. Arrowheads pointing down indicate the number of 5'-RACE clones in which the transcription start site was mapped to a particular residue and arrowheads pointing up indicate the number of $3^{\prime}-$ RACE clones in which the poly $(A)^{+}$tail was identified immediately $3^{\prime}$ of a particular residue. The amino acid sequence that is predicted to be encoded by the r127 transcript is indicated above the cDNA sequence. (D) RT-PCR. Portions of total RNA from salivary gland (lanes 2 and 8), spleen (lanes 3 and 9), kidney (lanes 4 and 10), liver (lanes 5 and 11) and lung (lanes 6 and 12) of RCMV-infected rats at 1 week p.i. were subjected to a nested RTPCR assay either with (+RT; lanes 8-13) or without (-RT; lanes 2-7) the addition of reverse transcriptase. The assay was also performed in the absence of RNA (-RNA; lanes 7 and 13). RTPCR products were analysed by agarose gel electrophoresis and ethidium bromide staining. The sizes of the DNA markers (lane 1) are shown on the left-hand side of the gel. The position of the 200-bp RT-PCR product is indicated on the right (r127).

annealing of the oligo(dT) primer, which was used for first-strand cDNA synthesis, on a stretch of $A$ residues near the $3^{\prime}$ end of the transcript rather than on the poly $(A)^{+}$tail.

The 1.1-kb r127 transcript that was identified by the RACE experiments (Fig. 2C) is likely to correspond to the 1.3-kb mRNA that was detected by Northern blot analysis (Fig. $2 A)$. We therefore conclude that the RCMV r127 gene is transcribed during the $E$ and $L$ phases of virus replication in vitro as an unspliced transcript of approximately $1.1 \mathrm{~kb}$, comprising the full-length r127 ORF.

\subsection{The r127 gene is transcribed during RCMV infection in vivo}

To examine whether the $r 127$ gene is transcribed during the acute phase of RCMV infection in vivo, an r127-specific, nested RT-PCR assay was performed on total RNA purified from salivary gland, spleen, kidney, liver and lung of RCMV-infected rats at 
either 1 week or 4 months p.i. The assay, which has a lower detection limit of approximately 10 copies of RNA (data not shown), was designed such as to amplify a 200-bp fragment. At 1 week p.i., r127-specific transcripts were detected in all five organs tested (Fig. 2D, lanes 8-12). As expected, transcripts of $\mathrm{r} 127$ were not detected when RNA was omitted from the reaction mixture (Fig. 2D, lane 13). Furthermore, amplified fragments were derived from RNA rather than from contaminating DNA, since they were not generated when samples were processed in the absence of reverse transcriptase (Fig. 2D, lanes 2-7). Spiking each sample with in vitro-synthesized RNA and subjecting each sample to an RT-PCR assay with a primer set specific for the rat $\beta$-actin gene confirmed the efficiency of all enzymatic reactions and the integrity of all RNA samples (data not shown). At 4 months p.i., r127-specific transcripts were only detected in the salivary gland and not in spleen, kidney, liver and lung (data not shown). This pattern of r127 transcription parallels the temporal production of infectious virus in organs of RCMV-infected rats (Bruggeman et al., 1985). Taken together, the RCMV r127 gene is widely transcribed during productive infection, both in vitro and in vivo.

\subsection{Generation of rabbit polyclonal antibodies directed against the RCMV pr127 protein}

In order to study expression of the RCMV r127-encoded protein, we set out to generate rabbit anti-pr127 polyclonal antibodies. To this end, an MBP-pr127 fusion protein was expressed in E. coli and purified by affinity chromatography (Fig. 3A, panel A). The purified protein (Fig. 3A, panel A, lanes 7-15) had a calculated molecular mass of $80 \mathrm{kDa}$ and was approximately $90 \%$ pure. Minor proteins in the MBP-pr127 preparation with molecular masses lower than $80 \mathrm{kDa}$ probably represented degradation products of the full-length fusion protein. Peak fractions of purified MBP-pr127 (Fig. 3A, panel A, lanes 8-15) were pooled, dialysed and used to immunize a rabbit. The reactivity of the resulting rabbit anti-MBP-pr127 antiserum against pr127 was tested by Western blot analysis (Fig. 3B). This antiserum reacted with MBP-pr127 (Fig. 3B, lane 2) as well as with $6 \mathrm{H}$-pr127 (lane 3 ). As might be expected, reactivity was also seen with a protein containing the bacterial $\beta$-galactosidase- $\alpha$ protein fused to MBP (MBP- $\beta$-gal- $\alpha$; Fig. 3B, lane 4), but not with a protein containing part of the RCMV IE1 protein fused to a combined 6H-thioredoxin tag (6H-TRX-IE1; lane 5) (Beuken et al., 1999). Rabbit preimmune serum did not react with any of these proteins (Fig. 3B, lanes 7-10). These data clearly indicate that the rabbit anti-MBP-pr127 antiserum contains antibodies directed 
against both MBP and pr127. Since eukaryotic cells do not express MBP, this antiserum is a useful tool to study expression of the pr127 protein in RCMV-infected cells.

\subsection{The pr127 protein is expressed within the nuclei of RCMV-infected cells in vitro}

To investigate expression of the pr127 protein during RCMV infection in vitro, and to determine the cellular localization of this protein, we applied the rabbit anti-MBP-pr127 antiserum (see above) in immunocytochemical analysis of RCMV-infected cells at 8, 12, 24 and $72 \mathrm{~h}$ p.i. Fig. $3 \mathrm{C}$ shows that pr127 is expressed within the nuclei of RCMVinfected cells at 12, 24 and $72 \mathrm{~h}$ p.i. (panels B-D), but not at $8 \mathrm{~h}$ p.i. (panel A). Expression of pr127 was dependent on RCMV infection, since it was not observed in mock-infected cells (data not shown). In addition, specific staining was not seen after incubation with rabbit pre-immune serum (data not shown). Staining with monoclonal antibody RCMV8, which is directed against a nuclear RCMV protein (pR44), also resulted in nuclear staining of RCMV-infected cells (Fig. $3 \mathrm{C}$, panels $\mathrm{E}-\mathrm{H}$ ), as shown previously (Bruning et al., 1987; Kaptein et al., 2001).

In conclusion, the pr127 protein is a nuclear protein that is expressed as early as 12 h p.i. in RCMV-infected cells in vitro. The kinetics of pr127 expression are in accordance with the early-late kinetics of r127 transcription (see above).

\subsection{The pr127 protein is expressed within the nuclei of RCMV-infected cells in vivo}

To examine in vivo expression of the pr127 protein during the acute phase of RCMV infection, immunohistochemical analysis using the rabbit anti-MBP-pr127 antiserum (see above) was performed on salivary gland, spleen and liver of RCMV-infected rats at 3 weeks p.i. As shown in Fig. 3D, pr127 is expressed within the nuclei of RCMV-infected cells in all three organs tested (panels A-C). As expected, specific staining was not observed either in corresponding tissue sections from mock-infected rats (data not shown) or after incubation with rabbit pre-immune serum (Fig. 3D, panels D-F). As shown previously (Bruning et al., 1987; Kaptein et al., 2001), staining with anti-pR44 monoclonal antibody RCMV8 also resulted in nuclear staining of RCMV-infected cells in these organs (data not shown). Taken together, the pr127 protein is widely expressed within the nuclei of RCMV-infected cells during productive infection, both in vitro and in vivo. 
A

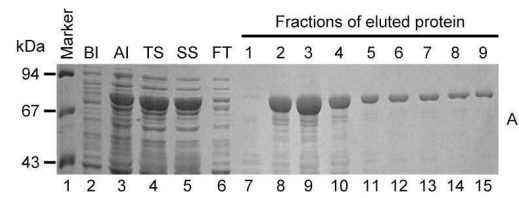

MBP- $\beta-$ gal- $\alpha$

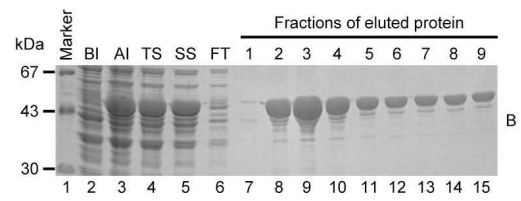

C
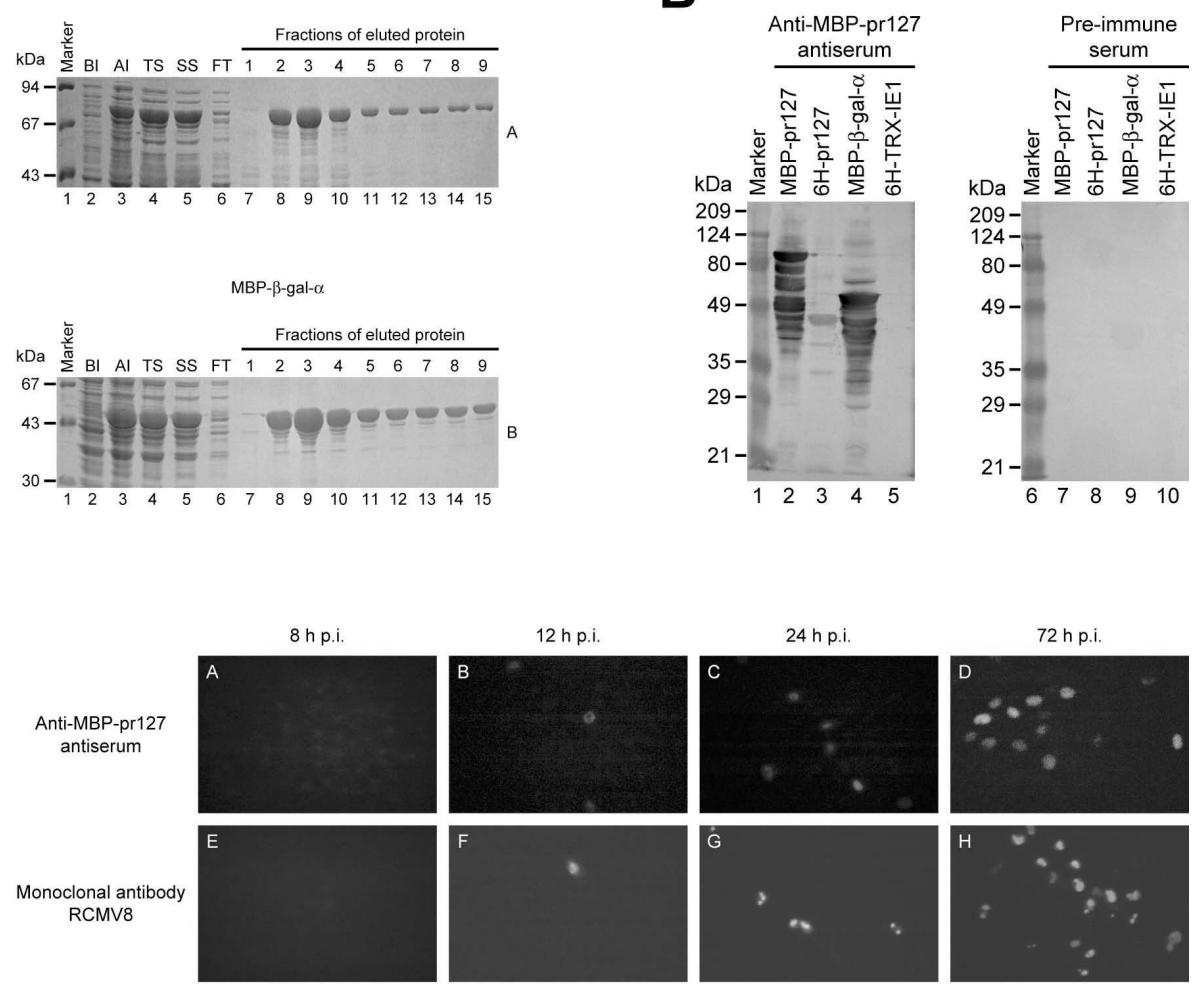

D

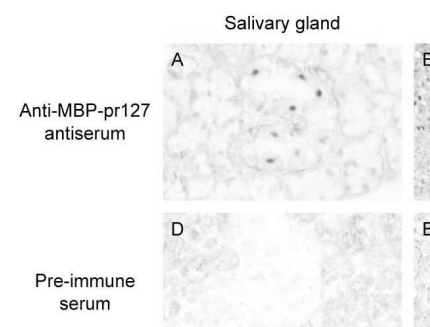

Spleen

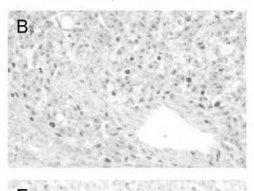

E
Liver

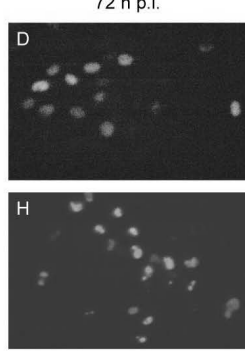

serum

Fig. 3. The pr127 protein is expressed within the nuclei of RCMV-infected cells in vitro and in vivo. (A) Expression and purification of MBP-pr127 and MBP- $\beta-$ gal- $\alpha$. MBP-pr127 (panel A) and MBP- $\beta$ gal- $\alpha$ (panel $B$ ) were purified by affinity chromatography on an amylose column and samples were analysed by SDS-PAGE and Coomassie blue staining. Samples include crude extracts of bacteria expressing MBP-pr127 and MBP- $\beta$-gal- $\alpha$ before (BI; lane 2$)$ and after ( $\mathrm{Al}$; lane 3$)$ induction with IPTG, the total sonication suspension (TS; lane 4), the supernatant of the suspension after 
centrifugation (SS; lane 5), the flow-through from the column (FT; lane 6) and the collected fractions of eluted protein (lanes 7-15). The sizes of the protein markers (lane 1) are shown on the left-hand side of each gel. (B) Western blot analysis. Proteins from crude extracts of bacteria expressing MBP-pr127 (lanes 2 and 7), 6H-pr127 (lanes 3 and 8), MBP- $\beta$-gal- $\alpha$ (lanes 4 and 9) and 6H-TRXIE1 (lanes 5 and 10) were separated by SDS-PAGE and transferred to a PROTRAN BA 83 nitrocellulose membrane. The blots were immunologically stained using either rabbit anti-MBPpr127 antiserum (lanes 2-5) or rabbit pre-immune serum (lanes 7-10). The sizes of the pre-stained protein markers (lanes 1 and 6) are shown on the left-hand side of each blot. (C) Immunocytochemical analysis of RCMV-infected cells. RCMV-infected cells were fixed, permeabilized and immunologically stained using either rabbit anti-MBP-pr127 antiserum (panels AD) or, as a control, anti-pR44 monoclonal antibody RCMV8 (panels E-H) at 8 (panels A and E), 12 (panels $B$ and F), 24 (panels $C$ and $G$ ) and 72 h p.i. (panels $D$ and H). (D) Immunohistochemical analysis of tissues of RCMV-infected rats. Paraffin tissue sections of salivary gland (panels $A$ and $D$ ), spleen (panels B and E) and liver (panels $C$ and F) of RCMV-infected rats at 3 weeks p.i. were deparaffinized and immunologically stained using either rabbit anti-MBP-pr127 antiserum (panels AC) or, as a control, rabbit pre-immune serum (panels D-F).

\subsection{The RCMV pr127 protein has single- and double-stranded DNA-binding activity}

There are several indications that the RepH6 proteins of HHV-6A and $-6 \mathrm{~B}$ might be involved in the regulation of viral and/or cellular gene expression. One of these is the ability of HHV-6B RepH6 to bind single-stranded DNA (Dhepakson et al., 2002). To determine whether the RCMV pr127 protein also possesses DNA-binding activity, we tested its capacity to bind to DNA-cellulose. First, fusion proteins MBP-pr127 (80 kDa) and MBP- $\beta$-gal- $\alpha$ (51 kDa) were purified from E. coli, as described above (Fig. 3A). The purified proteins were then tested for their affinity for single- and double-stranded DNAcellulose columns. As shown in Fig. 4, MBP-pr127 was found to bind single- (panel A, lane 4) as well as double-stranded DNA-cellulose (panel C, lane 4), although its affinity for single-stranded DNA-cellulose seemed somewhat more pronounced. Since MBPpr127 does not bind to cellulose alone (data not shown), we conclude that the affinity of this protein for DNA-cellulose is the result of DNA binding by MBP-pr127. The DNAbinding activity of this protein appears to be strong, given that the protein was only partially eluted from the columns with increasing concentrations of $\mathrm{NaCl}$ (Fig. 4, panels $\mathrm{A}$ and $C$, lanes 5-13). Furthermore, the DNA-binding activity of MBP-pr127 was pr127specific, since the columns did not retain MBP- $\beta$-gal- $\alpha$ (Fig. 4, panels B and D, lane 4). These results indicate that the RCMV pr127 protein has single- as well as doublestranded DNA-binding activity. 

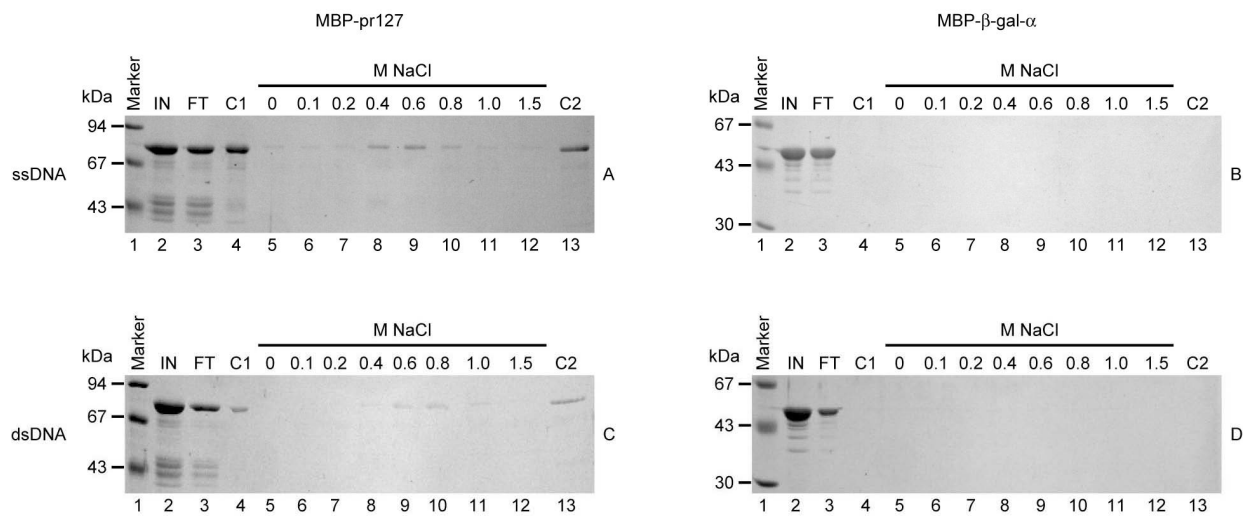

Fig. 4. The RCMV pr127 protein has single- and double-stranded DNA-binding activity. Purified MBP-pr127 (panels A and C) and MBP- $\beta$-gal- $\alpha$ (panels $B$ and $D$ ) were added to single- (ssDNA; panels $A$ and $B$ ) and double-stranded (dsDNA; panels $C$ and D) DNA-cellulose columns. The columns were washed and proteins were eluted with increasing concentrations of $\mathrm{NaCl}$. Samples were analysed by SDS-PAGE and Coomassie blue staining. Samples include the input (IN; lane 2), the flow-through from the column ( $\mathrm{FT}$; lane 3$)$, the material on the column before elution (C1; lane 4 ), the collected fractions of eluted protein (lanes 5-12) and the material on the column after elution (C2; lane 13). The sizes of the protein markers (lane 1) are shown on the left-hand side of each gel.

\subsection{Generation of an RCMV r127 deletion mutant}

The role of the herpesviral homologues of the parvoviral Rep proteins in the pathogenesis of viral infection is still enigmatic. We therefore decided to characterize the biological significance of the RCMV pr127 protein by generating and studying a recombinant RCMV strain (RCMV $\Delta \mathrm{r} 127$ ), in which the r127 gene is disrupted by replacing part of its ORF with a neo expression cassette (Fig. 5A). The mutation was first introduced into a plasmid that contains the RCMV Xbal O fragment (Meijer et al., 1986). The r127 gene within the RCMV genome was subsequently replaced with the mutated r127 gene by homologous recombination, after transfection of cells with the recombination plasmid followed by infection with RCMV. Recombinant virus was purified by several rounds of $\mathrm{G} 418$ selection and subsequent plaque purifications. The integrity and plaque purity of the RCMV r127 deletion mutant were verified by Southern blot analysis (Fig. 5B). Hybridization of the RXO-specific probe with Xbal- and Xhol-digested DNA from wt RCMV and RCMV $\Delta$ r127 should reveal 0.9- and 0.2-kb fragments for both viruses and either a 2.2- or 3.8-kb fragment for wt RCMV and RCMV $\Delta \mathrm{r} 127$, respectively. Hybridization of the neo-specific probe with Xbal- and Xhol-digested DNA from wt RCMV 
A
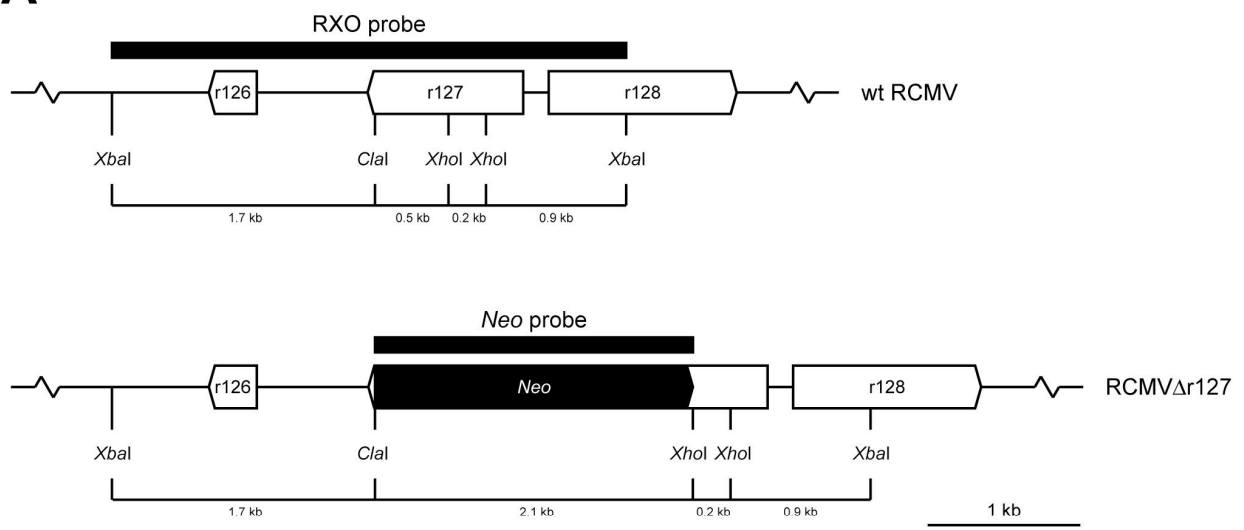

B

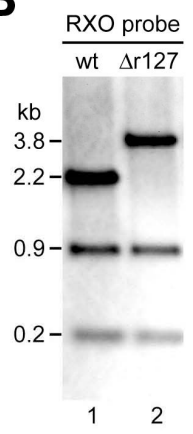

C o wt RCMv

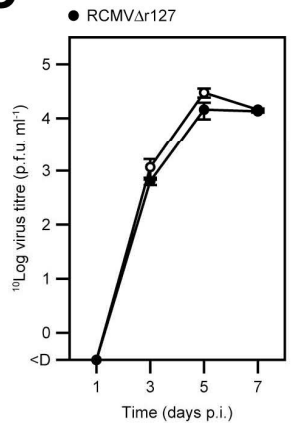

D

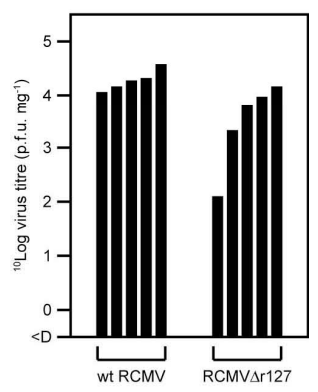

Fig. 5. The 127 gene is dispensable for RCMV replication in vitro and in vivo. (A) Generation of an RCMV r127 deletion mutant. RCMV $\Delta$ 127 was produced by replacing the $0.5-\mathrm{kb}$ Clal-Xhol fragment within RCMV ORF r127 with a 2.1-kb neo expression cassette. The positions of the RXO- and neospecific probes that were used for Southern blot analysis are indicated. (B) Southern blot analysis. Xbal- and Xhol-digested DNA from wt RCMV (wt; lanes 1 and 3) and RCMV $\Delta r 127$ ( $\Delta$ r127; lanes 2 and 4) was separated by agarose gel electrophoresis, blotted onto a Hybond-N+ nylon membrane and hybridized to either an RXO- (lanes 1 and 2) or neo-specific (lanes 3 and 4 ) probe. The lengths of the restriction fragments are shown on the left-hand side of each blot. (C) Replication of wt RCMV and RCMV $\Delta$ r127 in vitro. The graph shows the virus titres in the culture media of wt RCMV- and RCMV $\Delta$ r127-infected cells at 1, 3, 5 and 7 days p.i. Standard deviations are indicated by vertical bars. $<D$, below detection level. (D) Replication of wt RCMV and RCMV $\Delta r 127$ in vivo. The diagram shows the virus titres in the salivary glands of wt RCMV- and RCMV $\Delta$ r127-infected rats at 28 days p.i. Each bar represents the result from a single rat. $<D$, below detection level. 
and RCMV $\Delta$ r127 should only reveal a 3.8-kb fragment for RCMV $\Delta$ r127. As shown in Fig. $5 \mathrm{~B}$, the hybridization patterns were as predicted and therefore confirm the integrity and the plaque purity of the RCMV r127 deletion mutant.

\subsection{The r127 gene is dispensable for RCMV replication in vitro}

To compare the in vitro replication characteristics of wt RCMV and RCMV $\Delta \mathrm{r} 127$, multi-step growth curves were generated. The amount of infectious virus produced by wt RCMV- and RCMV $\triangle$ r127-infected cells was determined at 1, 3, 5 and 7 days p.i. Fig. 5C shows that the virus titres produced by wt RCMV- and RCMV $\Delta$ r127-infected cells did not differ significantly at any of the time-points tested. These data indicate that wt RCMV and $\mathrm{RCMV} \Delta \mathrm{r} 127$ replicate with similar efficiencies. We therefore conclude that the RCMV r127 gene is dispensable for virus replication in vitro.

Table 2. The r127 gene is dispensable for RCMV replication in vivo

\begin{tabular}{|c|c|c|c|c|}
\hline \multirow[b]{3}{*}{ Organ } & \multicolumn{4}{|c|}{ No. of positive rats / Total no. of rats tested ${ }^{*}$} \\
\hline & \multicolumn{2}{|c|}{ Day 4 p.i. } & \multicolumn{2}{|c|}{ Day 28 p.i. } \\
\hline & $w t^{* *}$ & $\Delta \mathrm{r} 127^{* * *}$ & wt & $\Delta \mathrm{r} 127$ \\
\hline Salivary gland & $0 / 5$ & $0 / 5$ & $5 / 5$ & $5 / 5$ \\
\hline Spleen & $2 / 5$ & $3 / 5$ & $0 / 5$ & $0 / 5$ \\
\hline Kidney & $1 / 5$ & $0 / 5$ & $0 / 5$ & $0 / 5$ \\
\hline Liver & $0 / 5$ & $0 / 5$ & $0 / 5$ & $0 / 5$ \\
\hline Pancreas & $1 / 5$ & $0 / 5$ & $0 / 5$ & $0 / 5$ \\
\hline Thymus & $2 / 5$ & $3 / 5$ & $0 / 5$ & $0 / 5$ \\
\hline
\end{tabular}




\subsection{The r127 gene is dispensable for RCMV replication in vivo}

To study the role of the pr127 protein in the pathogenesis of RCMV infection, we compared the in vivo replication characteristics of wt RCMV and RCMV $\Delta \mathrm{r} 127$ during productive infection by monitoring their dissemination in infected rats. The amount of infectious virus produced in salivary gland, spleen, kidney, liver, pancreas and thymus of wt RCMV- and RCMV $\Delta$ r127-infected rats was determined at 4 and 28 days p.i. Table 2 shows that there was no significant difference between wt RCMV and RCMV $\Delta$ r127 in tissue distribution at both 4 and 28 days p.i. High virus titres were predominantly detected in the salivary glands of infected rats at 28 days p.i. As shown in Fig. 5D, these titres did not differ significantly between wt RCMV and RCMV $\Delta \mathrm{r} 127$. The unlikely possibility that, within the RCMV $\Delta$ r127-infected rats, the recombinant virus was overgrown by contaminating wt RCMV, e.g. because of insufficient plaque purifications, was excluded by Southern blot analysis on DNA purified from virus that was derived from salivary gland homogenates of RCMV $\Delta$ r127-infected rats at 28 days p.i. (data not shown).

In general, the inclusion of either more than one type of mutant or a rescued virus is obligatory when assigning functions to mutated genes. However, since wt RCMV and RCMV $\Delta$ r127 were indistinguishable in their growth characteristics in vitro and in vivo, we decided not to test another independent RCMV r127 deletion mutant in our experimental systems.

Taken together, the RCMV r127 gene is dispensable for virus replication, not only in vitro, but also during the acute phase of infection in vivo.

\section{Discussion}

One of the most interesting features of the RCMV genome is the r127 gene, which is unique among the CMVs. This gene encodes a protein with similarity to the proteins that are encoded by the rep genes of parvoviruses as well as the U94 genes of HHV-6A and -6B (Vink et al., 2000). The proteins that are encoded by RCMV r127 and HHV-6A and 6B U94 are most closely related to the Rep proteins of the avian parvoviruses and the AAVs, respectively (Dominguez et al., 1999; Gompels et al., 1995; Isegawa et al., 1999; Srivastava et al., 1983; Thomson et al., 1991; Vink et al., 2000; Zadori et al., 1995). Interestingly, the avian parvoviruses and the AAVs are classified within different genera of the subfamily Parvovirinae within the family Parvoviridae (Lukashov and Goudsmit, 2001). Members of the family Parvoviridae possess linear, single-stranded DNA 
genomes with lengths of approximately $5 \mathrm{~kb}$ (reviewed by Berns, 1996). Their genomes contain only two genes: the cap gene, which encodes the structural proteins, and the rep gene, which encodes the non-structural proteins. The subfamily Parvovirinae consists of the genera Parvovirus, Dependovirus and Erythrovirus. Members of the genus Parvovirus can be pathogenic and are capable of autonomous replication, whereas members of the genus Dependovirus are non-pathogenic and require helper functions in order to replicate. These helper functions, which can be supplied by either genotoxic stimuli or coinfecting adeno- or herpesviruses, are needed for productive infection and rescue of integrated virus from the host genome (Berns, 1996). The avian parvoviruses and the AAVs belong to the genera Parvovirus and Dependovirus, respectively, and have different requirements for helper functions (Berns, 1996; Lukashov and Goudsmit, 2001). However, these viruses do have a close genetic relationship. Moreover, it has been suggested that the avian parvoviruses and the AAVs should be classified within the same evolutionary group of parvoviruses (Lukashov and Goudsmit, 2001). It is, therefore, likely that these viruses are derived from a common ancestor. This ancestral parvovirus may have been capable of (site-specific) integration into the host genome, a mechanism by which AAV-2 enters a latent state in the absence of helper functions (Berns, 1996). This mechanism of DNA integration might explain how the rep gene was acquired by RCMV and HHV-6A and $-6 \mathrm{~B}$, since an ancestral parvovirus may have integrated into the genome of an ancestral betaherpesvirus during coinfection. The rep gene may subsequently have developed a novel function in the replication cycle of its new herpesviral 'host', while other parvoviral sequences may have been lost from the herpesviral genome. But, if the rep gene was indeed introduced into the genome of an ancestral betaherpesvirus, then the question arises why rep gene homologues have not been found in the genomes of betaherpesviruses which are genetically closely related to RCMV and HHV-6A and $-6 \mathrm{~B}$. RCMV is more closely related to HCMV and MCMV than to the other betaherpesviruses, whereas HHV-6A and $-6 \mathrm{~B}$ are more closely related to HHV7 than to the CMVs (Chee et al., 1990; Dominguez et al., 1999; Gompels et al., 1995; Isegawa et al., 1999; Nicholas, 1996; Rawlinson et al., 1996; Vink et al., 2000). The absence of a rep gene homologue in the genomes of the closest relatives of RCMV and HHV-6A and $-6 \mathrm{~B}$ may indicate that RCMV has acquired the rep gene independently from HHV-6A and $-6 B$. However, this possibility is unlikely, since RCMV r127 and HHV-6A and -6B U94 are conserved not only in sequence, but also in genomic position and orientation (Dominguez et al., 1999; Gompels et al., 1995; Isegawa et al., 1999; Vink et al., 2000). These observations strongly suggest that these genes have diverged from a 
common ancestral betaherpesvirus origin. The absence of a rep gene homologue in the genomes of HCMV, MCMV and HHV-7 may be explained by loss of the rep gene during evolution due to lack of positive selective pressure.

To date, not much is known about the role of RepH6 in the pathogenesis of HHV-6A and $-6 \mathrm{~B}$ infection. Nevertheless, the $\mathrm{U} 94$ genes of HHV-6A and $-6 \mathrm{~B}$ are highly conserved (Rapp et al., 2000), which indicates that RepH6 may play an important role in the replication cycles of these viruses. Interestingly, RepH6 seems to share at least some function with its parvoviral counterparts, since HHV-6A U94 can complement the replication of a rep-deficient AAV-2 genome (Thomson et al., 1994). In addition, U94 is transcribed in latently infected PBMCs from HHV-6A-infected individuals, whereas both virus replication and expression of viral genes are restricted in HHV-6A-infected lymphocytes expressing HHV-6B U94 in vitro (Rotola et al., 1998). These observations point to a potential role for RepH6 in the regulation of latency. RepH6 may be involved in either establishment or maintenance of latency through a mechanism involving the regulation of gene expression. This notion is based on the observations that this protein can bind to the human TATA-binding protein, that it binds single-stranded DNA and that it is able to regulate expression from several promoters (Araujo et al., 1995, 1997; Dhepakson et al., 2002; Mori et al., 2000; Thomson et al., 1994).

At this point, we do not know whether pr127 has a similar role in the pathogenesis of RCMV infection. Although we found pr127 to share characteristics with RepH6, such as DNA-binding activity, we were unable to pinpoint a specific function for pr127 in RCMV replication. Furthermore, it is highly unlikely that pr127 has the same ability as RepH6 to complement parvoviral Rep proteins, since pr127 is considerably shorter than RepH6. More specifically, in comparison with the parvoviral Rep proteins, both pr127 and RepH6 are truncated at their $\mathrm{C}$ termini, while pr127 is also truncated at its $\mathrm{N}$ terminus (Vink et al., 2000). Nevertheless, although we found RCMV $\Delta \mathrm{r} 127$ to have replication characteristics indistinguishable from those of wt RCMV during the acute phase of infection in vivo, we cannot rule out the possibility that these viruses present with different features in the initiation and maintenance of latency. Due to the unavailability of an appropriate, reproducible experimental model in which to study RCMV latency and reactivation, we have not yet been able to investigate the role of pr127 in these biological processes. Although we detected transcripts of r127 at 4 months p.i. in the salivary glands of RCMV-infected rats, this does not represent latent gene expression, as infectious virus is still produced in the salivary glands at 4 months p.i. (Bruggeman et al., 
1985). It is clear, however, that the development of a model for RCMV latency and reactivation will have a high priority in future studies.

Regardless of its potential role in RCMV latency, it is to be expected that pr127 does have a function during the acute phase of infection. This notion is inferred from the finding that this protein is expressed during productive infection, both in vitro and in vivo. The function of pr127 may have been overseen, because either (i) the function is subtle, (ii) it is only apparent in specific host strains or (iii) we did not use a correct model system. Our future studies will be aimed at the elucidation of the physiological role of the nuclear localization and DNA-binding activity of pr127 and, more specifically, at the identification of viral and/or cellular proteins that bind to pr127. These studies will be likely to shed more light on the role of pr127 in RCMV replication.

\section{Acknowledgements}

The authors thank Nicolien van der Kolk for technical assistance and Rien Blok for critical reading of the manuscript. C.V. is supported by a fellowship of the Royal Netherlands Academy of Arts and Sciences (KNAW). K.W.R.v.C. is supported by grant 901-02-239 of the Netherlands Organization for Scientific Research (NWO) to C.V.

The nucleotide and amino acid sequences discussed in this paper have been deposited in the GenBank database under accession number AF232689.

\section{References}

Araujo JC, Doniger J, Kashanchi F, Hermonat PL, Thompson J, Rosenthal LJ. Human herpesvirus $6 \mathrm{~A}$ ts suppresses both transformation by $\mathrm{H}$-ras and transcription by the $\mathrm{H}$-ras and human immunodeficiency virus type 1 promoters. J Virol 1995;69:4933-40.

Araujo JC, Doniger J, Stoppler H, Sadaie MR, Rosenthal LJ. Cell lines containing and expressing the human herpesvirus $6 \mathrm{~A}$ ts gene are protected from both $\mathrm{H}$-ras and BPV-1 transformation. Oncogene 1997; 14:937-43.

Beisser PS, Vink C, van Dam JG, Grauls G, Vanherle SJV, Bruggeman CA. The R33 G proteincoupled receptor gene of rat cytomegalovirus plays an essential role in the pathogenesis of viral infection. J Virol 1998;72:2352-63.

Beisser PS, Grauls G, Bruggeman CA, Vink C. Deletion of the R78 G protein-coupled receptor gene from rat cytomegalovirus results in an attenuated, syncytium-inducing mutant strain. J Virol 1999;73:7218-30. 
Beisser PS, Kloover JS, Grauls GELM, Blok MJ, Bruggeman CA, Vink C. The r144 major histocompatibility complex class I-like gene of rat cytomegalovirus is dispensable for both acute and long-term infection in the immunocompromised host. J Virol 2000;74:1045-50.

Berns KI. Parvoviridae: the viruses and their replication. In: Fields BN, Knipe DM, Howley PM, Chanock RM, Melnick JL, Monath TP, Roizman B, Straus SE, editors. Fields Virology, 3rd ed, vol 2. Lippincott-Raven Publishers, Philadelphia 1996:2173-97.

Beuken E, Grauls G, Bruggeman CA, Vink C. The rat cytomegalovirus R32 gene encodes a virionassociated protein that elicits a strong humoral immune response in infected rats. J Gen Virol 1999;80:2719-28.

Bruggeman CA, Meijer H, Dormans PHJ, Debie WMH, Grauls GELM, van Boven CPA. Isolation of a cytomegalovirus-like agent from wild rats. Arch Virol 1982;73:231-41.

Bruggeman CA, Meijer H, Bosman F, van Boven CPA. Biology of rat cytomegalovirus infection. Intervirology 1985;24:1-9.

Bruning JH, Debie WHM, Dormans PHJ, Meijer H, Bruggeman CA. The development and characterization of monoclonal antibodies against rat cytomegalovirus induced antigens. Arch Virol 1987;94:55-70.

Chee MS, Bankier AT, Beck S, Bohni R, Brown CM, Cerny R, et al. Analysis of the protein-coding content of the sequence of human cytomegalovirus strain AD169. Curr Top Microbiol Immunol 1990;154:125-69.

Dhepakson P, Mori Y, Jiang YB, Huang HL, Akkapaiboon P, Okuno T, et al. Human herpesvirus-6 rep/U94 gene product has single-stranded DNA-binding activity. J Gen Virol 2002;83:847-54.

Dominguez G, Dambaugh TR, Stamey FR, Dewhurst S, Inoue N, Pellett PE. Human herpesvirus 6B genome sequence: coding content and comparison with human herpesvirus $6 \mathrm{~A}$. J Virol 1999;73:8040-52.

Gauthier ER, Madison SD, Michel RN. Rapid RNA isolation without the use of commercial kits: application to small tissue samples. Pflugers Arch 1997;433:664-8.

Gompels UA, Nicholas J, Lawrence G, Jones M, Thomson BJ, Martin MED, et al. The DNA sequence of human herpesvirus-6: structure, coding content, and genome evolution. Virology 1995;209:29-51.

Harlow E, Lane D. Antibodies: a laboratory manual. Cold Spring Harbor Laboratory, Cold Spring Harbor 1988.

Isegawa Y, Mukai T, Nakano K, Kagawa M, Chen J, Mori Y, et al. Comparison of the complete DNA sequences of human herpesvirus 6 variants A and B. J Virol 1999;73:8053-63.

Kaptein SJF, Beuken E, Grauls GELM, Bruggeman CA, Vink C. Rat cytomegalovirus open reading frame R44 is an early-late gene that encodes a nuclear protein. Arch Virol 2001;146:2211-8.

Kaptein SJF, Beisser PS, Gruijthuijsen YK, Savelkouls KGM, van Cleef KWR, Beuken E, et al. The rat cytomegalovirus $\mathrm{R} 78 \mathrm{G}$ protein-coupled receptor gene is required for production of infectious virus in the spleen. J Gen Virol 2003;84:2517-30. 
Lukashov VV, Goudsmit J. Evolutionary relationships among parvoviruses: virus-host coevolution among autonomous primate parvoviruses and links between adeno-associated and avian parvoviruses. J Virol 2001;75:2729-40.

Meijer H, Dreesen JCFM, van Boven CPA. Molecular cloning and restriction endonuclease mapping of the rat cytomegalovirus genome. J Gen Virol 1986;67:1327-42.

Mori $\mathrm{Y}$, Dhepakson P, Shimamoto T, Ueda K, Gomi $\mathrm{Y}$, Tani H, et al. Expression of human herpesvirus $6 \mathrm{~B}$ rep within infected cells and binding of its gene product to the TATA-binding protein in vitro and in vivo. J Virol 2000;74:6096-104.

Nicholas J. Determination and analysis of the complete nucleotide sequence of human herpesvirus 7. J Virol 1996;70:5975-89.

Rapp JC, Krug LT, Inoue N, Dambaugh TR, Pellett PE. U94, the human herpesvirus 6 homolog of the parvovirus nonstructural gene, is highly conserved among isolates and is expressed at low mRNA levels as a spliced transcript. Virology 2000;268:504-16.

Rawlinson WD, Farrell HE, Barrell BG. Analysis of the complete DNA sequence of murine cytomegalovirus. J Virol 1996;70:8833-49.

Rotola A, Ravaioli T, Gonelli A, Dewhurst S, Cassai E, Di Luca D. U94 of human herpesvirus 6 is expressed in latently infected peripheral blood mononuclear cells and blocks viral gene expression in transformed lymphocytes in culture. Proc Natl Acad Sci USA 1998;95:13911-6.

Speel EJM, Schutte B, Wiegant J, Ramaekers FCS, Hopman AHN. A novel fluorescence detection method for in situ hybridization, based on the alkaline phosphatase-Fast Red reaction. J Histochem Cytochem 1992;40:1299-308.

Srivastava A, Lusby EW, Berns KI. Nucleotide sequence and organization of the adeno-associated virus 2 genome. J Virol 1983;45:555-64.

Stals FS, Bosman F, van Boven CPA, Bruggeman CA. An animal model for therapeutic intervention studies of CMV infection in the immunocompromised host. Arch Virol 1990;114:91-107.

Tatusova TA, Madden TL. BLAST 2 Sequences, a new tool for comparing protein and nucleotide sequences. FEMS Microbiol Lett 1999;174:247-50.

Thomson BJ, Efstathiou S, Honess RW. Acquisition of the human adeno-associated virus type-2 rep gene by human herpesvirus type-6. Nature 1991;351:78-80.

Thomson BJ, Weindler FW, Gray D, Schwaab V, Heilbronn R. Human herpesvirus 6 (HHV-6) is a helper virus for adeno-associated virus type 2 (AAV-2) and the AAV-2 rep gene homologue in HHV-6 can mediate AAV-2 DNA replication and regulate gene expression. Virology 1994;204:304-11.

Vink C, Beuken E, Bruggeman CA. Complete DNA sequence of the rat cytomegalovirus genome. J Virol 2000;74:7656-65.

Zadori Z, Stefancsik R, Rauch T, Kisary J. Analysis of the complete nucleotide sequences of goose and muscovy duck parvoviruses indicates common ancestral origin with adeno-associated virus 2. Virology 1995;212:562-73. 


\section{Chapter 5}

Cytomegalovirus-encoded homologs of $\mathrm{G}$ protein-coupled receptors and chemokines

Koen W.R. van Cleef, Martine J. Smit, Cathrien A. Bruggeman, Cornelis Vink

J Clin Virol 2006;35:343-8 


\begin{abstract}
Background: Cytomegaloviruses (CMVs) have developed various sophisticated strategies to manipulate and evade the defense mechanisms of their hosts. Among the CMV genes that are predicted to be involved in these strategies are genes that encode mimics of cellular proteins, such as G protein-coupled receptors (GPCRs) and chemokines (CKs). These genes may have been pirated from the host genome during the long co-evolution of virus and host. Objectives: In this report, the putative functions of the CMV-encoded homologs of GPCRs and CKs in the pathogenesis of infection will be discussed. Study design: In order to present an overview of the current state of knowledge, the literature on the CMV-encoded homologs of GPCRs and CKs was reviewed. Results: The GPCR and CK homologs that are encoded by the CMVs represent immunomodulatory proteins with crucial roles in the pathogenesis of infection. Conclusions: In light of their function as well as accessibility on the cell surface, the CMV-encoded GPCR homologs are attractive targets for the development of new antiviral therapies.
\end{abstract}

\title{
1. Introduction
}

Cytomegaloviruses (CMVs) have developed various strategies to remain hidden from the defense mechanisms of their hosts. Interestingly, many of the CMV genes that are involved in manipulation of and evasion from the immune system encode immunomodulatory proteins that resemble cellular proteins. Among these genes, which appear to be hijacked from the host genome during the long co-evolution of pathogen and host, are genes that encode mimics of cellular $G$ protein-coupled receptors (GPCRs), chemokines (CKs) and major histocompatibility complex (MHC) class I heavy chains. In this review, we will focus on the putative functions of the CMV-encoded homologs of GPCRs and CKs in the pathogenesis of infection.

\section{CMV-encoded GPCR homologs}

Genes encoding homologs of host cellular GPCRs have been identified within the genomes of all sequenced CMVs. The human CMV (HCMV) genome was found to contain four putative GPCR genes, which are designated US27, US28, UL33 and UL78. In contrast to the US27 and US28 genes, which are unique for primate CMVs, the UL33 and UL78 genes have counterparts in all sequenced betaherpesviruses, including rat CMV (RCMV), murine CMV (MCMV), human herpesvirus type 6A (HHV-6A), HHV-6B and HHV-7. 


\subsection{The HCMV US27- and US28-encoded GPCRs}

The HCMV US27 and US28 genes were identified by Chee et al. (1990a,b). The proteins that are predicted to be encoded by these genes (pUS27 and pUS28, respectively) are closely related to the $\mathrm{CC} \mathrm{CK}$ receptors (CCRs). While little is known about pUS27, pUS28 is the best-characterized CMV-encoded GPCR. In accordance with its similarity to the CCRs, pUS28 was found to bind CC CKs CCL2 (MCP-1), CCL3 (MIP$1 \alpha$ ), CCL4 (MIP-1 $\beta$ ), CCL5 (RANTES) and CCL7 (MCP-3) (Billstrom et al., 1998; Gao and Murphy, 1994; Kuhn et al., 1995; Neote et al., 1993). Interestingly, pUS28 was not only found to bind $\mathrm{CC}$ CKs, but also the membrane-associated $\mathrm{CX}_{3} \mathrm{C} \mathrm{CK} \mathrm{CX}{ }_{3} \mathrm{CL} 1$ (fractalkine) (Kledal et al., 1998). The ability of pUS28 to bind and sequester CKs has led to the hypothesis that this protein might act as a CK sink (Billstrom et al., 1999; Bodaghi et al., 1998; Randolph-Habecker et al., 2002; Vieira et al., 1998). This possibility is supported by the observation that pUS28 undergoes constitutive endocytosis and recycling (Fraile-Ramos et al., 2001). Its high affinity for CKs and the high recycling rate of pUS28 might facilitate efficient CK sequestration. Nevertheless, it is highly unlikely that pUS28 merely functions as a CK sink, since it was found to trigger mobilization of intracellular calcium upon binding of CCL2, CCL3, CCL5 and CCL7 (Billstrom et al., 1998; Gao and Murphy, 1994). The mobilization of calcium in response to CCL5 and CCL7 is mediated by $G \alpha_{i}$ and $G \alpha_{16}$ (Billstrom et al., 1998) (Fig. 1). In addition, binding of CCL5 to pUS28 results in activation of extracellular signal-regulated kinase 2 (ERK2) through $\mathrm{G}_{16}$ coupling (Billstrom et al., 1998) (Fig. 1). Furthermore, pUS28 was found to induce vascular smooth muscle cell (SMC) migration in response to CCL2 and CCL5 (Streblow et al., 1999), which involves signaling through $\mathrm{G}_{12 / 13}$, RhoA, Src and focal adhesion kinase (FAK) (Melnychuk et al., 2004; Streblow et al., 2003) (Fig. 1). These observations indicate that pUS28 is a functional GPCR with a more diverse function than only the sequestration of CKs.

Apart from signaling in an agonist-dependent manner, pUS28 was also shown to signal in an agonist-independent, constitutive fashion (Fig. 1). This receptor was found to constitutively activate phospholipase $\mathrm{C}(\mathrm{PLC})$ as well as cAMP-responsive element (CRE)-, NFאB- and NFAT-driven transcription (Casarosa et al., 2001; McLean et al., 2004; Waldhoer et al., 2002). The activation of PLC and NFKB-driven transcription is mediated by $\mathrm{G}_{\mathrm{q} / 11}$ proteins, whereas the p38 mitogen-activated protein kinase (p38MAPK) pathway is involved in the activation of CRE (Casarosa et al., 2001; Waldhoer et al., 2002). Interestingly, $C X_{3} C L 1$ was found to act as a partial inverse agonist on the 
constitutive signaling activities of pUS28 (Casarosa et al., 2001; McLean et al., 2004; Waldhoer et al., 2002). Remarkably, $\mathrm{CX}_{3} \mathrm{CL} 1$ was reported to act as an agonist on a Cterminal truncated pUS28, which has a reduced constitutive endocytic activity (Waldhoer et al., 2003). Apparently, the agonistic properties of $\mathrm{CX}_{3} \mathrm{CL} 1$ are camouflaged by the constitutive endocytosis of pUS28.

The exact role of pUS28 in the pathogenesis of infection remains speculative. It is possible that pUS28 indeed acts as a CK sink to reduce the immune responses at the sites of infection. Alternatively, the signaling activities of pUS28 may interfere with intracellular signaling pathways to establish a modified intracellular environment that promotes virus replication, whereas the interaction of pUS28 with $\mathrm{CX}_{3} \mathrm{CL} 1$ might be involved in entry and/or cell-to-cell transfer of HCMV. In addition, the pUS28-induced SMC migration might play a role in the acceleration of vascular diseases which is thought to be induced by HCMV. However, due to the strict host species-specificity of the CMVs as well as ethical considerations, it is not possible to study the role of both pUS27 and pUS28 in physiological relevant situations in vivo. Thus, while both pUS27 and pUS28 were found to be dispensable for virus replication in vitro (Bodaghi et al., 1998; Vieira et al., 1998), it is still unknown whether or not these genes play essential roles in the pathogenesis of infection in vivo.
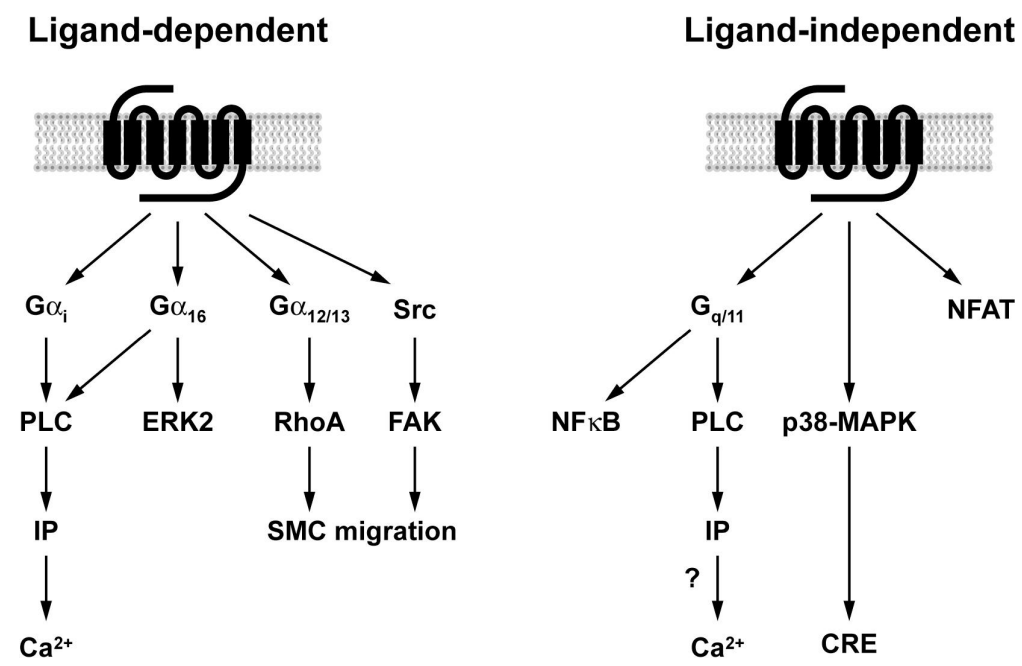

Fig. 1. Schematic representation of the ligand-dependent and ligand-independent signaling activities of pUS28. Stimulatory effects are indicated by $\downarrow$. A question mark is given when the signaling route has not yet been confirmed. IP, inositol phosphate. 


\subsection{The UL33 GPCR gene family}

All sequenced betaherpesviruses contain members of the UL33 GPCR gene family. This family comprises HCMV UL33, RCMV R33, MCMV M33, HHV-6A and -6B U12 and HHV-7 U12 (Beisser et al., 1998; Chee et al., 1990a,b; Dominguez et al., 1999; Gompels et al., 1995; Isegawa et al., 1999; Nicholas, 1996; Rawlinson et al., 1996; Vink et al., 2000). The proteins that are predicted to be encoded by the UL33-like genes, which are conserved in genomic position as well as orientation, are closely related to the CCRs.

In agreement with the high level of similarity to the CCRs, HHV-6B pU12 was found to mediate the release of calcium from intracellular stores upon binding of CCL2, CCL3, CCL4 and CCL5 (Isegawa et al., 1998), whereas HHV-7 pU12 was shown to induce calcium mobilization after binding of CCL17 (TARC), CCL19 (MIP-3 $\beta$ ), CCL21 (SLC) and CCL22 (MDC) (Nakano et al., 2003; Tadagaki et al., 2005). Until now, ligands for the CMV-encoded members of the pUL33 family have not been identified. However, the CMV-encoded pUL33 family members have been shown to represent functional GPCRs, since they were found to possess ligand-independent, constitutive signaling activities (Fig. 2). The UL33-encoded GPCR constitutively stimulates PLC and CRE-driven transcription (Casarosa et al., 2003a; Waldhoer et al., 2002). The activation of PLC is mediated by $G_{q / 11}$ and $G_{i / 0}$ proteins, whereas the enhancement of CRE-driven transcription results from activation of both $G_{s}$ and $G_{i / 0}$ proteins as well as from activation of the p38-MAPK pathway (Casarosa et al., 2003a; Waldhoer et al., 2002). Like pUL33, the R33-encoded GPCR constitutively stimulates PLC by interacting with $G_{q / 11}$ and $G_{i / 0}$ proteins (Gruijthuijsen et al., 2002). However, as opposed to pUL33, pR33 constitutively inhibits CRE-driven transcription, which is mediated by $\mathrm{G}_{\mathrm{i} / 0}$ proteins (Gruijthuijsen et al., 2002). Finally, pR33 stimulates both serum-responsive element (SRE)- and NFKB-driven transcription in a constitutive fashion, which also results from activation of $G_{i / 0}$ proteins (Gruijthuijsen et al., 2002). The M33-encoded GPCR constitutively stimulates PLC and transcription mediated by both CRE and NFKB (Waldhoer et al., 2002). While the activation of PLC is mediated by $G_{q / 11}$ proteins, the enhancement of CRE-driven transcription results from activation of the p38-MAPK pathway (Waldhoer et al., 2002).

The biological significance of the CMV-encoded members of the pUL33 family was demonstrated by studies using recombinant CMV strains that carry either a disrupted UL33, R33 or M33 gene. These recombinant viruses were found to replicate with similar efficiencies as their corresponding wild-type (wt) viruses in cell culture (Beisser et al., 1998; Davis-Poynter et al., 1997; Margulies et al., 1996). In vivo, however, significant 
differences were found between the recombinant and wt viruses. In contrast to their wt counterparts, the R33- and M33-disrupted viruses could not be detected in the salivary glands of infected animals (Beisser et al., 1998; Davis-Poynter et al., 1997). Furthermore, the R33-deleted virus was found to induce reduced RCMV-accelerated transplant vascular sclerosis and chronic rejection in a rat heart transplantation/chronic rejection model when compared to wt RCMV (Streblow et al., 2005). Moreover, a significantly lower mortality rate was seen among rats that were infected with the R33deleted strain than among wt RCMV-infected rats (Beisser et al., 1998). These results underline the importance of R33 and M33 in the pathogenesis of infection. The exact functions of the pUL33 family members, however, are still unknown.
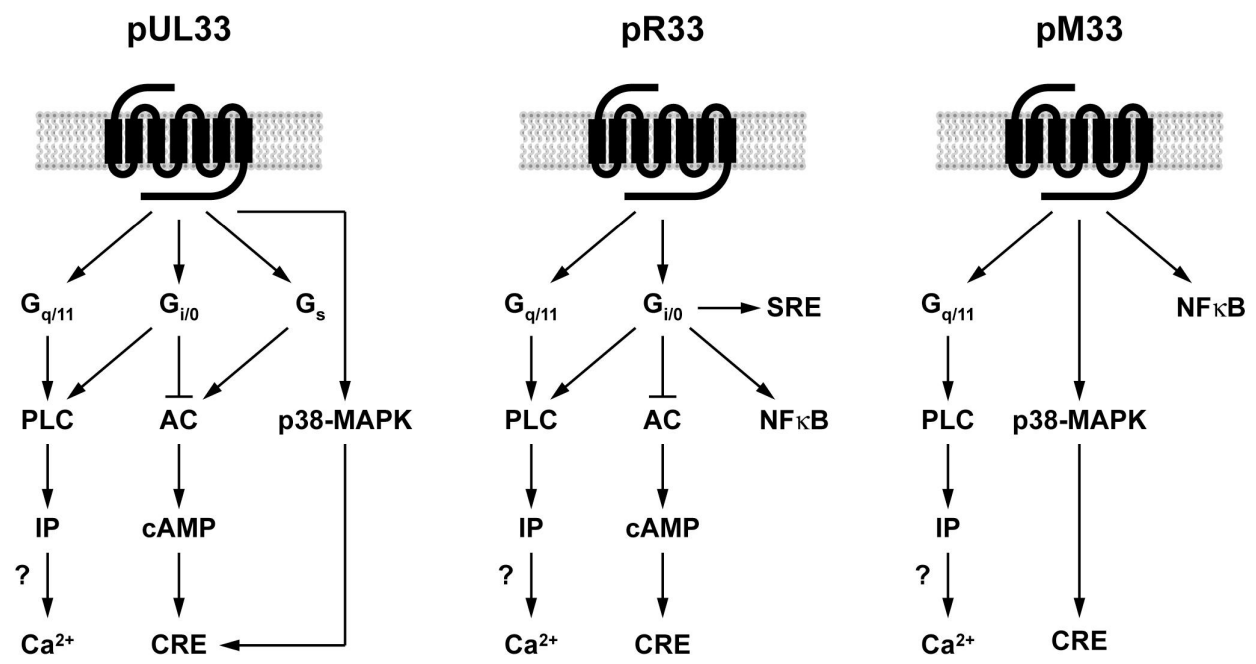

Fig. 2. Schematic representation of the ligand-independent signaling activities of pUL33, pR33 and pM33. Stimulatory and inhibitory effects are indicated by $\downarrow$ and $\perp$, respectively. A question mark is given when the signaling route has not yet been confirmed. IP, inositol phosphate; AC, adenylate cyclase.

\subsection{The UL78 GPCR gene family}

Like the UL33 GPCR gene family, the UL78 GPCR gene family has members in all sequenced betaherpesviruses. This family includes HCMV UL78, RCMV R78, MCMV M78, HHV-6A and -6B U51 and HHV-7 U51 (Beisser et al., 1999; Chee et al., 1990a; Dominguez et al., 1999; Gompels et al., 1995; Isegawa et al., 1999; Nicholas, 1996; Rawlinson et al., 1996; Vink et al., 2000). As with the UL33-like genes, both genomic 
position as well as orientation of the UL78-like genes are conserved. However, in contrast to the UL33-like genes, the proteins that are predicted to be encoded by the UL78-like genes are rather divergent and resemble neither CK receptors nor any other known GPCR.

Despite the low level of similarity to known CK receptors, HHV-7 pU51 was found to mobilize calcium upon binding of CCL17, CCL19, CCL21 and CCL22 (Tadagaki et al., 2005), whereas HHV-6A pU51 was found to bind CCL2, CCL5, CCL7, CCL11 (eotaxin), CCL13 (MCP-4) and HHV-8-encoded CK vMIPII (Milne et al., 2000). Nevertheless, the CMV-encoded members of the pUL78 family have neither been demonstrated to bind ligands nor to modulate intracellular signaling pathways.

In order to study the biological significance of the CMV-encoded members of the pUL78 family, recombinant CMV strains that carry either a disrupted UL78, R78 or M78 gene were generated. In cell culture, the UL78-disrupted virus was found to replicate similarly as its wt counterpart (Michel et al., 2005). Both the R78- and M78-disrupted viruses, however, showed a reduced production of progeny virus as compared to the wt viruses in vitro (Beisser et al., 1999; Oliveira and Shenk, 2001). In animals, the R78disrupted virus was shown to replicate with a lower efficiency as its corresponding wt virus in spleen (Kaptein et al., 2003), whereas replication of the M78-disrupted virus was found to be impaired in the salivary glands, spleen and liver (Oliveira and Shenk, 2001). Furthermore, animals that were infected with the R78- and M78-deleted viruses showed a significantly lower mortality rate than wt virus-infected animals (Beisser et al., 1999; Oliveira and Shenk, 2001). Although the exact roles of the pUL78 family members remain elusive, these results underline the importance of $\mathrm{R} 78$ and $\mathrm{M} 78$ in the pathogenesis of infection.

\section{CMV-encoded CK homologs}

Genes that encode homologs of host cellular CKs have been identified within the genomes of all sequenced CMVs. The HCMV genome was found to contain two CXC CK genes: UL146 and UL147 (Penfold et al., 1999). The proteins that are encoded by these genes were designated $\mathrm{VCXC}-1$ and $\mathrm{VCXC}-2$ (viral CXC CK 1 and 2), respectively (Penfold et al., 1999). Thus far, only vCXC-1 was demonstrated to represent a functional CK. It was found to bind CXC CK receptor CXCR2 and to induce calcium mobilization, chemotaxis and degranulation of neutrophils (Penfold et al., 1999). In addition to the two CXC CK genes, a single CC CK gene was identified within the HCMV genome, i.e. 
UL128 (Akter et al., 2003). This gene is part of a gene locus that is indispensable for virus replication in endothelial cells and virus transfer to leukocytes (Hahn et al., 2004).

Homologs of the HCMV UL146 and UL147 genes have not been found within the genome of RCMV. However, a homolog of the HCMV UL128 gene was found within the RCMV genome. This genome contains two genes that encode CC CKs: r129 and r131 (Akter et al., 2003; Kaptein et al., 2004; Vink et al., 2000). Of these genes, r129 represents the homolog of HCMV UL128 (Fig. 3). Nevertheless, only r131 has been studied so far. This gene encodes a protein that is dispensable for virus replication in cell culture, but that promotes inflammation at initial sites of infection and subsequent dissemination to or infection of the salivary glands (Kaptein et al., 2004). Furthermore, pr131 appears to be involved in the persistence of infection in the spleen (Kaptein et al., 2004).

Only a single CK gene was identified within the MCMV genome: m131/129 (Fleming et al., 1999; MacDonald et al., 1997, 1999). This gene represents the homolog of RCMV r131 (Fig. 3). It encodes a protein, designated MCK-2 (MCMV-encoded CK 2), that contains sequences derived from both open reading frames (ORFs) m131 and m129 (Fleming et al., 1999; MacDonald et al., 1999). However, only the N-terminal, m131derived part of this protein consists of CC CK-like sequences (MCK-1), whereas the Cterminal, m129-derived part consists of sequences that do not resemble any known protein motifs (Fleming et al., 1999; MacDonald et al., 1999). A synthetic polypeptide (MCK-1 peptide) exclusively containing m131-encoded sequences was found to induce calcium signaling and adherence in murine peritoneal macrophages (Saederup et al., 1999). In addition, CCR3-expressing cells as well as the human macrophage cell line THP1 were demonstrated to be responsive to MCK-1 (Saederup et al., 1999). These results indicated that MCK-2 could indeed have CK activity. Moreover, in analogy with RCMV pr131, MCK-2 is dispensable for virus replication in cell culture, but promotes inflammation at initial sites of infection, monocyte-associated viremia and subsequent dissemination to or infection of the salivary glands (Fleming et al., 1999; Saederup et al., 1999, 2001). Furthermore, MCK-2 prevents rapid clearance from spleen and liver by interfering with the natural killer (NK) and T cell responses of the host (Fleming et al., 1999).

A CC CK gene has also been identified within the genome of guinea pig CMV (GPCMV) (Haggerty and Schleiss, 2002). This gene, which is not related to the CC CK genes of HCMV, RCMV and MCMV, was found to encode a functional CK that signals via CCR1 (Penfold et al., 2003). 
Taken together, one of the most prominent roles of the CMV-encoded CK homologs in the pathogenesis of infection appears to be the modification of leukocyte homeostasis in order to recruit susceptible target cells to initial sites of infection, which in turn could serve as vehicles for virus dissemination. Alternatively, by attracting specific leukocytes, normal cellular migration patterns might be disrupted, allowing the virus to escape immune clearance.

HCMV (AD169)

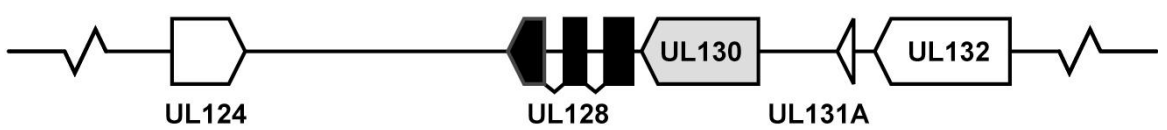

RCMV
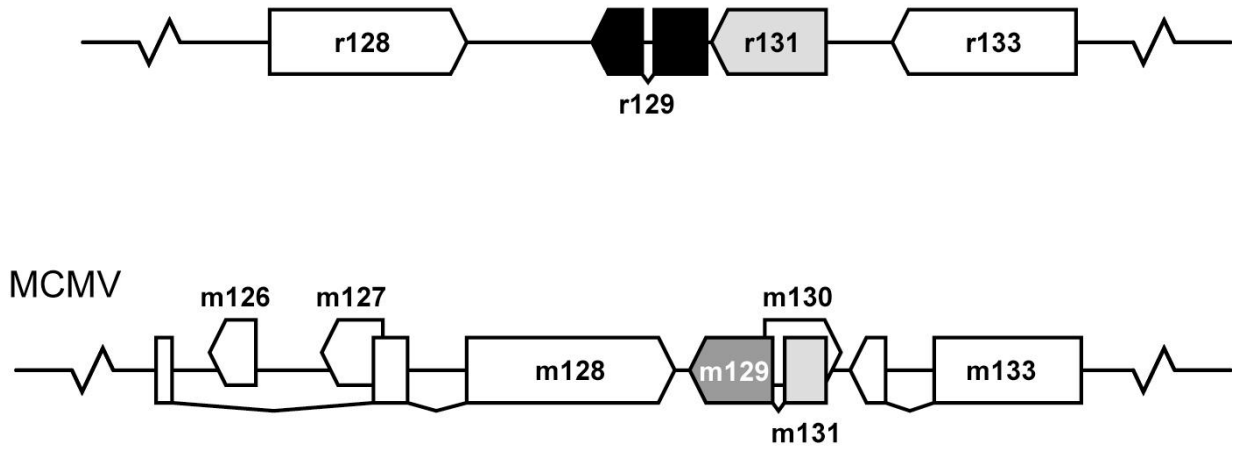

$1 \mathrm{~kb}$

Fig. 3. Illustration of the CC CK-like genes within the genomes of HCMV (AD169), RCMV and MCMV. The figure is adopted from Kaptein et al. (2004). ORFs are represented by arrow boxes that indicate their orientation and size. Shaded arrow boxes represent ORFs that encode CC CK-like sequences. The HCMV UL130-encoded sequence contains a putative $\mathrm{N}$-terminal signal sequence, but no additional features of typical CKs. An ancestral CMV genome was likely to contain two adjacent CC CK genes, i.e. a UL128/r129 predecessor and a UL130/r131 predecessor. The UL130/r131 predecessor in an ancestral HCMV genome may have lost its CC CK signature characteristics during evolution. In an ancestral MCMV genome, the UL128/r129 and UL130/r131 predecessor genes may have recombined into a single CC CK gene, which evolved into m131/129. 


\section{Concluding remarks}

In conclusion, the putative GPCR and CK homologs that are encoded by the CMVs seem to play vital immunomodulatory roles in the pathogenesis of infection. In light of their function as well as accessibility on the cell surface, the putative GPCR homologs are particularly attractive targets for the design of novel anti-viral therapies. The recent identification of a non-peptidergic inverse agonist for the constitutively active HCMV US28-encoded GPCR may serve as an important lead for the development of new therapies (Casarosa et al., 2003b).

\section{Acknowledgements}

M.J. Smit and C. Vink are supported by fellowships of the Royal Netherlands Academy of Arts and Sciences (KNAW). K.W.R. van Cleef is supported by grant 901-02239 of the Netherlands Organization for Scientific Research (NWO) to C. Vink.

\section{References}

Akter P, Cunningham C, McSharry BP, Dolan A, Addison C, Dargan DJ, et al. Two novel spliced genes in human cytomegalovirus. J Gen Virol 2003;84:1117-22.

Beisser PS, Vink C, van Dam JG, Grauls G, Vanherle SJV, Bruggeman C. The R33 G proteincoupled receptor gene of rat cytomegalovirus plays an essential role in the pathogenesis of viral infection. J Virol 1998;72:2352-63.

Beisser PS, Grauls G, Bruggeman CA, Vink C. Deletion of the R78 G protein-coupled receptor gene from rat cytomegalovirus results in an attenuated, syncytium-inducing mutant strain. $\mathrm{J}$ Virol 1999;73:7218-30.

Billstrom MA, Johnson GL, Avdi NJ, Scott Worthen G. Intracellular signaling by the chemokine receptor US28 during human cytomegalovirus infection. J Virol 1998;72:5535-44.

Billstrom MA, Lehman LA, Scott Worthen G. Depletion of extracellular RANTES during human cytomegalovirus infection of endothelial cells. Am J Respir Cell Mol Biol 1999;21:163-7.

Bodaghi B, Jones TR, Zipeto D, Vita C, Sun L, Laurent L, et al. Chemokine sequestration by viral chemoreceptors as a novel viral escape strategy: withdrawal of chemokines from the environment of cytomegalovirus-infected cells. J Exp Med 1998;188:855-66.

Casarosa P, Bakker RA, Verzijl D, Navis M, Timmerman H, Leurs R, et al. Constitutive signaling of the human cytomegalovirus-encoded chemokine receptor US28. J Biol Chem 2001;276:1133-7.

Casarosa P, Gruijthuijsen YK, Michel D, Beisser PS, Holl J, Fitzsimons CP, et al. Constitutive signaling of the human cytomegalovirus-encoded receptor UL33 differs from that of its rat cytomegalovirus homolog R33 by promiscuous activation of $G$ proteins of the $G_{q}, G_{i}$, and $G_{s}$ classes. J Biol Chem 2003a;278:50010-23. 
Casarosa P, Menge WM, Minisini R, Otto C, van Heteren J, Jongejan A, et al. Identification of the first nonpeptidergic inverse agonist for a constitutively active viral-encoded $\mathrm{G}$ protein-coupled receptor. J Biol Chem 2003b;278:5172-8.

Chee MS, Bankier AT, Beck S, Bohni R, Brown CM, Cerny R, et al. Analysis of the protein-coding content of the sequence of human cytomegalovirus strain AD169. Curr Top Microbiol Immunol 1990a;154:125-69.

Chee MS, Satchwell SC, Preddie E, Weston KM, Barrell BG. Human cytomegalovirus encodes three G protein-coupled receptor homologues. Nature 1990b;344:774-7.

Davis-Poynter NJ, Lynch DM, Vally H, Shellam GR, Rawlinson WD, Barrell BG, et al. Identification and characterization of a $G$ protein-coupled receptor homolog encoded by murine cytomegalovirus. J Virol 1997;71:1521-9.

Dominguez G, Dambaugh TR, Stamey FR, Dewhurst S, Inoue N, Pellett PE. Human herpesvirus 6B genome sequence: coding content and comparison with human herpesvirus 6A. J Virol 1999;73:8040-52.

Fleming P, Davis-Poynter N, Degli-Esposti M, Densley E, Papadimitriou J, Shellam G, et al. The murine cytomegalovirus chemokine homolog, $\mathrm{m} 131 / 129$, is a determinant of viral pathogenicity. J Virol 1999;73:6800-9.

Fraile-Ramos A, Kledal TN, Pelchen-Matthews A, Bowers K, Schwartz TW, Marsh M. The human cytomegalovirus US28 protein is located in endocytic vesicles and undergoes constitutive endocytosis and recycling. Mol Biol Cell 2001;12:1737-49.

Gao JL, Murphy PM. Human cytomegalovirus open reading frame US28 encodes a functional $\beta$ chemokine receptor. J Biol Chem 1994;269:28539-42.

Gompels UA, Nicholas J, Lawrence G, Jones M, Thomson BJ, Martin MED, et al. The DNA sequence of human herpesvirus-6: structure, coding content, and genome evolution. Virology 1995;209:29-51.

Gruijthuijsen YK, Casarosa P, Kaptein SJF, Broers JLV, Leurs R, Bruggeman CA, et al. The rat cytomegalovirus R33-encoded $\mathrm{G}$ protein-coupled receptor signals in a constitutive fashion. $\mathrm{J}$ Virol 2002;76:1328-38.

Haggerty SM, Schleiss MR. A novel CC-chemokine homolog encoded by guinea pig cytomegalovirus. Virus Genes 2002;25:271-9.

Hahn G, Revello MG, Patrone M, Percivalle E, Campanini G, Sarasini A, et al. Human cytomegalovirus UL131-128 genes are indispensable for virus growth in endothelial cells and virus transfer to leukocytes. J Virol 2004;78:10023-33.

Isegawa Y, Ping Z, Nakano K, Sugimoto N, Yamanishi K. Human herpesvirus 6 open reading frame U12 encodes a functional $\beta$-chemokine receptor. J Virol 1998;72:6104-12.

Isegawa Y, Mukai T, Nakano K, Kagawa M, Chen J, Mori Y, et al. Comparison of the complete DNA sequences of human herpesvirus 6 variants A and B. J Virol 1999;73:8053-63. 
Kaptein SJF, Beisser PS, Gruijthuijsen YK, Savelkouls KGM, van Cleef KWR, Beuken E, et al. The rat cytomegalovirus $\mathrm{R} 78 \mathrm{G}$ protein-coupled receptor gene is required for production of infectious virus in the spleen. J Gen Virol 2003;84:2517-30.

Kaptein SJF, van Cleef KWR, Gruijthuijsen YK, Beuken EVH, van Buggenhout L, Beisser PS, et al. The r131 gene of rat cytomegalovirus encodes a proinflammatory CC chemokine homolog which is essential for the production of infectious virus in the salivary glands. Virus Genes 2004;29:43-61.

Kledal TN, Rosenkilde MM, Schwartz TW. Selective recognition of the membrane-bound $\mathrm{CX}_{3} \mathrm{C}$ chemokine, fractalkine, by the human cytomegalovirus-encoded broad-spectrum receptor US28. FEBS Lett 1998;441:209-14.

Kuhn DE, Beall CJ, Kolattukudy PE. The cytomegalovirus US28 protein binds multiple CC chemokines with high affinity. Biochem Biophys Res Commun 1995;211:325-30.

MacDonald MR, Li XY, Virgin IV HW. Late expression of a $\beta$ chemokine homolog by murine cytomegalovirus. J Virol 1997;71:1671-8.

MacDonald MR, Burney MW, Resnick SB, Virgin IV HW. Spliced mRNA encoding the murine cytomegalovirus chemokine homolog predicts a $\beta$ chemokine of novel structure. J Virol 1999;73:3682-91.

Margulies BJ, Browne H, Gibson W. Identification of the human cytomegalovirus G protein-coupled receptor homologue encoded by UL33 in infected cells and enveloped virus particles. Virology 1996;225:111-25.

McLean KA, Holst PJ, Martini L, Schwartz TW, Rosenkilde MM. Similar activation of signal transduction pathways by the herpesvirus-encoded chemokine receptors US28 and ORF74. Virology 2004;325:241-51.

Melnychuk RM, Streblow DN, Smith PP, Hirsch AJ, Pancheva D, Nelson JA. Human cytomegalovirus-encoded $\mathrm{G}$ protein-coupled receptor US28 mediates smooth muscle cell migration through $\mathrm{G} \alpha 12$. J Virol 2004;78:8382-91.

Michel D, Milotić I, Wagner M, Vaida B, Holl J, Ansorge R, et al. The human cytomegalovirus UL78 gene is highly conserved among clinical isolates, but is dispensable for replication in fibroblasts and a renal artery organ-culture system. J Gen Virol 2005;86:297-306.

Milne RSB, Mattick C, Nicholson L, Devaraj P, Alcami A, Gompels UA. RANTES binding and downregulation by a novel human herpesvirus- $6 \beta$ chemokine receptor. J Immunol 2000;164:2396404.

Nakano K, Tadagaki K, Isegawa Y, Aye MM, Zou P, Yamanishi K. Human herpesvirus 7 open reading frame $U 12$ encodes a functional $\beta$-chemokine receptor. J Virol 2003;77:8108-15.

Neote K, DiGregorio D, Mak JY, Horuk R, Schall TJ. Molecular cloning, functional expression, and signaling characteristics of a C-C chemokine receptor. Cell 1993;72:415-25.

Nicholas J. Determination and analysis of the complete nucleotide sequence of human herpesvirus 7. J Virol 1996;70:5975-89. 
Oliveira SA, Shenk TE. Murine cytomegalovirus M78 protein, a G protein-coupled receptor homologue, is a constituent of the virion and facilitates accumulation of immediate-early viral mRNA. Proc Natl Acad Sci USA 2001;98:3237-42.

Penfold MET, Dairaghi DJ, Duke GM, Saederup N, Mocarski ES, Kemble GW, et al. Cytomegalovirus encodes a potent $\alpha$ chemokine. Proc Natl Acad Sci USA 1999;96:9839-44.

Penfold M, Miao Z, Wang Y, Haggerty S, Schleiss MR. A macrophage inflammatory protein homolog encoded by guinea pig cytomegalovirus signals via CC chemokine receptor 1 . Virology 2003;316:202-12.

Randolph-Habecker J, Rahill B, Torok-Storb B, Vieira J, Kolattukudy PE, Rovin BH, et al. The expression of the cytomegalovirus chemokine receptor homolog US28 sequesters biologically active CC chemokines and alters IL-8 production. Cytokine 2002;19:37-46.

Rawlinson WD, Farrell HE, Barrell BG. Analysis of the complete DNA sequence of murine cytomegalovirus. J Virol 1996;70:8833-49.

Saederup N, Lin YC, Dairaghi DJ, Schall TJ, Mocarski ES. Cytomegalovirus-encoded $\beta$ chemokine promotes monocyte-associated viremia in the host. Proc Natl Acad Sci USA 1999;96:10881-6.

Saederup N, Aguirre SA, Sparer TE, Bouley DM, Mocarski ES. Murine cytomegalovirus CC chemokine homolog MCK-2 (m131-129) is a determinant of dissemination that increases inflammation at initial sites of infection. J Virol 2001;75:9966-76.

Streblow DN, Soderberg-Naucler C, Vieira J, Smith P, Wakabayashi E, Ruchti F, et al. The human cytomegalovirus chemokine receptor US28 mediates vascular smooth muscle cell migration. Cell 1999;99:511-20.

Streblow DN, Vomaske J, Smith P, Melnychuk R, Hall L, Pancheva D, et al. Human cytomegalovirus chemokine receptor US28-induced smooth muscle cell migration is mediated by focal adhesion kinase and Src. J Biol Chem 2003;278:50456-65.

Streblow DN, Kreklywich CN, Smith P, Soule JL, Meyer C, Yin M, et al. Rat cytomegalovirusaccelerated transplant vascular sclerosis is reduced with mutation of the chemokine-receptor R33. Am J Transplant 2005;5:436-42.

Tadagaki K, Nakano K, Yamanishi K. Human herpesvirus 7 open reading frames U12 and U51 encode functional $\beta$-chemokine receptors. J Virol 2005;79:7068-76.

Vieira J, Schall TJ, Corey L, Geballe AP. Functional analysis of the human cytomegalovirus US28 gene by insertion mutagenesis with the green fluorescent protein gene. J Virol 1998;72:815865.

Vink C, Beuken E, Bruggeman CA. Complete DNA sequence of the rat cytomegalovirus genome. J Virol 2000;74:7656-65.

Waldhoer M, Kledal TN, Farrell H, Schwartz TW. Murine cytomegalovirus (CMV) M33 and human CMV US28 receptors exhibit similar constitutive signaling activities. J Virol 2002;76:8161-8.

Waldhoer M, Casarosa P, Rosenkilde MM, Smit MJ, Leurs R, Whistler JL, et al. The carboxyl terminus of human cytomegalovirus-encoded 7 transmembrane receptor US28 camouflages agonism by mediating constitutive endocytosis. J Biol Chem 2003;278:19473-82. 


\section{Chapter 6}

Summary and general discussion 
Although infections with human cytomegalovirus (HCMV) are usually not associated with clinical symptoms in immunocompetent individuals, they are a major cause of morbidity and mortality in immunocompromised individuals, such as AIDS patients and organ transplant recipients. The severity of HCMV-induced pathologies in immunocompromised individuals and the high prevalence of HCMV infections in the general population make of $\mathrm{HCMV}$ an important human pathogen. Furthermore, the clinical outcome of the treatment of HCMV infections is threatened by the generation of viruses that are resistant to current anti-viral therapies. The search for new anti-viral compounds to prevent or control the development of HCMV-induced disease is therefore an important goal in the field of CMV research.

The identification of new targets for the generation of novel anti-viral agents requires a thorough knowledge of the molecular mechanisms that are associated with CMVinduced pathologies. However, as a consequence of the strict host species-specificity of the CMVs, it is not possible to study the pathogenesis of HCMV infections in physiologically relevant situations in vivo. In order to study the pathogenesis of CMV infections in vivo, animal infection models are required. For this purpose, a rat CMV $(\mathrm{RCMV}) /$ rat model was developed in our laboratory (Bruggeman et al., 1982). The $\mathrm{RCMV} /$ rat model is a highly suitable model to study CMV infections in vivo, since the pathogenesis of RCMV infections in rats is similar to that of HCMV infections in humans (Stals et al., 1990). Moreover, the genomic sequence of RCMV is highly similar to those of other CMVs, such as HCMV and murine CMV (MCMV) (Chee et al., 1990a; Rawlinson et al., 1996; Vink et al., 2000). In this thesis, the RCMV/rat model is used to study several aspects of RCMV gene expression and the role of a selected set of RCMV genes in the pathogenesis of infection.

The RCMV/rat model and the knowledge of the complete RCMV genomic sequence are powerful instruments to study the role of viral genes in CMV-induced pathologies. However, the extent of RCMV gene expression is still unknown. In order to study transcription of all RCMV genes simultaneously, we have generated an RCMV-specific DNA microarray. In Chapter 2, this microarray is employed to monitor the viral genomewide transcription profiles in RCMV-infected cells in culture as well as in various organs and tissues of RCMV-infected rats. In this study, it is shown that the majority of the viral genes are transcribed during RCMV infection in vitro with only a few differences between different cell types. In contrast, transcription of viral genes during RCMV infection in vivo was found to be highly restricted and tissue-specific. Whereas $95 \%$ of the viral genome is transcribed in RCMV-infected cells in culture, only $38 \%$ of the viral genes is 
transcriptionally active in spleens of RCMV-infected rats. Even a lower percentage of the RCMV genes is transcribed in other tissues, including the salivary glands (25\%). These observations indicate that the RCMV transcription profiles in vitro do not reflect those in vivo. Interestingly, many of the viral genes that are transcribed to high levels during RCMV infection in vivo are predicted to encode immunomodulatory proteins that may be involved in immune evasion. Among these genes are several members of the m145 glycoprotein gene family. An MCMV member of this family was shown to interfere with the major histocompatibility complex $(\mathrm{MHC})$ class I pathway of antigen presentation (Ziegler et al., 1997). On the other hand, most of the viral genes that are known to encode proteins that are involved in virus replication are only transcribed at low levels during RCMV infection in vivo. One of these genes is immediate early 1 (IE1), which is crucial for RCMV replication. In accordance with these results, transcription of IE1 was previously also found to be restricted in various organs and tissues of RCMV-infected immunocompetent rats (Blok et al., 2001). The tightly regulated transcription of genes that play a role in either immune evasion or virus replication represents an effective and efficient way for RCMV to escape immune clearance. However, RCMV does not transcribe its full arsenal of immunomodulatory genes in each tissue, but it transcribes these genes in a tissue-specific manner. The tissue-specificity of the RCMV transcription profiles may reflect differences in the immune response of the host, which is probably not the same in each tissue. Consequently, the immunomodulatory mechanisms of RCMV need to be specific for each tissue as well. A good example is the tissue-specific transcription of the r138 gene, which encodes an Fc receptor homolog (Vink et al., 2000). This gene is only transcribed to high levels in spleen and lung. The tissuespecificity of the r138 transcription levels may be caused by differences in antibodymediated immune responses against RCMV in different tissues. RCMV might be more prone to these responses in spleen and lung than in other tissues. The ability of RCMV to regulate transcription of its genes in a tissue-specific manner may result from specific regulatory motifs within the viral promoters that are active in some tissues but not in others. Additional studies, however, are required to identify these motifs. Nevertheless, the identification of the tissue-specificity of the RCMV transcription profiles underlines the complex nature of CMV gene expression.

The viral genome-wide transcription profiles have previously also been monitored in HCMV-infected cells in culture. In one study, the temporal transcription profiles of HCMV in infected fibroblasts were determined (Chambers et al., 1999). Interestingly, many viral genes of a specific kinetic class were found to contain common potential regulatory 
motifs within their promoters (Chambers et al., 1999). This observation suggests that the HCMV genes are transcribed according to specific transcriptional programs. These specific transcriptional programs resemble the tissue-specificity of the RCMV transcription profiles. In two other studies, the transcription profiles of HCMV were determined in latently infected primary $\mathrm{CD}_{3} 4^{+}$hematopoietic progenitor cells (Goodrum et al., 2002, 2004). The HCMV transcription profiles in these cells were found to differ considerably from the profiles that were observed in productively infected fibroblasts (Goodrum et al., 2002). However, only the CD34 ${ }^{+} / C D 38^{-}$subpopulation of the heterogeneous $\mathrm{CD} 34^{+}$compartment was found to support an HCMV infection with the hallmarks of latency (Goodrum et al., 2004). HCMV infection in these cells initially results in transient transcription of many viral genes followed by viral transcriptional quiescence. Nevertheless, viral genomes are maintained in the absence of substantial virus replication. It is important to note that the $\mathrm{CD} 34^{+} / \mathrm{CD} 38^{-}$cells can reactivate the virus when they are co-cultured with permissive fibroblasts. Interestingly, most of the viral genes that are transcribed in the $\mathrm{CD} 34^{+} / \mathrm{CD} 38^{-}$cells during the initial burst of viral gene transcription are not required for efficient replication in fibroblasts (Goodrum et al., 2004). Some of these genes may have a role in the establishment of latency. However, latencyspecific transcription profiles were not identified. Although the in vitro model system for studying HCMV latency in $\mathrm{CD} 34^{+} / \mathrm{CD} 38^{-}$cells is attractive, it clearly has its limitations. It is not known whether the transcription profiles during HCMV infections in vitro indeed reflect the profiles that are observed during HCMV infections in vivo. However, the options for studying HCMV infections in vivo are very limited. For example, it is nearly impossible to analyze viral transcription profiles that contribute to HCMV-induced pathologies. This illustrates the strength of the RCMV/rat model, which allows us to investigate aspects of CMV infections that can only be studied in vivo. Future studies are necessary to identify specific viral transcription profiles that are associated with RCMV latency as well as with RCMV-induced pathologies.

In the majority of the previous studies on RCMV infections in vivo, rats were subjected to immune suppression prior to virus administration. As a consequence of the immune suppression, RCMV is able to replicate efficiently and induce a full-blown, severe infection (Stals et al., 1990). Nevertheless, natural CMV infections generally occur in immunocompetent hosts, which usually do not suffer from serious complications due to the infection. In order to study virus dissemination under 'natural' conditions in vivo, a study was initiated to monitor the course of RCMV infection within immunocompetent rats (Blok et al., 2001). Remarkably, while analyzing transcription of 
IE1 in various organs and tissues of these rats, two antisense transcripts from the RCMV major IE (MIE) region were identified (Chapter 3). These transcripts, termed IE-AS1 and IE-AS2, were not detected in a previous study in which the RCMV MIE region was identified and characterized (Beisser et al., 1998a). In this previous study, the MIE region of RCMV was found to generate three different sense transcripts, i.e. IE1, IE2 and IE2A (Beisser et al., 1998a). These sense RCMV MIE transcripts are similar to those of other CMVs and they are likely to encode proteins that are involved in the initiation of the gene expression cascade during lytic infection. The inability to detect the IE-AS transcripts in this previous study can be explained by the sense strand-specificity of most of the experiments that were performed in this study as well as by the relatively low transcription levels of these transcripts. The inability to detect these transcripts by Northern blot analysis is consistent with our findings.

The identification of the novel IE-AS transcripts is intriguing, but the function of these transcripts during RCMV infection is yet to be determined. Although these transcripts may encode functional proteins, it is also possible that the transcripts themselves are involved in the modulation of IE1 expression. The IE-AS transcripts are partly complementary to the IE1 transcript and they may silence expression of IE1 by the formation of double-stranded RNA molecules with the complementary IE1 transcript. However, there is no direct evidence for this mechanism of post-transcriptional gene silencing of IE1 during RCMV infection.

Interestingly, an antisense transcript from the MIE region has previously also been identified for HCMV (Kondo et al., 1996). This transcript, which was found to be transcribed in latently infected granulocyte-macrophage progenitor cells in culture and in bone marrow of healthy seropositive individuals, was defined as a CMV latencyassociated transcript (CLT) (Kondo et al., 1996). In light of the potential role of the HCMV antisense CLT in the regulation of latency, the identification of the RCMV IE-AS transcripts is fascinating. It is tempting to speculate that the HCMV antisense CLT as well as the RCMV IE-AS transcripts or their protein products are involved in either the establishment or maintenance of latency through post-transcriptional gene silencing of IE1. Interestingly, a comparable role in the regulation of latency has also been suggested for an antisense transcript from the HCMV UL81-82 region that has been identified recently in monocytes and bone marrow of healthy seropositive individuals (Bego et al., 2005). This transcript is partly complementary to the HCMV UL82 gene that encodes the pp71 tegument protein (upper matrix protein), a known transcriptional activator of the HCMV MIE promoter/enhancer (Bego et al., 2005). Therefore, it was hypothesized that 
the HCMV antisense UL81-82 transcript or its protein product might be involved in the regulation of latency by restricting expression of the HCMV MIE region by posttranscriptional gene silencing of UL82. Although the potential role of antisense transcripts from lytic CMV genes in the regulation of latency is interesting, their function has not yet been established experimentally. To investigate their function, the RCMV/rat model might be extremely useful. An RCMV counterpart of the HCMV antisense UL8182 transcript has thus far not been identified, but a more extensive characterization of the potential role of the RCMV IE-AS transcripts in the modulation of IE1 expression and the regulation of latency might lead to a better understanding of the potential function of the HCMV antisense CLT. However, it is currently unknown whether the IE-AS transcripts are actually transcribed during RCMV latency. To investigate this, a model of RCMV latency and reactivation should be developed. Although there are several data on RCMV latency, data on RCMV reactivation are very limited (Blok et al., 2001; Bruggeman et al., 1983; Bruning et al., 1986, 1988, 1989; Yagyu et al., 1992, 1993). It is expected that further experiments on the molecular mechanisms that regulate RCMV latency and reactivation can be done in the near future, when more precise data on these biological processes will become available. Especially the role of the IE-AS transcripts in the regulation of latency could be an interesting subject for further studies.

With regard to latency, the identification of a homolog of the rep genes of parvoviruses in the RCMV genome is intriguing (Vink et al., 2000). A homolog of these genes was previously also found at a congruent position in the genomes of human herpesvirus type 6A (HHV-6A) and 6B (HHV-6B) (Dominguez et al., 1999; Gompels et al., 1995; Isegawa et al., 1999; Thomson et al., 1991), but not in the genome of any other herpesvirus. The rep gene homologs of RCMV (r127) and HHV-6A and -6B (U94) are probably derived from a common ancestral betaherpesvirus gene, as they are conserved in sequence, genomic position as well as orientation (Dominguez et al., 1999; Gompels et al., 1995; Isegawa et al., 1999; Vink et al., 2000). The absence of rep gene homologs in the genomes of other betaherpesviruses is therefore remarkable. We hypothesize that the rep gene was acquired by an ancestral betaherpesvirus during a coinfection with an ancestral parvovirus and that it has developed a novel function in the replication cycles of RCMV and HHV-6A and $-6 B$, but that it has been lost from the genomes of other betaherpesviruses due to lack of positive selective pressure. However, the role of the proteins that are encoded by the rep gene homologs of RCMV and HHV$6 \mathrm{~A}$ and $-6 \mathrm{~B}$ in the pathogenesis of infection is still unclear. Nevertheless, U94 was found to be transcribed in latently infected peripheral blood mononuclear cells (PBMCs) from 
HHV-6A-infected individuals, whereas both virus replication and expression of viral genes were found to be restricted in HHV-6A-infected lymphocytes expressing HHV-6B U94 in vitro (Rotola et al., 1998). This led to the hypothesis that the U94-encoded protein $(\mathrm{RepH} 6)$ is involved in either the establishment or maintenance of HHV-6A and -6B latency. Whether the r127-encoded protein ( $p r 127$ ) is involved in the regulation of RCMV latency is currently unknown. In order to begin and unravel the role of pr127 in the replication cycle of RCMV, we started experiments to characterize the RCMV r127 gene during lytic infection in vitro and during the acute phase of infection in vivo (Chapter 4). For this purpose, an RCMV r127 deletion mutant (RCMV $\Delta \mathrm{r} 127)$ was generated. In this deletion mutant, part of the $\mathrm{r} 127$ open reading frame (ORF) is replaced with a neomycin resistance gene (neo). The replication characteristics of RCMV $\Delta \mathrm{r} 127$ were compared to those of wild-type RCMV (wt RCMV). This study shows that RCMV $\Delta \mathrm{r} 127$ replicates with a similar efficiency as wt RCMV, both during lytic infection in vitro and during the acute phase of infection in vivo. These results indicate that $\mathrm{r} 127$ is dispensable for virus replication and raise the question whether pr127 could play a similar role as RepH6 in the regulation of latency. It is not unlikely that pr127 indeed has a conserved function with respect to $\mathrm{RepH} 6$, since these proteins were found to share several characteristics. For example, we have shown that pr127 possesses DNA-binding activity. This feature was previously also attributed to RepH6 (Dhepakson et al., 2002), although the DNAbinding activities of pr127 and RepH6 appear to be distinct. Whereas pr127 was found to bind to single- as well as double-stranded DNA, RepH6 was found to bind exclusively to single-stranded DNA (Dhepakson et al., 2002). Furthermore, when compared to RepH6, pr127 is severely truncated at its $N$ terminus (Vink et al., 2000). Due to this truncation, it is highly unlikely that pr127 shares several other characteristics of RepH6, such as the ability to complement parvoviral Rep proteins (Thomson et al., 1994). It therefore remains speculative as to whether pr127 indeed represents the functional homolog of RepH6. Nevertheless, in addition to its potential role in the regulation of latency, pr127 is also hypothesized to have a function during productive infection. This hypothesis is based on the observation that this protein is expressed during lytic infection in vitro and during the acute phase of infection in vivo. Although we found pr127 to be dispensable for virus replication, the function of this protein may be subtle and may thus have been overlooked in our study.

To date, the regulation of CMV latency and reactivation is poorly understood. However, it is clear that the ability of the CMVs to maintain a life-long, stable relationship 
with their hosts requires strategies to evade and manipulate the immune system. Interestingly, among the CMV genes that are involved in these strategies are genes that encode homologs of cellular G protein-coupled receptors (GPCRs) and chemokines (CKs). These genes have probably been pirated from the host genome during the long co-evolution of virus and host. In Chapter 5, the current state of knowledge on the CMVencoded homologs of GPCRs and CKs is discussed. These proteins appear to interfere with CK signaling pathways, which are essential for proper functioning of the immune system. By interfering with these pathways, the CMV-encoded GPCRs and CKs may enable the virus to escape immune clearance by disrupting normal cellular migration patterns of leukocytes. Alternatively, the interference with CK signaling pathways might contribute to recruitment of susceptible leukocytes to initial sites of infection. These leukocytes could serve as vehicles for virus dissemination.

GPCR- and CK-encoding genes have been found within the genomes of all sequenced CMVs. Of particular interest are the UL33 and UL78 GPCR gene families, since members of these families are present in all sequenced betaherpesviruses, including HCMV, RCMV, MCMV, HHV-6A, HHV-6B and HHV-7 (Beisser et al., 1998b, 1999; Chee et al., 1990a,b; Dominguez et al., 1999; Gompels et al., 1995; Isegawa et al., 1999; Nicholas, 1996; Rawlinson et al., 1996; Vink et al., 2000). The UL33-like genes of the CMVs have been demonstrated to encode functional GPCRs with ligandindependent, constitutive signaling activities (Casarosa et al., 2003; Gruijthuijsen et al., 2002; Waldhoer et al., 2002). Whether the UL78-like genes of the CMVs also encode functional GPCRs has not yet been reported. Nevertheless, as they are conserved among all sequenced betaherpesviruses, it was deemed likely that both the UL33- as well as the UL78-like genes would encode proteins with important roles in the pathogenesis of infection. Indeed, the generation and characterization of recombinant CMV strains has shown that the UL33- and UL78-like genes of RCMV and MCMV encode proteins that are of crucial importance in the pathogenesis of infection (Beisser et al., 1998b, 1999; Davis-Poynter et al., 1997; Kaptein et al., 2003; Oliveira and Shenk, 2001; Streblow et al., 2005). In light of their conservation among the betaherpesviruses, it is likely that other UL33- and UL78-like genes are of similar importance. Furthermore, the GPCRs that are encoded by these genes are readily accessible on the cell surface. The HCMV UL33- and UL78-encoded GPCRs are therefore interesting targets for the development of novel anti-viral therapies. This also holds true for the HCMV US27- and US28-encoded GPCRs (Chee et al., 1990a,b). While little is known about US27, US28 was found to encode a functional GPCR with both ligand-dependent as well as ligand- 
independent, constitutive signaling activities (Billstrom et al., 1998; Casarosa et al., 2001; Gao and Murphy, 1994; McLean et al., 2004; Melnychuk et al., 2004; Streblow et al., 1999, 2003; Waldhoer et al., 2002). However, in contrast to UL33 and UL78, US27 and US28 do not have counterparts in RCMV and MCMV. The biological significance of these genes in the pathogenesis of infection is therefore not known. This also applies to the HCMV CXC CK-encoding genes UL146 and UL147 (Penfold et al., 1999). The CKs that are encoded by these genes are also potential targets for the development of novel anti-viral therapies. However, in analogy to US27 and US28, homologs of UL146 and UL147 are not present in RCMV and MCMV. The HCMV CC CK-encoding gene UL128, however, has a counterpart in RCMV (Akter et al., 2003). The UL128 homolog of RCMV was designated r129 (Kaptein et al., 2004). We are currently generating recombinant RCMV strains in order to study the biological significance of r129. These studies will not only shed more light on the role of the r129-encoded CK in the pathogenesis of RCMV infection, they will also indicate whether HCMV UL128 can be regarded as a potential target for the development of novel anti-viral compounds. Clearly, the exploitation of the $\mathrm{RCMV} /$ rat model will be of great importance for the design and evaluation of these compounds.

Taken together, several aspects of RCMV gene expression and a selected set of RCMV genes have been studied in this thesis. Although the role of most RCMV genes in the pathogenesis of infection remains to be elucidated, our data contribute to the knowledge of the complex molecular biology of the CMVs. Furthermore, the results described in this thesis underline the suitability of the RCMV/rat model to study the function of CMV genes during different stages of infection. Substantial data show that most RCMV properties are common to all CMVs, which make the RCMV/rat model an attractive model to study the mechanisms that are involved in CMV-induced pathologies. However, RCMV has also several unique properties that are not shared by other CMVs, such as the r127 parvoviral rep gene homolog. Due to these unique properties, it is sometimes difficult to extrapolate the results from RCMV studies in rats to HCMV infections in humans. Nevertheless, animal infection models offer the opportunity to study the interaction between virus and host. These models are therefore indispensable in the field of CMV research.

\section{References}

Akter P, Cunningham C, McSharry BP, Dolan A, Addison C, Dargan DJ, et al. Two novel spliced genes in human cytomegalovirus. J Gen Virol 2003;84:1117-22. 
Bego M, Maciejewski J, Khaiboullina S, Pari G, St. Jeor S. Characterization of an antisense transcript spanning the UL81-82 locus of human cytomegalovirus. J Virol 2005;79:11022-34.

Beisser PS, Kaptein SJF, Beuken E, Bruggeman CA, Vink C. The Maastricht strain and England strain of rat cytomegalovirus represent different betaherpesvirus species rather than strains. Virology 1998a;246:341-51.

Beisser PS, Vink C, van Dam JG, Grauls G, Vanherle SJV, Bruggeman CA. The R33 G proteincoupled receptor gene of rat cytomegalovirus plays an essential role in the pathogenesis of viral infection. J Virol 1998b;72:2352-63.

Beisser PS, Grauls G, Bruggeman CA, Vink C. Deletion of the R78 G protein-coupled receptor gene from rat cytomegalovirus results in an attenuated, syncytium-inducing mutant strain. J Virol 1999;73:7218-30.

Billstrom MA, Johnson GL, Avdi NJ, Scott Worthen G. Intracellular signaling by the chemokine receptor US28 during human cytomegalovirus infection. J Virol 1998;72:5535-44.

Blok MJ, Savelkouls KGM, Grauls GELM, Bruggeman CA, Vink C. Immediate early-1 mRNA expression and virus production are restricted during the acute phase of rat cytomegalovirus infection in immunocompetent rats. In: Blok MJ, editor. Monitoring the course of CMV infection by detection of specific viral transcripts. ANDI Press, Geleen, The Netherlands 2001:91-124.

Bruggeman CA, Meijer H, Dormans PHJ, Debie WMH, Grauls GELM, van Boven CPA. Isolation of a cytomegalovirus-like agent from wild rats. Arch Virol 1982;73:231-41.

Bruggeman CA, Debie WMH, Grauls G, Majoor G, van Boven CPA. Infection of laboratory rats with a new cytomegalo-like virus. Arch Virol 1983;76:189-99.

Bruning JH, Bruggeman CA, van Boven CP, van Breda Vriesman PJ. Passive transfer of cytomegalovirus by cardiac and renal organ transplants in a rat model. Transplantation 1986;41:695-8.

Bruning JH, Bruggeman CA, van Breda Vriesman PJ. The transfer of cytomegalovirus infection in rats by latently infected renal allografts, and the role of various immunosuppressive regimens in virus reactivation. Transplantation 1988;46:623-4.

Bruning JH, Bruggeman CA, van Boven $\mathrm{CP}$, van Breda Vriesman PJ. Reactivation of latent rat cytomegalovirus by a combination of immunosuppression and administration of allogeneic immunocompetent cells. Transplantation 1989;47:917-8.

Casarosa P, Bakker RA, Verzijl D, Navis M, Timmerman H, Leurs R, et al. Constitutive signaling of the human cytomegalovirus-encoded chemokine receptor US28. J Biol Chem 2001;276:1133-7.

Casarosa P, Gruijthuijsen YK, Michel D, Beisser PS, Holl J, Fitzsimons CP, et al. Constitutive signaling of the human cytomegalovirus-encoded receptor UL33 differs from that of its rat cytomegalovirus homolog R33 by promiscuous activation of $G$ proteins of the $G_{q}$, $G_{i}$, and $G_{s}$ classes. J Biol Chem 2003;278:50010-23.

Chambers J, Angulo A, Amaratunga D, Guo H, Jiang Y, Wan JS, et al. DNA microarrays of the complex human cytomegalovirus genome: profiling kinetic class with drug sensitivity of viral gene expression. J Virol 1999;73:5757-66. 
Chee MS, Bankier AT, Beck S, Bohni R, Brown CM, Cerny R, et al. Analysis of the protein-coding content of the sequence of human cytomegalovirus strain AD169. Curr Top Microbiol Immunol 1990a;154:125-69.

Chee MS, Satchwell SC, Preddie E, Weston KM, Barrell BG. Human cytomegalovirus encodes three G protein-coupled receptor homologues. Nature 1990b;344:774-7.

Davis-Poynter NJ, Lynch DM, Vally H, Shellam GR, Rawlinson WD, Barrell BG, et al. Identification and characterization of a $G$ protein-coupled receptor homolog encoded by murine cytomegalovirus. J Virol 1997;71:1521-9.

Dhepakson P, Mori Y, Jiang YB, Huang HL, Akkapaiboon P, Okuno T, et al. Human herpesvirus-6 rep/U94 gene product has single-stranded DNA-binding activity. J Gen Virol 2002;83:847-54.

Dominguez G, Dambaugh TR, Stamey FR, Dewhurst S, Inoue N, Pellett PE. Human herpesvirus 6B genome sequence: coding content and comparison with human herpesvirus 6A. J Virol 1999;73:8040-52.

Gao JL, Murphy PM. Human cytomegalovirus open reading frame US28 encodes a functional $\beta$ chemokine receptor. J Biol Chem 1994;269:28539-42.

Gompels UA, Nicholas J, Lawrence G, Jones M, Thomson BJ, Martin MED, et al. The DNA sequence of human herpesvirus-6: structure, coding content, and genome evolution. Virology 1995;209:29-51.

Goodrum FD, Jordan CT, High K, Shenk T. Human cytomegalovirus gene expression during infection of primary hematopoietic progenitor cells: a model for latency. Proc Natl Acad Sci USA 2002;99:16255-60.

Goodrum F, Jordan CT, Terhune SS, High K, Shenk T. Differential outcomes of human cytomegalovirus infection in primitive hematopoietic cell subpopulations. Blood 2004;104:68795.

Gruijthuijsen YK, Casarosa P, Kaptein SJF, Broers JLV, Leurs R, Bruggeman CA, et al. The rat cytomegalovirus R33-encoded $\mathrm{G}$ protein-coupled receptor signals in a constitutive fashion. $\mathrm{J}$ Virol 2002;76:1328-38.

Isegawa Y, Mukai T, Nakano K, Kagawa M, Chen J, Mori Y, et al. Comparison of the complete DNA sequences of human herpesvirus 6 variants A and B. J Virol 1999;73:8053-63.

Kaptein SJF, Beisser PS, Gruijthuijsen YK, Savelkouls KGM, van Cleef KWR, Beuken E, et al. The rat cytomegalovirus $\mathrm{R} 78 \mathrm{G}$ protein-coupled receptor gene is required for production of infectious virus in the spleen. J Gen Virol 2003;84:2517-30.

Kaptein SJF, van Cleef KWR, Gruijthuijsen YK, Beuken EVH, van Buggenhout L, Beisser PS, et al. The r131 gene of rat cytomegalovirus encodes a proinflammatory CC chemokine homolog which is essential for the production of infectious virus in the salivary glands. Virus Genes 2004;29:43-61.

Kondo $\mathrm{K}, \mathrm{Xu} \mathrm{J}$, Mocarski ES. Human cytomegalovirus latent gene expression in granulocytemacrophage progenitors in culture and in seropositive individuals. Proc Natl Acad Sci USA 1996;93:11137-42. 
McLean KA, Holst PJ, Martini L, Schwartz TW, Rosenkilde MM. Similar activation of signal transduction pathways by the herpesvirus-encoded chemokine receptors US28 and ORF74. Virology 2004;325:241-51.

Melnychuk RM, Streblow DN, Smith PP, Hirsch AJ, Pancheva D, Nelson JA. Human cytomegalovirus-encoded G protein-coupled receptor US28 mediates smooth muscle cell migration through $\mathrm{G} \alpha 12$. J Virol 2004;78:8382-91.

Nicholas J. Determination and analysis of the complete nucleotide sequence of human herpesvirus 7. J Virol 1996;70:5975-89.

Oliveira SA, Shenk TE. Murine cytomegalovirus M78 protein, a G protein-coupled receptor homologue, is a constituent of the virion and facilitates accumulation of immediate-early viral mRNA. Proc Natl Acad Sci USA 2001;98:3237-42.

Penfold MET, Dairaghi DJ, Duke GM, Saederup N, Mocarski ES, Kemble GW, et al. Cytomegalovirus encodes a potent $\alpha$ chemokine. Proc Natl Acad Sci USA 1999;96:9839-44.

Rawlinson WD, Farrell HE, Barrell BG. Analysis of the complete DNA sequence of murine cytomegalovirus. J Virol 1996;70:8833-49.

Rotola A, Ravaioli T, Gonelli A, Dewhurst S, Cassai E, Di Luca D. U94 of human herpesvirus 6 is expressed in latently infected peripheral blood mononuclear cells and blocks viral gene expression in transformed lymphocytes in culture. Proc Natl Acad Sci USA 1998;95:13911-6.

Stals FS, Bosman F, van Boven CPA, Bruggeman CA. An animal model for therapeutic intervention studies of CMV infection in the immunocompromised host. Arch Virol 1990;114:91-107.

Streblow DN, Soderberg-Naucler C, Vieira J, Smith P, Wakabayashi E, Ruchti F, et al. The human cytomegalovirus chemokine receptor US28 mediates vascular smooth muscle cell migration. Cell 1999;99:511-20.

Streblow DN, Vomaske J, Smith P, Melnychuk R, Hall L, Pancheva D, et al. Human cytomegalovirus chemokine receptor US28-induced smooth muscle cell migration is mediated by focal adhesion kinase and Src. J Biol Chem 2003;278:50456-65.

Streblow DN, Kreklywich CN, Smith P, Soule JL, Meyer C, Yin M, et al. Rat cytomegalovirusaccelerated transplant vascular sclerosis is reduced with mutation of the chemokine-receptor R33. Am J Transplant 2005;5:436-42.

Thomson BJ, Efstathiou S, Honess RW. Acquisition of the human adeno-associated virus type-2 rep gene by human herpesvirus type-6. Nature 1991;351:78-80.

Thomson BJ, Weindler FW, Gray D, Schwaab V, Heilbronn R. Human herpesvirus 6 (HHV-6) is a helper virus for adeno-associated virus type 2 (AAV-2) and the AAV-2 rep gene homologue in HHV-6 can mediate AAV-2 DNA replication and regulate gene expression. Virology 1994;204:304-11.

Vink C, Beuken E, Bruggeman CA. Complete DNA sequence of the rat cytomegalovirus genome. J Virol 2000;74:7656-65.

Waldhoer M, Kledal TN, Farrell H, Schwartz TW. Murine cytomegalovirus (CMV) M33 and human CMV US28 receptors exhibit similar constitutive signaling activities. J Virol 2002;76:8161-8. 
Yagyu K, Steinhoff G, Duijvestijn AM, Bruggeman CA, Matsumoto H, van Breda Vriesman PJ. Reactivation of rat cytomegalovirus in lung allografts: an experimental and immunohistochemical study in rats. J Heart Lung Transplant 1992;11:1031-40.

Yagyu K, van Breda Vriesman PJ, Duijvestijn AM, Bruggeman CA, Steinhoff G. Reactivation of cytomegalovirus with acute rejection and cytomegalovirus infection with obliterative bronchiolitis in rat lung allografts. Transplant Proc 1993;25:1152-4.

Ziegler $\mathrm{H}$, Thale $\mathrm{R}$, Lucin $\mathrm{P}$, Muranyi $\mathrm{W}$, Flohr $\mathrm{T}$, Hengel $\mathrm{H}$, et al. A mouse cytomegalovirus glycoprotein retains MHC class I complexes in the ERGIC/cis-Golgi compartments. Immunity 1997;6:57-66. 
Samenvatting en algehele discussie 
Infecties met het humaan cytomegalovirus (HCMV) gaan meestal niet gepaard met klinische symptomen in immuuncompetente personen, maar ze zijn een belangrijke oorzaak van morbiditeit en mortaliteit in immuungecompromitteerde personen, zoals AIDS-patiënten en patiënten die een orgaantransplantatie hebben ondergaan. De ernst van de door HCMV geïnduceerde pathologieën in immuungecompromitteerde personen en de hoge prevalentie van HCMV-infecties in de algehele populatie maken van HCMV een belangrijk humaan pathogeen. De klinische uitkomst van de behandeling van HCMV-infecties wordt bovendien bedreigd door het ontstaan van virussen die resistent zijn tegen de huidige antivirale therapieën. Het zoeken naar nieuwe antivirale middelen om de ontwikkeling van de door HCMV geïnduceerde ziektebeelden te voorkomen of te genezen is daarom een belangrijk onderwerp in het CMV-onderzoek.

De identificatie van nieuwe aangrijpingspunten voor de ontwikkeling van nieuwe antivirale stoffen vereist een gedegen kennis van de moleculaire mechanismen die geassocieerd zijn met de door CMV geïnduceerde pathologieën. Door de strikte soortspecificiteit van de CMV's is het echter niet mogelijk om de pathogenese van HCMV-infecties te bestuderen in fysiologisch relevante situaties in vivo. Om de pathogenese van CMV-infecties in vivo te kunnen bestuderen zijn diermodellen vereist. Daarom werd in ons laboratorium een rat CMV (RCMV)/ratmodel ontwikkeld (Bruggeman et al., 1982). Het RCMV/ratmodel is een uitermate geschikt model voor het bestuderen van CMV-infecties in vivo, aangezien de pathogenese van RCMV-infecties in ratten gelijk is aan die van HCMV-infecties in mensen (Stals et al., 1990). Bovendien komt de sequentie van het genoom van RCMV sterk overeen met die van andere CMV's, zoals HCMV en muis CMV (MCMV) (Chee et al., 1990a; Rawlinson et al., 1996; Vink et al., 2000). In dit proefschrift wordt het RCMV/ratmodel gebruikt voor het bestuderen van verschillende aspecten van RCMV-genexpressie en de rol van een geselecteerde set van RCMV-genen in de pathogenese van infectie.

Het RCMV/ratmodel en de kennis van de complete sequentie van het genoom van RCMV zijn krachtige instrumenten voor het bestuderen van de rol van virale genen in de door CMV geïnduceerde pathologieën. De mate van RCMV-genexpressie is echter nog steeds onbekend. Om de transcriptie van alle RCMV-genen tegelijkertijd te kunnen bestuderen hebben we een RCMV-specifieke DNA-microarray ontwikkeld. In Hoofdstuk 2 wordt deze microarray gebruikt voor het bepalen van de virale genoomwijde transcriptieprofielen in RCMV-geïnfecteerde cellen in kweek en in verschillende organen en weefsels van RCMV-geïnfecteerde ratten. In deze studie wordt aangetoond dat de meerderheid van de virale genen getranscribeerd wordt tijdens een 
RCMV-infectie in vitro met slechts een beperkt aantal verschillen tussen verschillende celtypen. De transcriptie van virale genen tijdens een RCMV-infectie in vivo bleek daarentegen sterk beperkt en weefselspecifiek te zijn. Terwijl $95 \%$ van het virale genoom getranscribeerd wordt in RCMV-geïnfecteerde cellen in kweek is slechts $38 \%$ van de virale genen transcriptioneel actief in de milt van RCMV-geïnfecteerde ratten. Zelfs een lager percentage van de RCMV-genen wordt getranscribeerd in andere weefsels, waaronder de speekselklieren (25\%). Dit toont aan dat de RCMVtranscriptieprofielen in vivo niet gereflecteerd worden door die in vitro. Het is interessant dat veel van de virale genen die hoge transcriptieniveaus bereiken tijdens een RCMVinfectie in vivo lijken te coderen voor immuunmodulerende eiwitten die betrokken zouden kunnen zijn bij immuunevasie. Onder deze genen bevinden zich verschillende leden van de m145 glycoproteïne-genfamilie. Voor een MCMV-lid van deze familie is aangetoond dat het interfereert met de door 'major histocompatibility complex' (MHC) klasse I gemedieerde antigeenpresentatie (Ziegler et al., 1997). Daar staat tegenover dat de meeste virale genen waarvan bekend is dat ze coderen voor eiwitten die betrokken zijn bij virusreplicatie slechts lage transcriptieniveaus bereiken tijdens een RCMV-infectie in vivo. Eén van deze genen is 'immediate early 1' (IE1), dat cruciaal is voor RCMVreplicatie. De eerdere bevinding dat transcriptie van IE1 ook beperkt is in verschillende organen en weefsels van RCMV-geïnfecteerde immuuncompetente ratten is in overeenstemming met deze resultaten (Blok et al., 2001). De strikt gereguleerde transcriptie van genen die betrokken zijn bij immuunevasie en virusreplicatie vertegenwoordigt een effectieve en efficiënte manier voor RCMV om aan klaring door het immuunsysteem te ontsnappen. RCMV transcribeert echter niet zijn volledige arsenaal aan immuunmodulerende genen in elk weefsel, maar het transcribeert deze genen op een weefselspecifieke manier. De weefselspecificiteit van de RCMVtranscriptieprofielen is mogelijk een reflectie van verschillen in de immuunreactie van de gastheer, die waarschijnlijk niet hetzelfde is in elk weefsel. Hierdoor moeten de immuunmodulerende mechanismen van RCMV ook specifiek zijn voor elk weefsel. Een goed voorbeeld is de weefselspecifieke transcriptie van het r138-gen, dat codeert voor een Fc-receptorhomoloog (Vink et al., 2000). Dit gen bereikt alleen hoge transcriptieniveaus in de milt en longen. De weefselspecificiteit van de transcriptieniveaus van r138 wordt mogelijk veroorzaakt door verschillen in de door antilichamen gemedieerde immuunreacties tegen RCMV in verschillende weefsels. RCMV wordt mogelijk meer blootgesteld aan deze reacties in de milt en longen dan in andere weefsels. Het vermogen van RCMV om transcriptie van zijn genen op een 
weefselspecifieke manier te reguleren zou het resultaat kunnen zijn van specifieke regulatieve elementen in de virale promoters die actief zijn in sommige weefsels, maar niet in andere. Voor het identificeren van deze elementen zijn echter aanvullende studies noodzakelijk. De identificatie van de weefselspecificiteit van de RCMVtranscriptieprofielen onderstreept desalniettemin de complexe aard van CMVgenexpressie.

De virale genoomwijde transcriptieprofielen werden eerder ook bestudeerd in HCMVgeïnfecteerde cellen in kweek. In één studie werden de temporele transcriptieprofielen van HCMV in geïnfecteerde fibroblasten bepaald (Chambers et al., 1999). Interessant is dat veel virale genen van een bepaalde kinetische klasse gemeenschappelijke potentiële regulatieve elementen in hun promoters bleken te bevatten (Chambers et al., 1999). Dit suggereert dat de HCMV-genen worden getranscribeerd volgens specifieke transcriptieprogramma's. Deze specifieke transcriptieprogramma's lijken op de weefselspecifieke transcriptieprofielen van RCMV. In twee andere studies werden de transcriptieprofielen van HCMV bepaald in latent geïnfecteerde primaire CD34 ${ }^{+}$ hematopoïetische voorlopercellen (Goodrum et al., 2002, 2004). De HCMVtranscriptieprofielen in deze cellen bleken sterk te verschillen van de profielen die gezien werden in productief geïnfecteerde fibroblasten (Goodrum et al., 2002). Alleen de CD34 ${ }^{+} / \mathrm{CD} 38^{-}$-subpopulatie van het heterogene CD34 ${ }^{+}$-compartiment bleek echter een HCMV-infectie met de kenmerken van latentie te ondersteunen (Goodrum et al., 2004). Een HCMV-infectie in deze cellen resulteert aanvankelijk in een kortstondige transcriptie van veel virale genen, waarna de virale transcriptie stil komt te liggen. Het virale genoom blijft echter behouden in de afwezigheid van substantiële virusreplicatie. Het is belangrijk om te vermelden dat de $\mathrm{CD} 34^{+} / \mathrm{CD} 38^{-}$-cellen het virus kunnen reactiveren als ze worden gekweekt in de aanwezigheid van permissieve fibroblasten. Het is interessant dat de meerderheid van de virale genen die getranscribeerd worden in de CD $34^{+} / C^{-} 8^{-}$-cellen tijdens de aanvankelijke uitbraak van virale gentranscriptie niet noodzakelijk is voor efficiënte replicatie in fibroblasten (Goodrum et al., 2004). Sommige van deze genen zouden een rol kunnen spelen in het tot stand brengen van latentie. Latentiespecifieke transcriptieprofielen werden echter niet geïdentificeerd. Het in vitro modelsysteem voor het bestuderen van HCMV-latentie in $\mathrm{CD}^{+} 4^{+}$/CD38-cellen is aantrekkelijk, maar het heeft duidelijk zijn beperkingen. Het is niet bekend of de transcriptieprofielen tijdens HCMV-infecties in vitro daadwerkelijk de profielen reflecteren die gezien worden tijdens HCMV-infecties in vivo. De mogelijkheden voor het bestuderen van HCMV-infecties in vivo zijn echter erg beperkt. Het is bijvoorbeeld bijna onmogelijk om virale 
transcriptieprofielen te analyseren die bijdragen aan de door HCMV geïnduceerde pathologieën. Dit illustreert de kracht van het RCMV/ratmodel, dat ons in staat stelt om aspecten van CMV-infecties te onderzoeken die alleen in vivo kunnen worden bestudeerd. Toekomstige studies zijn noodzakelijk om specifieke virale transcriptieprofielen die geassocieerd zijn met RCMV-latentie en met de door RCMV geïnduceerde pathologieën te identificeren.

In de meerderheid van de eerdere studies naar RCMV-infecties in vivo werden de ratten onderworpen aan immuunsuppressie voorafgaand aan de virustoediening. Door de immuunsuppressie is RCMV in staat om efficiënt te repliceren en een volledig ontwikkelde, ernstige infectie te induceren (Stals et al., 1990). Natuurlijke CMV-infecties vinden over het algemeen echter plaats in immuuncompetente gastheren die meetal niet lijden aan ernstige complicaties als gevolg van de infectie. Om virusdisseminatie onder 'natuurlijke' condities in vivo te bestuderen werd een studie opgezet om het verloop van een RCMV-infectie in immuuncompetente ratten te bepalen (Blok et al., 2001). Tijdens het analyseren van de transcriptie van IE1 in verschillende organen en weefsels van deze ratten werden twee antisense transcripten van het RCMV 'major IE' (MIE)-gebied geïdentificeerd (Hoofdstuk 3). Deze transcripten, die IE-AS1 en IE-AS2 werden genoemd, werden niet gedetecteerd in een eerdere studie waarin het RCMV MIE-gebied werd geïdentificeerd en gekarakteriseerd (Beisser et al., 1998a). In deze eerdere studie werd gevonden dat het MIE-gebied van RCMV drie verschillende sense transcripten genereert, namelijk IE1, IE2 en IE2A (Beisser et al., 1998a). Deze sense RCMV MIEtranscripten komen overeen met die van andere CMV's en ze coderen waarschijnlijk voor eiwitten die betrokken zijn bij de initiatie van de genexpressiecascade tijdens een lytische infectie. Het niet detecteren van de IE-AS-transcripten in deze eerdere studie kan verklaard worden door de specificiteit voor de sense streng van de meeste experimenten die werden uitgevoerd in deze studie en door de relatief lage transcriptieniveaus van deze transcripten. Het niet detecteren van deze transcripten met Northern blot analyse is in overeenstemming met onze bevindingen.

De identificatie van de nieuwe IE-AS-transcripten is intrigerend, maar de functie van deze transcripten tijdens een RCMV-infectie moet nog worden bepaald. Deze transcripten coderen mogelijk voor functionele eiwitten, maar het is ook mogelijk dat de transcripten zelf betrokken zijn bij de modulatie van IE1-expressie. De IE-AS-transcripten zijn deels complementair aan het IE1-transcript en ze zouden de expressie van IE1 kunnen onderdrukken door de formatie van dubbelstrengs RNA-moleculen met het complementaire IE1-transcript. $\mathrm{Er}$ is echter geen direct bewijs voor dit 
posttranscriptionele mechanisme voor het onderdrukken van IE1-genexpressie tijdens een RCMV-infectie.

Het is interessant dat een antisense transcript van het MIE-gebied eerder ook geïdentificeerd is voor HCMV (Kondo et al., 1996). Dit transcript, dat getranscribeerd wordt in latent geïnfecteerde granulocyt-macrofaag voorlopercellen in kweek en in beenmerg van gezonde seropositieve personen, werd omschreven als een 'CMV latency-associated transcript' (CLT) (Kondo et al., 1996). In het licht van de potentiële rol van de HCMV antisense CLT in de regulatie van latentie is de identificatie van de RCMV IE-AS-transcripten fascinerend. Het is verleidelijk om te speculeren dat de HCMV antisense CLT en de RCMV IE-AS-transcripten of hun eiwitproducten betrokken zijn bij het tot stand brengen of het in stand houden van latentie door middel van posttranscriptionele onderdrukking van IE1-genexpressie. Interessant is dat een vergelijkbare rol in de regulatie van latentie ook is voorgesteld voor een antisense transcript van het HCMV UL81-82-gebied dat recent geïdentificeerd werd in monocyten en beenmerg van gezonde seropositieve personen (Bego et al., 2005). Dit transcript is deels complementair aan het HCMV UL82-gen dat codeert voor het pp71-tegumenteiwit ('upper matrix protein'), een bekende transcriptionele activator van de HCMV MIEpromoter/enhancer (Bego et al., 2005). Er werd daarom gesuggereerd dat het HCMV antisense UL81-82-transcript of zijn eiwitproduct betrokken zou kunnen zijn bij de regulatie van latentie door het beperken van de expressie van het HCMV MIE-gebied door posttranscriptionele onderdrukking van UL82-genexpressie. De potentiële rol van antisense transcripten van lytische CMV-genen in de regulatie van latentie is interessant, maar hun functie is nog niet experimenteel vastgesteld. Het RCMV/ratmodel zou zeer bruikbaar kunnen zijn bij het onderzoeken van hun functie. Een RCMV-tegenhanger van het HCMV antisense UL81-82-transcript is tot nog toe niet geïdentificeerd, maar een uitgebreidere karakterisatie van de potentiële rol van de RCMV IE-AS-transcripten in de modulatie van IE1-expressie en de regulatie van latentie zou kunnen leiden tot een beter begrip van de potentiële functie van de HCMV antisense CLT. Het is op dit moment echter onbekend of de IE-AS-transcripten ook daadwerkelijk getranscribeerd worden tijdens RCMV-latentie. Om dit te onderzoeken zal er een model voor RCMV-latentie en reactivatie moeten worden ontwikkeld. Er zijn diverse data over RCMV-latentie, maar de data over RCMV-reactivatie zijn erg beperkt (Blok et al., 2001; Bruggeman et al., 1983; Bruning et al., 1986, 1988, 1989; Yagyu et al., 1992, 1993). Naar alle waarschijnlijkheid kunnen verdere experimenten naar de moleculaire mechanismen die RCMV-latentie en reactivatie reguleren gedaan worden in de nabije toekomst, wanneer meer precieze 
gegevens over deze biologische processen beschikbaar komen. Met name de rol van de IE-AS-transcripten in de regulatie van latentie zou een interessant onderwerp kunnen zijn voor verdere studies.

Met betrekking tot latentie is de identificatie van een homoloog van de rep-genen van parvovirussen in het RCMV-genoom intrigerend (Vink et al., 2000). Een homoloog van deze genen werd eerder ook gevonden op een vergelijkbare positie in de genomen van humaan herpesvirus type 6A (HHV-6A) en 6B (HHV-6B) (Dominguez et al., 1999; Gompels et al., 1995; Isegawa et al., 1999; Thomson et al., 1991), maar niet in het genoom van elk ander herpesvirus. De rep-gen homologen van RCMV (r127) en HHV6A en -6B (U94) zijn waarschijnlijk ontstaan uit een gemeenschappelijk voorouderlijk bèta-herpesvirus-gen, aangezien ze geconserveerd zijn in sequentie, genomische positie en oriëntatie (Dominguez et al., 1999; Gompels et al., 1995; Isegawa et al., 1999; Vink et al., 2000). De afwezigheid van rep-gen homologen in de genomen van andere bèta-herpesvirussen is daarom opmerkelijk. Wij veronderstellen dat het rep-gen verkregen werd door een voorouderlijk bèta-herpesvirus tijdens een coïnfectie met een voorouderlijk parvovirus en dat het een nieuwe functie heeft ontwikkeld in de replicatiecycli van RCMV en HHV-6A en $-6 \mathrm{~B}$, maar dat het uit de genomen van andere bèta-herpesvirussen verloren is gegaan door een gebrek aan positieve selectiedruk. De rol van de eiwitten die gecodeerd worden door de rep-gen homologen van RCMV en HHV-6A en $-6 \mathrm{~B}$ in de pathogenese van infectie is echter nog steeds onduidelijk. Desalniettemin is gebleken dat U94 getranscribeerd wordt in latent geïnfecteerde perifere bloed mononucleaire cellen (PBMC's) van HHV-6A-geïnfecteerde personen, terwijl zowel virusreplicatie als expressie van virale genen beperkt blijken te zijn in HHV6A-geïnfecteerde lymfocyten die HHV-6B U94 tot expressie brengen in vitro (Rotola et al., 1998). Dit heeft geleid tot de hypothese dat het door U94 gecodeerde eiwit (RepH6) betrokken is bij het tot stand brengen of het in stand houden van HHV-6A- en -6Blatentie. Of het door r127 gecodeerde eiwit (pr127) betrokken is bij de regulatie van RCMV-latentie is op dit moment onbekend. Om een begin te maken met het ontrafelen van de rol van pr127 in de replicatiecyclus van RCMV hebben we experimenten opgezet om het RCMV r127-gen te karakteriseren tijdens een lytische infectie in vitro en tijdens de acute fase van infectie in vivo (Hoofdstuk 4). Hiertoe werd een RCMV r127deletiemutant (RCMV $\Delta \mathrm{r} 127)$ gegenereerd. In deze deletiemutant is een deel van het 'open reading frame' (ORF) van r127 vervangen door een neomycine-resistentiegen (neo). De replicatiekarakteristieken van RCMV $\Delta \mathrm{r} 127$ werden vergeleken met die van 
wildtype RCMV (wt RCMV). Deze studie laat zien dat RCMV $\Delta$ r127 met dezelfde efficiëntie repliceert als wt RCMV, zowel tijdens een lytische infectie in vitro als tijdens de acute fase van infectie in vivo. Dit toont aan dat r127 niet noodzakelijk is voor virusreplicatie en doet de vraag rijzen of pr127 mogelijk een vergelijkbare rol speelt als $\mathrm{RepH} 6$ in de regulatie van latentie. Het is niet onwaarschijnlijk dat pr127 inderdaad een geconserveerde functie heeft met betrekking tot $\mathrm{RepH} 6$, aangezien deze eiwitten verschillende karakteristieken blijken te delen. Zo hebben wij bijvoorbeeld laten zien dat pr127 een DNA-bindingsactiviteit bezit. Deze eigenschap werd eerder ook toegekend aan RepH6 (Dhepakson et al., 2002), hoewel de DNA-bindingsactiviteiten van pr127 en RepH6 verschillend lijken te zijn. Terwijl pr127 blijkt te binden aan zowel enkel- als dubbelstrengs DNA, blijkt RepH6 uitsluitend te binden aan enkelstrengs DNA (Dhepakson et al., 2002). In vergelijking met RepH6 is pr127 bovendien ernstig verkort aan zijn N-terminus (Vink et al., 2000). Door deze verkorting is het erg onwaarschijnlijk dat pr127 een aantal andere karakteristieken van RepH6 deelt, zoals het vermogen om parvovirale Rep-eiwitten te complementeren (Thomson et al., 1994). Het blijft daarom speculatief of pr127 inderdaad de functionele homoloog van $\mathrm{RepH} 6$ vertegenwoordigd. Toch heeft pr127, naast zijn potentiële rol in de regulatie van latentie, waarschijnlijk ook een functie tijdens een productieve infectie. Deze hypothese is gebaseerd op de observatie dat dit eiwit tot expressie komt tijdens een lytische infectie in vitro en tijdens de acute fase van infectie in vivo. We hebben weliswaar gevonden dat pr127 niet noodzakelijk is voor virusreplicatie, maar de functie van dit eiwit is mogelijk subtiel en is daardoor misschien niet opgemerkt in onze studie.

Over de regulatie van CMV-latentie en -reactivatie is op dit moment nog erg weinig bekend. Het is echter duidelijk dat het vermogen van de CMV's om een levenslange, stabiele relatie te onderhouden met hun gastheren strategieën vereist om het immuunsysteem te ontwijken en te manipuleren. Het is interessant dat onder de CMVgenen die betrokken zijn bij deze strategieën zich genen bevinden die coderen voor homologen van cellulaire G-eiwit-gekoppelde receptoren (GPCR's) en chemokinen (CK's). Deze genen zijn waarschijnlijk geroofd uit het genoom van de gastheer tijdens de lange co-evolutie van virus en gastheer. In Hoofdstuk 5 wordt de huidige staat van kennis over de door de CMV's gecodeerde homologen van GPCR's en CK's besproken. Deze eiwitten lijken te interfereren met CK-signaleringsroutes die essentieel zijn voor het goed functioneren van het immuunsysteem. Door te interfereren met deze routes stellen de door de CMV's gecodeerde GPCR's en CK's het virus mogelijk in staat om te 
ontsnappen aan klaring door het immuunsysteem door de normale cellulaire migratiepatronen van leukocyten te verstoren. De interferentie met CKsignaleringsroutes zou ook kunnen bijdragen aan het aantrekken van ontvankelijke leukocyten naar de oorspronkelijke infectiehaarden. Deze leukocyten zouden kunnen dienen als dragers voor virusdisseminatie.

Voor GPCR's en CK's coderende genen zijn gevonden in de genomen van alle gesequenste CMV's. Bijzonder interessant zijn met name de UL33 en UL78 GPCRgenfamilies, aangezien leden van deze families aanwezig zijn in alle gesequenste bètaherpesvirussen, waaronder HCMV, RCMV, MCMV, HHV-6A, HHV-6B en HHV-7 (Beisser et al., 1998b, 1999; Chee et al., 1990a,b; Dominguez et al., 1999; Gompels et al., 1995; Isegawa et al., 1999; Nicholas, 1996; Rawlinson et al., 1996; Vink et al., 2000). Voor de UL33-achtige genen van de CMV's is aangetoond dat ze coderen voor functionele GPCR's met ligand-onafhankelijke, constitutieve signaleringsactiviteiten (Casarosa et al., 2003; Gruijthuijsen et al., 2002; Waldhoer et al., 2002). Of de UL78achtige genen van de CMV's eveneens coderen voor functionele GPCR's is nog niet gerapporteerd. Toch werd het aannemelijk geacht dat zowel de UL33- als de UL78achtige genen zouden coderen voor eiwitten met belangrijke functies in de pathogenese van infectie, aangezien ze geconserveerd zijn onder alle gesequenste bètaherpesvirussen. De generatie en karakterisatie van recombinante CMV-stammen heeft inderdaad aangetoond dat de UL33- en UL78-achtige genen van RCMV en MCMV coderen voor eiwitten die van cruciaal belang zijn in de pathogenese van infectie (Beisser et al., 1998b, 1999; Davis-Poynter et al., 1997; Kaptein et al., 2003; Oliveira en Shenk, 2001; Streblow et al., 2005). Gezien hun conservatie onder de bètaherpesvirussen is het waarschijnlijk dat andere UL33- en UL78-achtige genen van vergelijkbaar belang zijn. De GPCR's die gecodeerd worden door deze genen zijn bovendien gemakkelijk toegankelijk op het celoppervlak. De door UL33 en UL78 gecodeerde GPCR's van HCMV zijn daarom interessante aangrijpingspunten voor de ontwikkeling van nieuwe antivirale therapieën. Dit geldt eveneens voor de door US27 en US28 gecodeerde GPCR's van HCMV (Chee et al., 1990a,b). Er is weinig bekend over US27, maar voor US28 is aangetoond dat het codeert voor een functionele GPCR met zowel ligand-afhankelijke als ligand-onafhankelijke, constitutieve signaleringsactiviteiten (Billstrom et al., 1998; Casarosa et al., 2001; Gao en Murphy, 1994; McLean et al., 2004; Melnychuk et al., 2004; Streblow et al., 1999, 2003; Waldhoer et al., 2002). In tegenstelling tot UL33 en UL78 hebben US27 en US28 echter geen tegenhangers in RCMV en MCMV. De biologische significantie van deze genen in de pathogenese van 
infectie is daarom niet bekend. Dit geldt eveneens voor de voor CXC-CK coderende genen UL146 en UL147 van HCMV (Penfold et al., 1999). De CK's die gecodeerd worden door deze genen zijn eveneens potentiële aangrijpingspunten voor de ontwikkeling van nieuwe antivirale therapieën. In analogie met US27 en US28 zijn homologen van UL146 en UL147 echter niet aanwezig in RCMV en MCMV. Het voor een CC-CK coderende gen UL128 van HCMV heeft echter wel een tegenhanger in RCMV (Akter et al., 2003). De UL128-homoloog van RCMV werd r129 genoemd (Kaptein et al., 2004). Op dit moment zijn we recombinante RCMV-stammen aan het genereren om de biologische significantie van r129 te bestuderen. Deze studies zullen niet alleen meer duidelijkheid verschaffen over de functie van de door r129 gecodeerde CK in de pathogenese van een RCMV-infectie, maar ze zullen ook aantonen of HCMV UL128 gezien kan worden als een potentieel aangrijpingspunt voor de ontwikkeling van nieuwe antivirale middelen. Het is duidelijk dat het RCMV/ratmodel van groot belang zal zijn voor de ontwikkeling en evaluatie van deze middelen.

Verschillende aspecten van RCMV-genexpressie en een geselecteerde set van RCMV-genen werden bestudeerd in dit proefschrift. De rol van de meeste RCMV-genen in de pathogenese van infectie moet nog worden opgehelderd, maar onze data dragen bij aan de kennis van de complexe moleculaire biologie van de CMV's. De resultaten die beschreven worden in dit proefschrift onderstrepen bovendien de geschiktheid van het RCMV/ratmodel voor het bestuderen van de functie van CMV-genen tijdens verschillende stadia van infectie. Aanzienlijk wat data laten zien dat de meeste eigenschappen van RCMV gedeeld worden door alle CMV's, waardoor het $\mathrm{RCMV/ratmodel} \mathrm{een} \mathrm{aantrekkelijk} \mathrm{model} \mathrm{is} \mathrm{voor} \mathrm{het} \mathrm{bestuderen} \mathrm{van} \mathrm{de} \mathrm{mechanismen}$ die betrokken zijn bij de door CMV geïnduceerde pathologieën. RCMV bezit echter ook een aantal unieke eigenschappen die niet gedeeld worden door de andere CMV's, zoals de parvovirale rep-gen homoloog $\mathrm{r} 127$. Door deze unieke eigenschappen is het soms moeilijk om de resultaten van RCMV-studies in ratten te extrapoleren naar HCMVinfecties in mensen. Desalniettemin bieden diermodellen de mogelijkheid om de interactie tussen virus en gastheer te bestuderen. Deze modellen zijn daarom onmisbaar in het CMV-onderzoek.

\section{Referenties}

Akter P, Cunningham C, McSharry BP, Dolan A, Addison C, Dargan DJ, et al. Two novel spliced genes in human cytomegalovirus. J Gen Virol 2003;84:1117-22. 
Bego M, Maciejewski J, Khaiboullina S, Pari G, St. Jeor S. Characterization of an antisense transcript spanning the UL81-82 locus of human cytomegalovirus. J Virol 2005;79:11022-34.

Beisser PS, Kaptein SJF, Beuken E, Bruggeman CA, Vink C. The Maastricht strain and England strain of rat cytomegalovirus represent different betaherpesvirus species rather than strains. Virology 1998a;246:341-51.

Beisser PS, Vink C, van Dam JG, Grauls G, Vanherle SJV, Bruggeman CA. The R33 G proteincoupled receptor gene of rat cytomegalovirus plays an essential role in the pathogenesis of viral infection. J Virol 1998b;72:2352-63.

Beisser PS, Grauls G, Bruggeman CA, Vink C. Deletion of the R78 G protein-coupled receptor gene from rat cytomegalovirus results in an attenuated, syncytium-inducing mutant strain. J Virol 1999;73:7218-30.

Billstrom MA, Johnson GL, Avdi NJ, Scott Worthen G. Intracellular signaling by the chemokine receptor US28 during human cytomegalovirus infection. J Virol 1998;72:5535-44.

Blok MJ, Savelkouls KGM, Grauls GELM, Bruggeman CA, Vink C. Immediate early-1 mRNA expression and virus production are restricted during the acute phase of rat cytomegalovirus infection in immunocompetent rats. In: Blok MJ, editor. Monitoring the course of CMV infection by detection of specific viral transcripts. ANDI Press, Geleen, The Netherlands 2001:91-124.

Bruggeman CA, Meijer H, Dormans PHJ, Debie WMH, Grauls GELM, van Boven CPA. Isolation of a cytomegalovirus-like agent from wild rats. Arch Virol 1982;73:231-41.

Bruggeman CA, Debie WMH, Grauls G, Majoor G, van Boven CPA. Infection of laboratory rats with a new cytomegalo-like virus. Arch Virol 1983;76:189-99.

Bruning $\mathrm{JH}$, Bruggeman $\mathrm{CA}$, van Boven $\mathrm{CP}$, van Breda Vriesman PJ. Passive transfer of cytomegalovirus by cardiac and renal organ transplants in a rat model. Transplantation 1986;41:695-8.

Bruning JH, Bruggeman CA, van Breda Vriesman PJ. The transfer of cytomegalovirus infection in rats by latently infected renal allografts, and the role of various immunosuppressive regimens in virus reactivation. Transplantation 1988;46:623-4.

Bruning JH, Bruggeman CA, van Boven $\mathrm{CP}$, van Breda Vriesman PJ. Reactivation of latent rat cytomegalovirus by a combination of immunosuppression and administration of allogeneic immunocompetent cells. Transplantation 1989;47:917-8.

Casarosa P, Bakker RA, Verzijl D, Navis M, Timmerman H, Leurs R, et al. Constitutive signaling of the human cytomegalovirus-encoded chemokine receptor US28. J Biol Chem 2001;276:1133-7.

Casarosa P, Gruijthuijsen YK, Michel D, Beisser PS, Holl J, Fitzsimons CP, et al. Constitutive signaling of the human cytomegalovirus-encoded receptor UL33 differs from that of its rat cytomegalovirus homolog $R 33$ by promiscuous activation of $G$ proteins of the $G_{q}, G_{i}$, and $G_{s}$ classes. J Biol Chem 2003;278:50010-23.

Chambers J, Angulo A, Amaratunga D, Guo H, Jiang Y, Wan JS, et al. DNA microarrays of the complex human cytomegalovirus genome: profiling kinetic class with drug sensitivity of viral gene expression. J Virol 1999;73:5757-66. 
Chee MS, Bankier AT, Beck S, Bohni R, Brown CM, Cerny R, et al. Analysis of the protein-coding content of the sequence of human cytomegalovirus strain AD169. Curr Top Microbiol Immunol 1990a;154:125-69.

Chee MS, Satchwell SC, Preddie E, Weston KM, Barrell BG. Human cytomegalovirus encodes three G protein-coupled receptor homologues. Nature 1990b;344:774-7.

Davis-Poynter NJ, Lynch DM, Vally H, Shellam GR, Rawlinson WD, Barrell BG, et al. Identification and characterization of a $G$ protein-coupled receptor homolog encoded by murine cytomegalovirus. J Virol 1997;71:1521-9.

Dhepakson P, Mori Y, Jiang YB, Huang HL, Akkapaiboon P, Okuno T, et al. Human herpesvirus-6 rep/U94 gene product has single-stranded DNA-binding activity. J Gen Virol 2002;83:847-54.

Dominguez G, Dambaugh TR, Stamey FR, Dewhurst S, Inoue N, Pellett PE. Human herpesvirus 6B genome sequence: coding content and comparison with human herpesvirus 6A. J Virol 1999;73:8040-52.

Gao JL, Murphy PM. Human cytomegalovirus open reading frame US28 encodes a functional $\beta$ chemokine receptor. J Biol Chem 1994;269:28539-42.

Gompels UA, Nicholas J, Lawrence G, Jones M, Thomson BJ, Martin MED, et al. The DNA sequence of human herpesvirus-6: structure, coding content, and genome evolution. Virology 1995;209:29-51.

Goodrum FD, Jordan CT, High K, Shenk T. Human cytomegalovirus gene expression during infection of primary hematopoietic progenitor cells: a model for latency. Proc Natl Acad Sci USA 2002;99:16255-60.

Goodrum F, Jordan CT, Terhune SS, High K, Shenk T. Differential outcomes of human cytomegalovirus infection in primitive hematopoietic cell subpopulations. Blood 2004;104:68795.

Gruijthuijsen YK, Casarosa P, Kaptein SJF, Broers JLV, Leurs R, Bruggeman CA, et al. The rat cytomegalovirus R33-encoded $\mathrm{G}$ protein-coupled receptor signals in a constitutive fashion. $\mathrm{J}$ Virol 2002;76:1328-38.

Isegawa Y, Mukai T, Nakano K, Kagawa M, Chen J, Mori Y, et al. Comparison of the complete DNA sequences of human herpesvirus 6 variants A and B. J Virol 1999;73:8053-63.

Kaptein SJF, Beisser PS, Gruijthuijsen YK, Savelkouls KGM, van Cleef KWR, Beuken E, et al. The rat cytomegalovirus $\mathrm{R} 78 \mathrm{G}$ protein-coupled receptor gene is required for production of infectious virus in the spleen. J Gen Virol 2003;84:2517-30.

Kaptein SJF, van Cleef KWR, Gruijthuijsen YK, Beuken EVH, van Buggenhout L, Beisser PS, et al. The r131 gene of rat cytomegalovirus encodes a proinflammatory CC chemokine homolog which is essential for the production of infectious virus in the salivary glands. Virus Genes 2004;29:43-61.

Kondo $\mathrm{K}, \mathrm{Xu} \mathrm{J}$, Mocarski ES. Human cytomegalovirus latent gene expression in granulocytemacrophage progenitors in culture and in seropositive individuals. Proc Natl Acad Sci USA 1996;93:11137-42. 
McLean KA, Holst PJ, Martini L, Schwartz TW, Rosenkilde MM. Similar activation of signal transduction pathways by the herpesvirus-encoded chemokine receptors US28 and ORF74. Virology 2004;325:241-51.

Melnychuk RM, Streblow DN, Smith PP, Hirsch AJ, Pancheva D, Nelson JA. Human cytomegalovirus-encoded $G$ protein-coupled receptor US28 mediates smooth muscle cell migration through $\mathrm{G} \alpha 12$. J Virol 2004;78:8382-91.

Nicholas J. Determination and analysis of the complete nucleotide sequence of human herpesvirus 7. J Virol 1996;70:5975-89.

Oliveira SA, Shenk TE. Murine cytomegalovirus M78 protein, a G protein-coupled receptor homologue, is a constituent of the virion and facilitates accumulation of immediate-early viral mRNA. Proc Natl Acad Sci USA 2001;98:3237-42.

Penfold MET, Dairaghi DJ, Duke GM, Saederup N, Mocarski ES, Kemble GW, et al. Cytomegalovirus encodes a potent $\alpha$ chemokine. Proc Natl Acad Sci USA 1999;96:9839-44.

Rawlinson WD, Farrell HE, Barrell BG. Analysis of the complete DNA sequence of murine cytomegalovirus. J Virol 1996;70:8833-49.

Rotola A, Ravaioli T, Gonelli A, Dewhurst S, Cassai E, Di Luca D. U94 of human herpesvirus 6 is expressed in latently infected peripheral blood mononuclear cells and blocks viral gene expression in transformed lymphocytes in culture. Proc Natl Acad Sci USA 1998;95:13911-6.

Stals FS, Bosman F, van Boven CPA, Bruggeman CA. An animal model for therapeutic intervention studies of CMV infection in the immunocompromised host. Arch Virol 1990;114:91-107.

Streblow DN, Soderberg-Naucler C, Vieira J, Smith P, Wakabayashi E, Ruchti F, et al. The human cytomegalovirus chemokine receptor US28 mediates vascular smooth muscle cell migration. Cell 1999;99:511-20.

Streblow DN, Vomaske J, Smith P, Melnychuk R, Hall L, Pancheva D, et al. Human cytomegalovirus chemokine receptor US28-induced smooth muscle cell migration is mediated by focal adhesion kinase and Src. J Biol Chem 2003;278:50456-65.

Streblow DN, Kreklywich CN, Smith P, Soule JL, Meyer C, Yin M, et al. Rat cytomegalovirusaccelerated transplant vascular sclerosis is reduced with mutation of the chemokine-receptor R33. Am J Transplant 2005;5:436-42.

Thomson BJ, Efstathiou S, Honess RW. Acquisition of the human adeno-associated virus type-2 rep gene by human herpesvirus type-6. Nature 1991;351:78-80.

Thomson BJ, Weindler FW, Gray D, Schwaab V, Heilbronn R. Human herpesvirus 6 (HHV-6) is a helper virus for adeno-associated virus type 2 (AAV-2) and the AAV-2 rep gene homologue in HHV-6 can mediate AAV-2 DNA replication and regulate gene expression. Virology 1994;204:304-11.

Vink C, Beuken E, Bruggeman CA. Complete DNA sequence of the rat cytomegalovirus genome. J Virol 2000;74:7656-65.

Waldhoer M, Kledal TN, Farrell H, Schwartz TW. Murine cytomegalovirus (CMV) M33 and human CMV US28 receptors exhibit similar constitutive signaling activities. J Virol 2002;76:8161-8. 
Yagyu K, Steinhoff G, Duijvestijn AM, Bruggeman CA, Matsumoto H, van Breda Vriesman PJ. Reactivation of rat cytomegalovirus in lung allografts: an experimental and immunohistochemical study in rats. J Heart Lung Transplant 1992;11:1031-40.

Yagyu K, van Breda Vriesman PJ, Duijvestijn AM, Bruggeman CA, Steinhoff G. Reactivation of cytomegalovirus with acute rejection and cytomegalovirus infection with obliterative bronchiolitis in rat lung allografts. Transplant Proc 1993;25:1152-4.

Ziegler $\mathrm{H}$, Thale $\mathrm{R}$, Lucin $\mathrm{P}$, Muranyi W, Flohr $\mathrm{T}$, Hengel $\mathrm{H}$, et al. A mouse cytomegalovirus glycoprotein retains MHC class I complexes in the ERGIC/cis-Golgi compartments. Immunity 1997;6:57-66. 
Dankwoord 
Zo, mijn proefschrift is bijna af. En dat al na zes jaar. Er rest mij nog slechts één hoofdstuk: het dankwoord. Er zijn zoveel mensen die hun steentje hebben bijgedragen aan het tot stand komen van dit proefschrift dat ik nauwelijks weet waar ik moet beginnen. Ik heb mijn tijd bij de capaciteitsgroep Medische Microbiologie ervaren als een geweldige periode en ik zou iedereen waarmee ik in de afgelopen zes jaar heb samengewerkt hiervoor hartelijk willen bedanken.

Cathrien. Ik wil je bedanken dat je me de mogelijkheid hebt geboden om binnen jouw groep te promoveren. Ik heb je betrokkenheid bij mijn onderzoek bijzonder gewaardeerd en heb onze samenwerking als zeer prettig ervaren. Met name je hulp bij de laatste zware loodjes heb ik erg op prijs gesteld.

Kees. Een betere baas had ik me niet kunnen wensen. Hoewel het op het voetbalveld meestal andersom was heb je me op moleculair virologisch vlak erg veel geleerd. Zonder jou was dit proefschrift er nooit gekomen en ik ben je dan ook enorm dankbaar voor de goede begeleiding tijdens het vervaardigen ervan. Daarnaast was je ook nooit te beroerd om mij op persoonlijk vlak van de nodige tips te voorzien: 'zou je dat stuk vlaai wel nemen? Je bent al zo dik!'. Subtiel, maar toch leuk. Je was dan ook zoveel meer dan een gewone baas. Ondanks het grote leeftijdsverschil met de rest van de groep kwam je regelmatig achter de geraniums vandaan om allerlei leuke activiteiten met ons te ondernemen. In menig restaurant heb je ongezouten kritiek geleverd op het evenzo ongezouten eten. Ik hoop dat het dankwoord smeuïg genoeg voor je is.

Suzanne (of was het Yvonne?). Wat hebben wij het zwaar gehad. We hebben samen heel wat pesterijen van onze collega's moeten doorstaan (èch wel!). Waar we de bijnaam 'de monsters' aan hebben verdiend is mij dan ook volkomen onduidelijk. Toch hebben we samen ook heel wat leuke momenten beleefd: vele mooie wandelingen, diverse concerten en festivals, een aantal leuke vakanties en een kwart triatlon. Je was niet alleen een goede collega, maar ook een echte vriendin.

Selma. Ook jij bent de afgelopen jaren uitgegroeid tot een ware vriendin. Op bezoek bij Selma is als een korte vakantie in Italië. We hebben samen heel wat mooie wandelingen gemaakt en deze wandelingen werden niet zelden gevolgd door een heerlijk Italiaans etentje. Je kookkunsten zijn dan ook van ongekend hoog niveau. Ik hoop dat er in de toekomst nog veel mooie wandelingen zullen volgen.

Erik. Als er iemand een belangrijke bijdrage aan dit proefschrift heeft geleverd dan ben jij het wel. Je hebt me niet alleen ontzettend geholpen met veel praktisch werk, maar je was ook een erg fijne kamergenoot. Hoe je het al die jaren met ons hebt kunnen uithouden is mij overigens nog steeds een raadsel. Regelmatig hebben we de grenzen 
van het toelaatbare getart door onze zitkamer om te toveren tot een waar gekkenhuis. Kosten nog moeite werden gespaard om onze kamer op te fleuren met een paar ballonnen of slingers tijdens carnaval, Pasen, Kerstmis en het EK voetbal. Als de rust zelve heb je dus heel wat moeten verduren bij ons op de zitkamer die doorgaans meer weg had van de koffiekamer, maar na zes jaar heb je nu eindelijk rust. $O$ ja, nu het proefschrift af is heb ik eindelijk tijd voor die pepersteak.

Yvonne (of was het Suzanne?). Ondanks het feit dat je al een aantal jaar in Oostenrijk woont ben ik je nog steeds niet vergeten, maar ik beschik dan ook over een uitstekend geheugen. Vooral onze fietstocht van bijna $200 \mathrm{~km}$ om het gras in Eindhoven te gaan maaien staat in mijn geheugen gegrift.

Patrick. Bedankt voor je boeiende verhalen over George Bush, Ren en Stimpy, zwarte gaten, Guust Flater en Bill Gates. Ze hebben menig koffiepauze kleur gegeven.

Hilde. Ook $u$ wil ik seffes nochtans ferm bedanken voor de plezante samenwerking. Het was precies goe en dat heb ik bijzonder geapprecieerd. Merciekes.

Kim. Ook jij bedankt. Het ontzettend handige ezelsbruggetje voor de kleurcodes van het sequensen komt nog steeds van pas: akelig groen; blauwe clauwen; geel; root.

Rien. Dank voor de belangrijke bijdrage aan Hoofdstuk 3.

Karen. Ik wil je bedanken voor het verbeteren van mijn Nederlands. Je hebt elke foute 'als mij' feilloos veranderd in het correcte 'dan ik', maar als echte Brabander zal ik het verschil waarschijnlijk nooit leren.

Lieve. De meeste mensen zien op tegen hun dertigste verjaardag, maar ik kan niet wachten tot het eindelijk zo ver is. Hopelijk valt het niet tegen.

Martijn. 'Ik kijk omhoog en ik zie groen, dan plotsklaps blauw en dan denk ik aan jou'. Dit gedicht illustreert het taalkundig talent dat er in jou schuil gaat. In korte tijd heb je mijn woordenschat uitgebreid met een onuitputtelijk aantal nuttige woorden en termen, zoals lekker belangrijk, prima, schraal en niets meer aan doen. Bedankt!

Ook de mensen van de 'allochtonenkamer' en het 'voorste lab' (Ellen, Frank, Geoffrey, Gert, Inge, Jeroen, Manuela, Rajaa, Rick, Tryfon en Xavier) zou ik willen bedanken voor de geweldige samenwerking en de goede sfeer. Een aantal van jullie kan opgelucht adem halen nu deze 'steukminol' eindelijk is vertrokken.

De mensen van de spoelkeuken (Ans, John en Verius) en het secretariaat (Angèle, Fia, José en Patricia) mogen in dit dankwoord natuurlijk niet ontbreken. Dit geldt eveneens voor alle stagiaires die in de afgelopen zes jaar bij ons stage hebben gelopen, waaronder Aafke, Alice, Astrid, Bart, Benno, Carola, Evi, Frank, Marijn, Martijn, Peggy 
en Perry. Met name mijn eigen stagiaires (Christine, Karen, kleine Erik, Nicolien en Wendy) zou ik willen bedanken voor hun bijdrage aan dit proefschrift.

Andere mensen die ik niet mag vergeten zijn Guy, Hanne, Joanne, John, Peter, Petra, Ruud, Sita, Tim en Wil.

Dan Streblow. Thanks for all the work you did on Chapter 2. I really appreciate it.

Ruud en Ivo. Hoewel ik me had voorgenomen om vrienden buiten het werk niet in dit dankwoord te vernoemen kan ik om jullie niet heen. Het begrip 'vrienden voor het leven' is zeker op jullie van toepassing.

Pap, mam, Inge en Anne. Jullie ben ik nog de meeste dank verschuldigd. Bedankt voor jullie onvoorwaardelijke steun in de afgelopen zes jaar en in al die tijd daarvoor.

Mochten er mensen in dit lijstje ontbreken (en dat zal zeker het geval zijn) dan spijt mij dit ten zeerste. Mijn dank is er echter niet minder om.

Koen 
Curriculum vitae en publicaties 


\section{Curriculum vitae}

Koen van Cleef werd op 1 december 1977 geboren te Boxtel. In 1990 begon hij zijn middelbare schoolopleiding aan de Stedelijke Scholengemeenschap te Roermond, alwaar hij in 1996 zijn VWO-diploma behaalde. In datzelfde jaar begon hij met de studie Gezondheidswetenschappen aan de Universiteit Maastricht. Hij koos voor de afstudeerrichting Biologische Gezondheidkunde. Tijdens zijn afstudeerstage bij de capaciteitsgroep Medische Microbiologie van het academisch ziekenhuis Maastricht heeft hij, onder leiding van Prof. Dr. C.A. Bruggeman en Dr. C. Vink, moleculair biologisch onderzoek verricht naar het rat cytomegalovirus (RCMV). In 2000 behaalde hij zijn doctoraal diploma, waarna hij zijn onderzoek naar RCMV als promovendus bij dezelfde capaciteitsgroep vervolgde. Sinds 2006 is hij werkzaam bij de werkgroep Neuromedische Genetica van het Nederlands Instituut voor Neurowetenschappen te Amsterdam. Hier werkt hij, onder leiding van Dr. J. Wijnholds, op een gentherapieproject voor CRB1.

\section{Publicaties}

Streblow DN, van Cleef KWR, Kreklywich CN, Meyer C, Smith P, Defilippis V, Grey F, Früh K, Searles R, Bruggeman C, Vink C, Nelson JA, Orloff SL. Rat cytomegalovirus gene expression in cardiac allograft recipients is tissue-specific and does not parallel the profiles detected in vitro. $J$ Virol 2007;in press.

van Cleef KWR, Smit MJ, Bruggeman CA, Vink C. Cytomegalovirus-encoded homologs of G protein-coupled receptors and chemokines. J Clin Virol 2006;35:343-8.

van Cleef KWR, Blok MJ, Savelkouls KGM, Grauls GELM, Bruggeman CA, Vink C. Identification and characterization of two antisense transcripts from the major immediate early region of rat cytomegalovirus. Arch Virol 2005;150:2593-9.

van Cleef KWR, Scaf WMA, Maes K, Kaptein SJF, Beuken E, Beisser PS, Stassen FRM, Grauls GELM, Bruggeman CA, Vink C. The rat cytomegalovirus homologue of parvoviral rep genes, r127, encodes a nuclear protein with single- and double-stranded DNA-binding activity that is dispensable for virus replication. J Gen Virol 2004;85:2001-13.

Kaptein SJF, van Cleef KWR, Gruijthuijsen YK, Beuken EVH, van Buggenhout L, Beisser PS, Stassen FRM, Bruggeman CA, Vink C. The r131 gene of rat cytomegalovirus encodes a proinflammatory CC chemokine homolog which is essential for the production of infectious virus in the salivary glands. Virus Genes 2004;29:43-61.

Kaptein SJF, Beisser PS, Gruijthuijsen YK, Savelkouls KGM, van Cleef KWR, Beuken E, Grauls GELM, Bruggeman CA, Vink C. The rat cytomegalovirus R78 G protein-coupled receptor gene is required for production of infectious virus in the spleen. J Gen Virol 2003;84:2517-30. 